RACHAEL BRANT MACHADO RODRIGUES

\title{
Avaliação quantitativa dos efeitos da levodopa e da estimulação do núcleo subtalâmico sobre o equilíbrio em pacientes com doença de Parkinson
}

Tese apresentada à Faculdade de Medicina da Universidade de São Paulo para obtenção do título de Doutor em Ciências

Programa de Neurologia

Orientador: Prof. Dr. Egberto Reis Barbosa Coorientador: Prof. Dr. Erich Talamoni Fonoff 
Dados Internacionais de Catalogação na Publicação (CIP)

Preparada pela Biblioteca da

Faculdade de Medicina da Universidade de São Paulo

Creprodução autorizada pelo autor

\section{Rodrigues, Rachael Brant Machado}

Avaliação quantitativa dos efeitos da levodopa e da estimulação do núcleo subtalâmico sobre o equilíbrio em pacientes com doença de Parkinson / Rachael Brant Machado Rodrigues. -- São Paulo, 2015.

Tese(doutorado)--Faculdade de Medicina da Universidade de São Paulo. Programa de Neurologia.

Orientador: Egberto Reis Barbosa.

Coorientador: Erich Talamoni Fonoff.

Descritores: 1.Doença de Parkinson 2.Estimulação encefálica profunda 3.Equilíbrio postural 4.Núcleo subtalâmico 5.Hipocinesia 6.Levodopa

7.Acidentes por quedas

USP/FM/DBD-485/15 


\section{AGRADECIMENTOS}

Primeiramente a Deus, que sempre me abençoa, guia meus passos e permite este momento.

Ao meu orientador, Prof. Egberto Barbosa, pelo exemplo, pelos ensinamentos, pela paciência e sabedoria de um grande mestre.

Ao meu coorientador, Prof. Erich Fonoff, pela receptividade, ensinamentos e parceria profissional que me estimula a evoluir.

Demais colegas e professores da equipe de Neurologia, em especial do grupo de Distúrbios do Movimento, pelo contínuo estímulo ao crescimento e aprimoramento profissional.

Aos pacientes, dispostos a participar das avaliações e compartilhar experiências de vida enriquecedoras.

A minha família, porto seguro. Papai, Mamãe, André, lanna, Gui e João Pedro, meus amores e maiores incentivadores sempre. Alexandre, pelo apoio nesta fase conclusiva e futura.

Aos colegas do Hospital Mater Dei e a equipe Neurovida, Viviane Amaral, Thais Machado, Fernanda Dornas, Flavia Bispo, Tiago Garcia, Nubia Moura e Osvaldo Bramussi, parceria diária.

Enfim, a todos que contribuíram para a realização deste trabalho até hoje e sua continuação futura em todas as esferas, muito obrigada. 
Esta tese está de acordo com as seguintes normas, em vigor no momento desta publicação:

Referências: adaptado de International Committee of Medical Journals Editors (Vancouver).

Universidade de São Paulo. Faculdade de Medicina. Serviço de Biblioteca e Documentação. Guia de apresentação de dissertações, teses e monografias.

Elaborado por Anneliese Carneiro da Cunha, Maria Julia de A. L. Freddi, Maria F. Crestana, Marinalva de Souza Aragão, Suely Campos Cardoso, Valéria Vilhena. $3^{a}$ ed. São Paulo: Divisão de Biblioteca e Documentações; 2011.

Abreviatura dos títulos dos periódicos de acordo com List of Journals Indexed in Index Medicus. 
Lista de abreviaturas e siglas

\section{SUMÁRIO}

Lista de tabelas

Lista de gráficos

Resumo

Summary

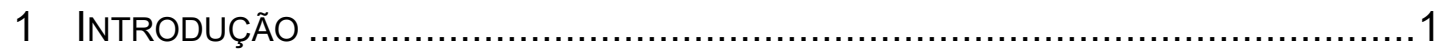

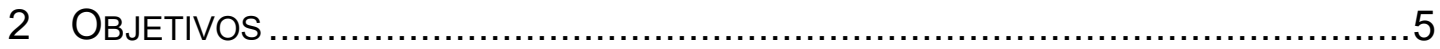

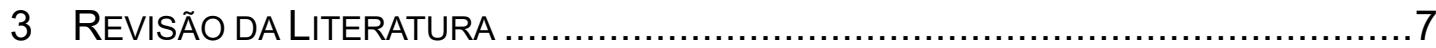

3.1 O Quadro Clínico ...................................................................... 12

3.2 O Diagnóstico da Doença de Parkinson......................................... 13

3.2.1 Identificação da causa da síndrome parkinsoniana ......................14

3.2.2 A confirmação do diagnóstico da DP com base na resposta terapêutica e evolução ...................................................... 15

3.2.3 Exames complementares no diagnóstico da DP ........................16

3.3 Doença de Parkinson - Tratamento ............................................. 18

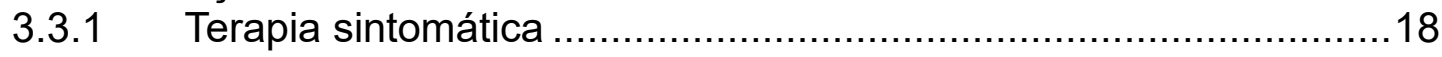

3.3.1.1 Levodopa ................................................................ 18

3.3.1.2 Inibidores da catecol-orto-metiltransferase $(\mathrm{COMT})$.................22

3.3.1.3 Agonistas dopaminérgicos ..........................................23

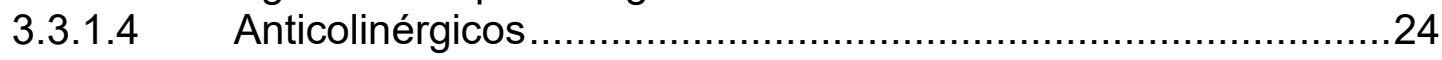

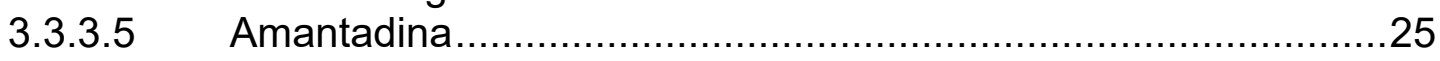

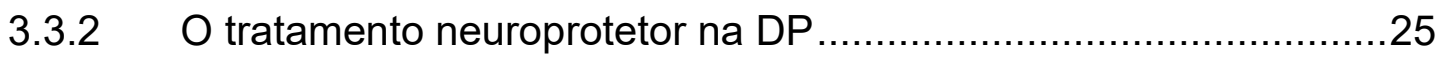

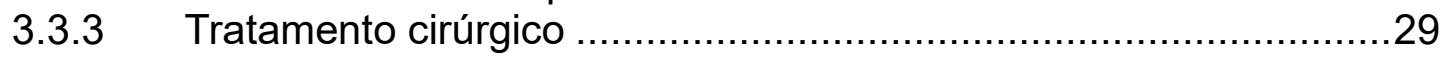

3.4 Complicações da DP avançada................................................. 31

3.5 Sistemas de controle do equilíbrio.................................................. 31

3.5.1 Mecanismos e sistemas neurais envolvidos .............................. 32

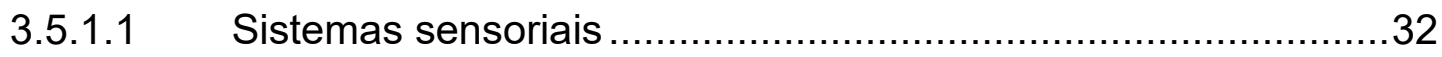

3.5.1.2 Sistemas de Integração sensório-motora ...............................33

3.5.1.3 Mecanismos fisiopatológicos do equilíbrio na DP .....................35

3.6 Alterações Posturais na Doença de Parkinson ..................................37

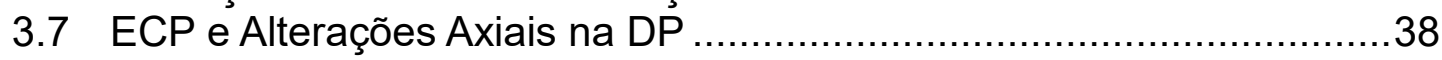

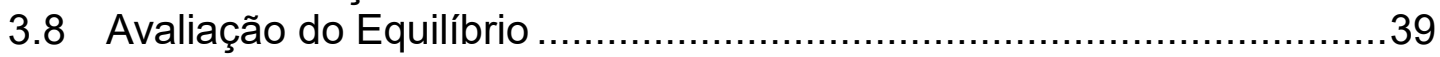

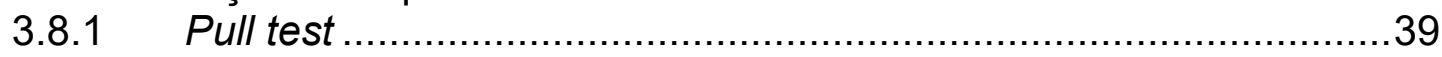

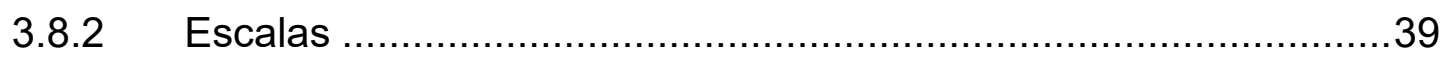

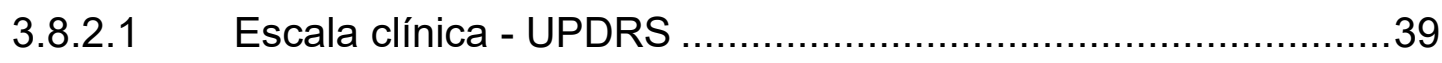

3.8.2.2 Escalas de avaliação de equilibrio ...................................40

3.8.2.3 Posturografia............................................................ 42

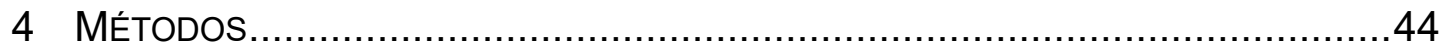

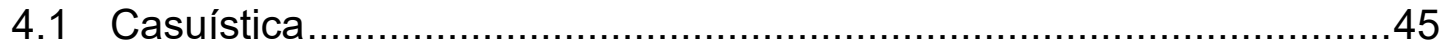

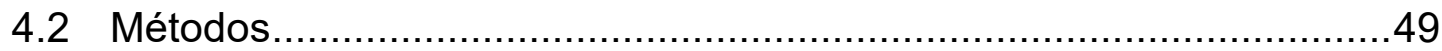

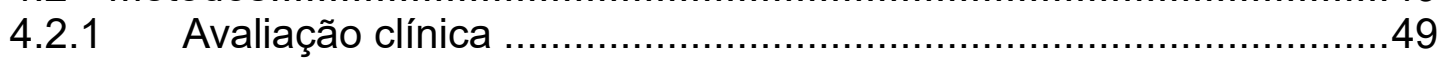




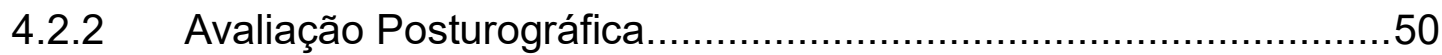

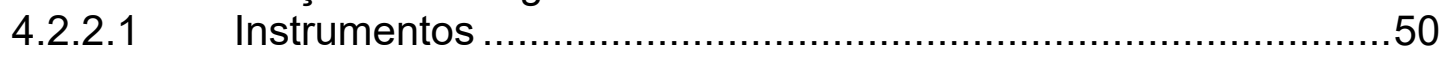

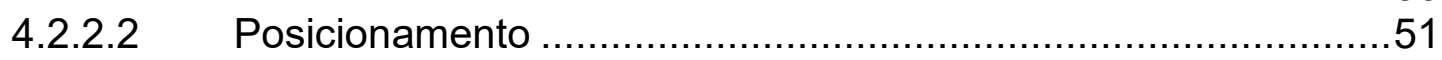

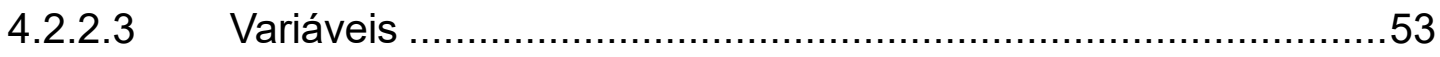

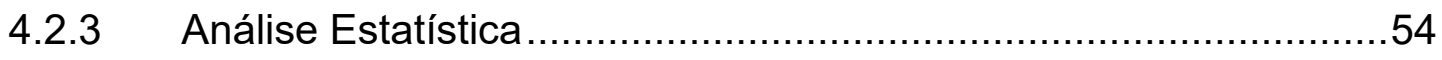

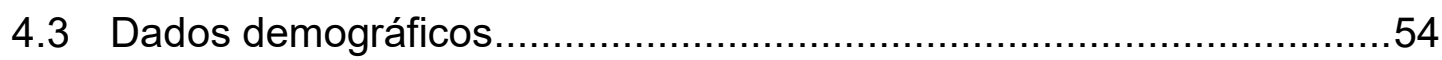

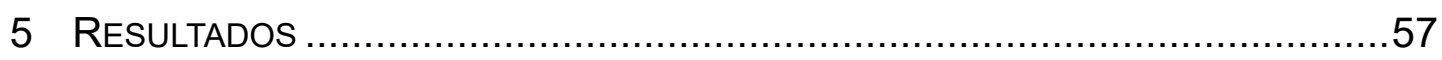

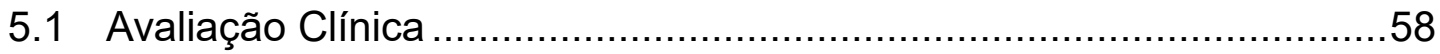

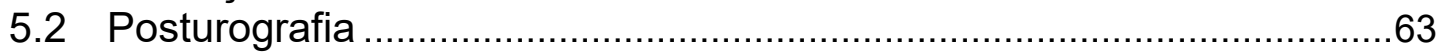

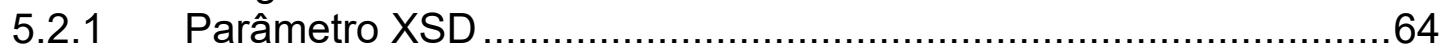

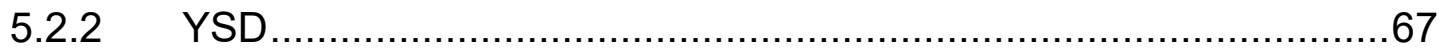

5.2.3 Path Length ....................................................................

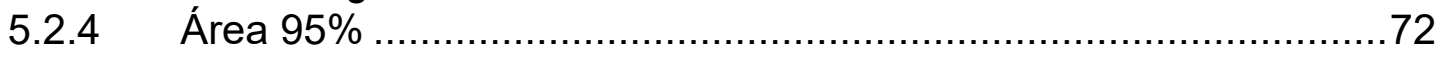

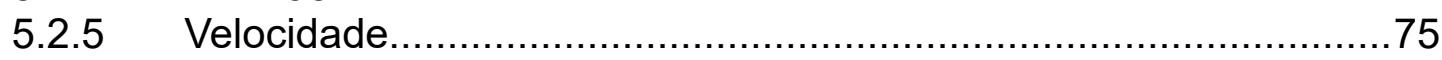

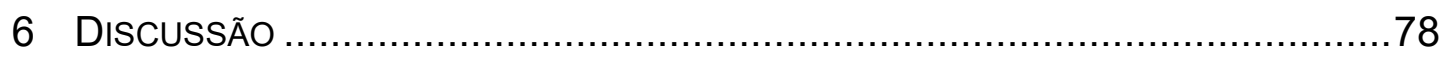

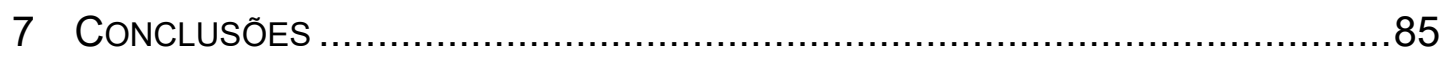

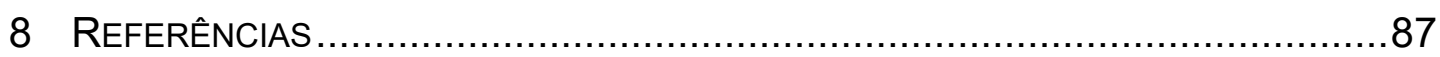




\section{LISTA DE ABREVIATURAS E SIGLAS}

$\begin{array}{ll}\text { 3-OMD } & \text { - 3-orto metildopa } \\ \text { AD } & \text { - Agonistas dopaminergicos } \\ \text { AMS } & \text { - Atrofia de múltiplos sistemas } \\ \text { AP } & \text { - Direção anteroposterior } \\ \text { BBS } & \text { - Berg Balance Scale } \\ \text { COMT } & \text { - Catecol-orto-metiltransferase } \\ \text { COP } & \text { - Oscilações do centro de pressão } \\ \text { CP } & \text { - Centro de pressão } \\ \text { DA } & \text { - Dopamina } \\ \text { DP } & \text { - Doença de Parkinson } \\ \text { ECP } & \text { - Estimulação cerebral profunda } \\ \text { F } & \text { - Força } \\ \text { HC-FMUSP } & \text { - Hospital das Clínicas da Faculdade de Medicina da } \\ & \text { Universidade de São Paulo } \\ \text { IRM } & \text { - Ressonância magnética } \\ \text { LD } & \text { - Levodopa } \\ \text { LL } & \text { - Direção laterolateral } \\ \text { M } & \text { - Movimento } \\ \text { MAO } & \text { - Enzima monoaminooxidase } \\ \text { MAO-B } & \text { - Enzima monoaminooxidase-B } \\ \text { MBT } & \text { - MiniBEST Test } \\ \text { NMDA } & \text { - N-Metil-D-aspartato } \\ \text { NST } & \text { - Nucleo subtalamico } \\ \text { OA } & \text { - Olhos abertos } \\ \text { OF } & \text { - Olhos fechados } \\ \text { PET } & \text { - Positron emission tomography } \\ \text { PL } & \text { - Path Length } \\ \text { PPN } & \text { - Núcleo pedúnculo-pontino } \\ \text { REM } & \text { - Rapid Eye Movement } \\ \text { RMS } & \text { - Raiz quadrática média } \\ \text { SNC } & \text { - Sistema Nervoso Central } \\ \text { STN } & \text { - Núcleo subtalâmico } \\ \text { TC } & \text { - Tomografia computadorizada } \\ \text { TE } & \text { - Tremor essencial } \\ & \end{array}$


UPDRS - Unified Parkinson's Disease Rating Scale

VAvg - Velocidade média

XSD - Oscilação no plano laterolateral

YSD - Oscilação no plano anteroposterior 


\section{LISTA DE TABELAS}

Tabela 1 - Dados demográficos da população estudada ..............................55

Tabela 2 - UPDRS axial e geral dos pacientes não-operados .....................58

Tabela 3 - UPDRS global e axial dos pacientes operados..........................60

Tabela 4 - Comparação do UPDRS axial dos grupos operados e não-operados.

Tabela 5 - Comparação do UPDRS geral dos pacientes operados e não-operados.

Tabela 6 - Gravidade segundo a escala de Hoehn e Yahr (on e off)

Tabela 7 - Raiz quadrática média da oscilação mediolateral com olhos abertos

Tabela 8 - Raiz quadrática média da oscilação laterolateral com olhos fechados.

Tabela 9 - Raiz quadrática média da oscilação anteroposterior com olhos abertos

Tabela 10 - Raiz quadrática média da oscilação anteroposterior com olhos fechado.

Tabela 11 - Path length da oscilação em um minuto com olhos abertos

Tabela 12 - Path length da oscilação em um minuto com olhos fechados

Tabela 13 - Área correspondente a 95\% da elipse ocupada pela oscilação dos pacientes com olhos abertos

Tabela 14 - Área correspondente à $95 \%$ da elipse ocupada pela

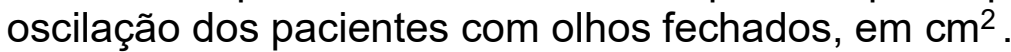

Tabela 15 - Velocidade de oscilação dos pacientes com olhos abertos

Tabela 16 - Velocidade de oscilação dos pacientes com olhos fechados 


\section{LISTA DE GRÁFICOS}

Gráfico 1 - Boxplot da dosagem de medicação ………………………........56

Gráfico 2 - Boxplot UPDRS axial dos pacientes não-operados..................59

Gráfico 3 - Boxplot UPDRS geral dos pacientes não-operados ………......59

Gráfico 4 - Boxplot do desvio padrão da oscilação laterolateral com

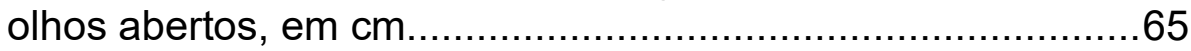

Gráfico 5 - Boxplot do desvio-padrão da oscilação laterolateral

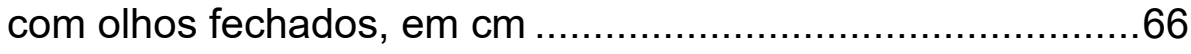

Gráfico 6 - Boxplot do desvio-padrão da oscilação anteroposterior

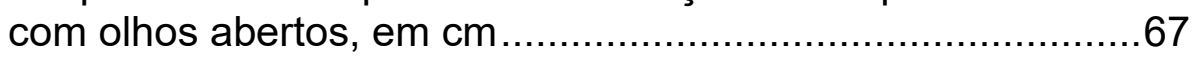

Gráfico 7 - Boxplot do desvio-padrão da oscilação anteroposterior com olhos fechados em $\mathrm{cm}$...

Gráfico 8 - Boxplot path length da oscilação em um minuto com olhos abertos em $\mathrm{cm}$.

Gráfico 9 - Boxplot path length da oscilação em um minuto com olhos fechados, em $\mathrm{cm}$

Gráfico 10 - Boxplot da área correspondente à $95 \%$ da elipse ocupada pela oscilação dos pacientes com olhos abertos, em $\mathrm{cm}^{2}$

Gráfico 11 - Boxplot da área correspondente a 95\% da elipse ocupada pela oscilação dos pacientes com olhos fechados em $\mathrm{cm}^{2}$

Gráfico 12 - Boxplot da velocidade de oscilação dos pacientes com olhos abertos $\mathrm{em} \mathrm{cm} / \mathrm{seg}$.

Gráfico 13 - Boxplot da velocidade de oscilação dos pacientes com olhos fechados, em $\mathrm{cm} / \mathrm{seg}$. 


\section{RESUMO}

Rodrigues RBM. Avaliação quantitativa dos efeitos da levodopa e da estimulação de núcleo subtalâmico sobre o equilíbrio em pacientes com doença de Parkinson [tese]. São Paulo: Faculdade de Medicina, Universidade de São Paulo; 2015.

INTRODUÇÃO: Os efeitos da levodopa (LD) e da estimulação cerebral profunda (ECP) de núcleo subtalâmico (STN) sobre o equilíbrio e sintomas axiais são até o momento controversos. OBJETIVOS: Avaliar quantitativamente os efeitos da ECP de STN e da LD sobre o equilibrio estático em pacientes com DP operados, em comparação com a LD em pacientes não operados. MÉTODOS: Trinta e um pacientes submetidos a ECP de STN entre 3 meses e 1 ano e meio antes da avaliação e 26 controles portadores de DP não operados, estágios Hoehn e Yahr 2 a 4 foram avaliados usando UPDRS para avaliação clínica e plataforma de força para avaliar oscilações posturais. $O$ primeiro grupo foi avaliado com ECP e sem medicação, com ECP e com medicação e sem ECP e sem medicação. $O$ segundo grupo foi avaliado com e sem medicação. Cada paciente foi avaliado com os olhos abertos e fechados. O deslocamento do centro de pressão anteroposterior, laterolateral, a área, velocidade e deslocamento total linear foram medidos pela plataforma de força. Os dados paramétricos foram comparados usando o teste t de Student e os dados não-paramétricos foram comparados pelo teste de Kruskal-Wallis. A avaliação clínica consistiu na parte 3 da escala UPDRS e na escala Hoehn e Yahr. Nível de significância estatística considerada foi $p=0,05$. RESULTADOS: Os pacientes não operados oscilaram mais quando sob efeito da levodopa do que sem medicação. No grupo operado, a maior oscilação é no grupo com ECP desligada e sem medicação. Tende a reduzir sob efeito da ECP apresenta redução significativa sob efeito simultâneo de ECP e levodopa. CONCLUSÃO: A associação da ECP de NST com medicação tem impacto positivo sobre o controle postural. O efeito da ECP de NST reverte o efeito negativo da levodopa sobre as oscilações observadas em pacientes não operados.

Descritores: Doença de Parkinson. Estimulação encefálica profunda. Equilíbrio postural. Núcleo subtalâmico. Hipocinesia. Levodopa. Acidentes por quedas. 


\begin{abstract}
Rodrigues RBM. Quantitative evaluation of the effects of levodopa and bilateral subthalamic stimulation on postural control in patients with Parkinson's disease [thesis]. São Paulo: "Faculdade de Medicina, Universidade de São Paulo"; 2015.
\end{abstract}

INTRODUCTION: The effects of bilateral subthalamic (STN) DBS and medication on balance and on axial symptoms in PD have been so far inconsistent. OBJECTIVE: To assess quantitatively the effects of DBS on static balance in PD. METHODS: Thirty-one patients submitted to STN DBS over 3 months before and 26 non-operated controls with PD on Hoehn \& Yahr stage "on" 2 to 4 were evaluated using UPDRS and a force plate to measure sway. The first group was evaluated on-DBS/off-medication, onDBS/on-medication and off-DBS/off-medication. The second group was evaluated on and off medication. Each group was assessed with eyes open and then closed. Antero-posterior, laterolateral postural displacements of the center of pressure (COP), as well as 95\% sway area, path length and speed of oscillation were analyzed and compared using t-Student test for parametrical data and Kruskal-Wallis test for non-parametrical data. Level of significance was set to $p<0.05$. Clinical assessment consisted of UPDRS part 3 and Hoehn \& Yahr scores for each of the conditions. RESULTS: Control patients tended to oscillate more in the on medication condition than off medication. DBS patients tended to oscillate more in the off-DBS/off medication condition, with a tendency to decrease the sway when on DBS/off medication with additional decrease when on DBS/on medication. CONCLUSION: Association of bilateral STN DBS and medication positively influences postural control in PD and surgery reverses the tendency of medication to increase body sway in non-operated patients.

Descriptors: Parkinson disease. Deep brain stimulation. Postural balance. Subthalamic nucleus. Hypokinesia. Levedopa. Accidental falls. 
1 INTRODUÇÃO 
A Doença de Parkinson (DP) é a segunda doença neurodegenerativa mais frequente na população, com estudos de prevalência variando entre 18 e 418 casos para cada 100000 habitantes em estudos de todo o mundo e entre 102 e 190 casos por 100000 habitantes nos países ocidentais (Schrag, 2007), com maior incidência na população mais idosa.

A DP é caracterizada por degeneração do sistema nervoso central e periférico. As alterações anatomopatológicas iniciam-se décadas antes das primeiras manifestações motoras, com o comprometimento dos plexos mioentéricos de Meissner e Auerbach, do bulbo olfatório e porção inferior do tronco cerebral, evoluindo com acometimento então do locus ceruleus, substancia negra, prosencéfalo basal e sistema límbico. $O$ estágio neuropatológico tardio é caracterizado pela presença de corpos de Lewy em áreas corticais associativas (Braak et al., 2004) A fase inicial, ou pré-motora, portanto, inicia-se frequentemente com alterações clínicas como hiposmia, constipação intestinal, depressão e alterações do sono "Rapid Eye Movement" (REM). Os sintomas cardinais, que definem o início da fase motora, se relacionam à deficiência dopaminérgica estabelecida e permitem o diagnóstico da DP são a bradicinesia associada a tremor de repouso, rigidez muscular ou instabilidade postural. A perda da estabilidade postural é sinal associado com agravamento das limitações motoras e aumento da 
mortalidade nos portadores da síndrome, assim como disfagia e comprometimento cognitivo (Fall et al. 2003).

Nos anos 1960 foi introduzida a levodopa como forma eficaz de reposição da dopamina e controle sintomático da DP. Vários outros agentes foram desde então introduzidos com objetivo de otimizar o controle sintomático da DP ou de tratar os efeitos colaterais do tratamento com levodopa, como flutuações motoras e discinesias. Estas complicações são atribuídas à reposição da dopamina de forma não-fisiológica e muitas vezes são de difícil tratamento.

A neurocirurgia funcional, que teve um importante papel inicial no tratamento da DP antes do surgimento da levodopa por meio de cirurgias ablativas, retoma nas últimas décadas a função de possibilitar o controle de alguns sintomas incapacitantes induzidos pelo próprio tratamento também através de neuromodulação. Eletrodos ligados a um gerador são posicionados em alvos estratégicos na circuitaria dos núcleos da base com o objetivo de corrigir disfunções decorrentes da DP. Esta técnica traz a vantagem de permitir uma modulação ajustável às necessidades do paciente e produz benefícios semelhante à reposição dopaminérgica farmacológica, contornando seus efeitos colaterais e complicações (Kleiner-Fisman et al., 2006).

A alteração clínica de equilíbrio surge apenas em momento mais tardio na DP. Segundo a estimativa de Sampaio e Rascol baseada no estudo Datatop e na escala clínica (Hoehn e Yahr 3,0) trinta por cento dos pacientes a desenvolvem em cerca de quatro anos de DP; $50 \%$ em sete anos e o restante ainda mais tardiamente (Sampaio e Rascol, 2007). Caso sejam 
usados instrumentos sensíveis o suficiente, no entanto, esta alteração se mostrará presente desde o início (Frenklach et al., 2009).

A escala Unified Parkinson's Disease Rating Scale (UPDRS) é considerada o padrão-ouro na avaliação do comprometimento do paciente pelos sintomas parkinsonianos. A seção que avalia o considerado componente axial da DP inclui postura, resposta ao pull test, bradicinesia global, marcha e como o paciente se levanta de uma cadeira. Estes componentes nem sempre respondem à terapia de reposição dopaminérgica como a rigidez, bradicinesia e tremor. Esta disparidade possivelmente decorre do fato de que na instabilidade postural há outros mecanismos envolvidos além da deficiência dopaminérgica, e pode sofrer piora pela reposição de dopamina através das discinesias. A perda da estabilidade postural, bem como os riscos de queda que dela decorrem, leva a importante perda de funcionalidade e seu entendimento merece, portanto, ser priorizado nas pesquisas atuais em busca de novas formas de tratamento (Boonstra et al., 2008).

A neuromodulação do núcleo subtalâmico gera respostas que se correlacionam com o tratamento dopaminérgico. $O$ efeito da cirurgia isoladamente ou associada a medicação no pós-operatório sobre o equilíbrio, no entanto, ainda não foi elucidado e gera este estudo. Enfatizouse o equilíbrio estático, ou seja, a capacidade de manter-se em ortostatismo, avaliada quantitativamente por meio de plataforma de força, uma estrutura estática com sensores que captam as oscilações do centro de gravidade do paciente associada à avaliação clínica do quadro parkinsoniano obtida por meio do UPDRS. 


\section{Objetivos}


Considerando a complexidade do manejo das quedas na DP avançada, bem como outras morbidades que advém das alterações de equilíbrio, temos como objetivo estudar o tema analisando os aspectos a seguir:

a) Avaliar de forma quantitativa o efeito da levodopa e da ECP de NST em pacientes com DP sobre o equilíbrio estático.

b) Comparar o efeito da medicação e da ECP em pacientes com DP, bem como definir se há efeito somatório de ambos.

c) Comparar a eficácia da análise quantificada do equilíbrio por meio da plataforma de força e o método clássico de avaliação pelo escore motor da escala clínica UPDRS. 
3 REVISÃo dA LITERATURA 
Entre as doenças neurológicas, a doença de Parkinson apresenta importância especial por se incluir entre as mais frequentes. A estimativa é de que com o aumento da população idosa esta prevalência possa vir a dobrar até 2050 (Bach et al., 2011).

A doença de Parkinson, nomeada em homenagem a James Parkinson, que descreveu suas características clínicas em 1817, é uma degeneração progressiva de neurônios do sistema nervoso central e periférico que acomete principalmente o sistema motor. No entanto, manifestações não-motoras, como distúrbios cognitivos, psiquiátricos, autonômicos, e sensoriais, como hiposmia, dor e fadiga.

A DP inicia-se geralmente após os 50 anos, e chega a atingir $2 \%$ da população com idade superior a 65 anos. Acomete ambos os sexos, sendo ligeiramente mais comum em homens e diferentes raças (de Rijk et al., 1997).

Os casos que se iniciam antes dos 40 anos são considerados DP de início precoce e antes dos 21 anos, DP juvenil.

A etiologia da DP ainda não foi elucidada, mas supõe-se que esteja relacionada à complexa interação entre fatores ambientais, genéticos e fisiológicos, como o próprio envelhecimento.

As evidências da participação de fatores ambientais advêm de relatos de casos de parkinsonismo em humanos por exposição a agentes tóxicos, 
por modelos experimentais de parkinsonismo com o uso de neurotoxinas e estudos epidemiológicos sobre fatores de risco para DP. Desta forma, uma metanálise de 16 estudos caso-controle realizada por Priyadarshi et al. (2001) mostrou que viver ou trabalhar em ambiente rural e beber água de poço são fatores de risco para DP. Mais recentemente em revisão sistemática e metanálise de coortes Van Maele-Fabry et al. (2012) constataram que indivíduos expostos a pesticidas em atividades profissionais têm risco aumentado para DP. Os principais agentes tóxicos implicados na etiologia da DP são metais pesados (p.ex., manganês), pesticidas (p.ex., rotenona) e herbicidas (p.ex., paraquat).

Os conhecimentos sobre os fatores genéticos envolvidos na DP avançaram consideravelmente desde a identificação do primeiro gene relacionado à DP (PARK 1), por Nussbaum e Polymeropoulos, em 1997. Desde então, até o momento, 20 loci (PARK1 a 20) relacionados a formas genéticas da DP foram descritos e em vários deles o gene foi identificado. Essas formas genéticas podem ser autossômicas dominantes, recessivas ou ligadas ao cromossomo X. Há ainda a participação de genes nos quais as mutações não são patológicas, mas conferem suscetibilidade à DP atuando como fatores de risco.

O papel do envelhecimento na gênese da DP pode ser avaliado por dados epidemiológicos. A doença é rara antes dos 40 anos, mas atinge $1 \%$ dos indivíduos acima de 60 anos e $5 \%$ da população de idosos com mais de 85 anos (de Lau e Breteler, 2006).

A degeneração dos neurônios na pars compacta da substância negra é irreversível e resulta na redução da produção de dopamina (DA), 
acarretando alterações funcionais na circuitaria dos núcleos da base. Estudos neuropatológicos indicam que a perda neuronal na $\mathrm{SN}$ avança em uma escala entre $5 \%$ e $10 \%$ a cada década de vida. Esse ritmo de despopulação neuronal fica muito acima do que ocorre em outros sistemas neuronais, como os neurônios neocorticais que sofrem redução de apenas $10 \%$ ao longo de toda a vida (Fearnley e Lees, 1991, Pakkenberg e Gundersen, 1997; Ma et al., 1999).

Os estudos de Braak et al. (2003) indicam que as manifestações prémotoras da DP estão relacionadas ao acometimento de estruturas do bulbo e ponte no tronco encefálico, além do sistema olfatório. Portanto o processo degenerativo na DP parece ter uma progressão caudo-cranial iniciando-se no tronco baixo (fase pré-motora), evoluindo de forma ascendente, passando pelo mesencéfalo (fase motora) até atingir estruturas corticais que integram funções cognitivas (fase avançada). Manifestações não-motoras da DP como hiposmia, constipação intestinal, depressão, fadiga e transtorno do sono REM estão presentes antes do surgimento das dificuldades motoras (Barbosa, 2010).

A anatomia patológica revela que a DP é caracterizada por degeneração dos neurônios dopaminérgicos da substância negra pars compacta, associada a inclusões intracitoplasmáticas denominadas corpúsculos de Lewy, marcadores patológicos da DP. Há também extensa degeneração nãodopaminérgica, envolvendo os neurônios colinérgicos do núcleo basal de Meynert e núcleo pedunculopontino, neurônios noradrenérgicos do locus coeruleus, neurônios serotoninérgicos da rafe, além de neurônios do córtex 
cerebral, tronco cerebral, medula espinhal e neurônios periféricos do sistema autonômico (Olanow et al., 2009b; Tolosa et al., 2009).

Desde a descoberta de que a alfasinucleína (AS) é um dos principais componentes estruturais dos corpos de Lewy, inclusões citoplasmáticas sistematicamente encontradas em neurônios de pacientes com DP, tem-se buscado entender a participação desta proteína nos mecanismos que levam à morte neuronal nesta doença. Admite-se atualmente que oligômeros ou polímeros da AS, formas não solúveis desta proteína e não degradáveis pelos sistemas proteassoma-ubiquitina e de autofagia acumulam-se nos neurônios e interferem decisivamente em mecanismos críticos para a função e vitalidade destas células, particularmente na atividade mitocondrial e no fluxo axonal.

Ainda quanto à participação da AS na etiopatogenia da DP é relevante mencionar a hipótese de que alterações na conformação molecular desta proteína poderiam levar à propagação e ao acúmulo nos tecidos por um mecanismo semelhante ao que ocorre em doenças priônicas. Essa hipótese foi inicialmente levantada com base em estudos post mortem de pacientes com DP que haviam recebido implantes neurais de material obtido de SN de fetos. No cérebro destes pacientes, surpreendentemente, no tecido transplantado, inicialmente sem qualquer alteração patológica, haviam se formado aglomerados de AS e corpos de Lewy. Esta observação levantou a possibilidade de uma propagação de acúmulo de AS do tecido afetado pela DP para o tecido normal por um mecanismo príon-like.

O papel das mitocôndrias é fundamental na etiopatogenia da DP, e o bloqueio de seu complexo I da cadeia transportadora de elétrons é o mecanismo de ação de neurotoxinas como rotatenona e metilfenil- 
tetrahidropiridina (MPTP). Algumas formas genéticas da DP também ocorrem devido a genes que interferem na função mitocondrial ou no processo de mitofagia, que consiste na eliminação das mitocôndrias defeituosas pelos lisossomas gerando assim acúmulo dessas organelas danificadas e comprometimento da função neuronal. Atividade inflamatória também participa na patogênese da DP. Sinais histológicos de ativação microglial, assim como infiltração de linfócitos $\mathrm{T}$ em áreas atingidas pelo processo degenerativo e evidências in vivo de desregulação de mediadores moleculares, como citocinas e sistema de complemento e respectivos receptores, corroboram a atividade inflamatória na DP. Possivelmente o acúmulo anormal de alfa-sinucleína em células da microglia desencadearia a atividade de mediadores inflamatórios. Desta forma, há vários alvos possíveis de desenvolvimento de terapia neuroprotetora, assunto que será abordado adiante (Appel, 2012; Kannarkat et al., 2013, Thobois, 2015).

\subsection{O Quadro Clínico}

As manifestações cardinais da doença de Parkinson são tremor de repouso, rigidez, bradicinesia e instabilidade postural, sendo que a bradicinesia associada a outro dentre estes componentes é necessária para a caracterização da síndrome, que decorre do comprometimento da via dopaminérgica nigro-estriatal. Sabe-se atualmente que também há associação a diversas características não-motoras, já mencionadas, decorrentes do envolvimento de estruturas fora dos núcleos da base, que podem inclusive preceder os sintomas motores (Tolosa et al., 2009). 
Micrografia, hipomimia facial, redução do balanço passivo de um braço durante a marcha, passos curtos, tremor, dificuldade para realizar movimentos finos, como abotoar e usar faca para partir os alimentos podem estar entre os sintomas descritos pelo paciente desde o princípio. As alterações de equilíbrio tendem a surgir mais tardiamente e quedas são a queixa mais associada à sua presença. Por ser tema desta tese este tópico será discutido mais detalhadamente adiante (Speciali et al., 2014; Fonoff et al., 2015; Souza et al., 2015).

\subsection{O Diagnóstico da Doença de Parkinson}

O diagnóstico da DP é fundamentado na avaliação clínica do paciente e os exames complementares são realizados com o intuito de descartar diagnósticos diferenciais.

De acordo com Lees, 1992, os melhores preditores para acurácia diagnóstica na DP são: a) ausência de características atípicas de DP (disfunção autonômica precoce, demência severa precoce, disfunção do trato córtico-espinhal, paralisia supranuclear do olhar, medicação neuroléptica em uso, múltiplos eventos cerebrovasculares prévios e episódio de encefalite próximo ao início do quadro) e b) início assimétrico (Hughes et al., 1992a e 1992b). 


\subsubsection{Identificação da causa da síndrome parkinsoniana}

A identificação da causa da síndrome parkinsoniana implica no reconhecimento de causas específicas (parkinsonismo secundário) ou de formas atípicas de parkinsonismo degenerativo. Excluídas estas possibilidades estaremos diante de uma forma primária de parkinsonismo, ou seja, a DP.

A principal causa de parkinsonismo secundário é a exposição a drogas podem agir no Sistema Nervoso Central (SNC) como agentes bloqueadores de receptores dopaminérgicos de tipo D1 e D2, presentes no striatum (putâmen/núcleo caudado) para onde se projetam as terminações dos neurônios dopaminérgicos nigrais. Nesta categoria de drogas, as que mais frequentemente são encontradas como causa de parkinsonismo secundário são os neurolépticos. Dentre estes, a única exceção é a clozapina, que atua predominantemente em receptores $\mathrm{D} 4$, fora do striatum. Outras drogas que podem causar parkinsonismo são antivertiginosos bloqueadores de canal de cálcio e antieméticos aceleradores do trânsito gástrico. Os sintomas parkinsonianos induzidos pelo uso destas drogas podem persistir por semanas ou meses após sua retirada.

Causas de parkinsonismo secundário podem ser identificadas pela anamnese ou exames de neuroimagem, como processos expansivos do SNC, hidrocefalia e calcificações dos núcleos da base.

O parkinsonismo atípico ou parkinsonismo-plus é a denominação empregada para caracterizar quadros neurológicos em que uma síndrome parkinsoniana, geralmente apenas expressada por acinesia e rigidez (sem 
tremor), associa-se a distúrbios autonômicos, cerebelares, piramidais, de neurônio motor inferior ou, ainda, de motricidade ocular extrínseca. O parkinsonismo atípico, ao contrário do que ocorre com a DP, geralmente instala-se de forma simétrica, e responde mal a drogas de efeito antiparkinsoniano, inclusive a levodopa. Essa forma de parkinsonismo está presente em um grupo de moléstias neurológicas degenerativas constituído pelas seguintes doenças: paralisia supranuclear progressiva, atrofia de múltiplos sistemas, degeneração córtico-basal e demência com corpos de Lewy (Tolosa et al., 2009, Vaillancourt et al., 2009, Foulds et al., 2010).

\subsubsection{A confirmação do diagnóstico da DP com base na resposta terapêutica e evolução}

A boa resposta às medicações dopaminérgicas, em especial a levodopa, é um critério obrigatório para confirmação diagnóstica da DP. Entretanto, pacientes com outras doenças que se manifestam com parkinsonismo podem apresentar resposta positiva a essas drogas, ainda que inferior à observada na DP. Estima-se que $20 \%$ dos pacientes com PSP (Josephs et al., 2003) e 50\% dos casos de AMS (Gilman et al., 2008) respondam à levodopa em fases iniciais dessas doenças. Particularmente na atrofia de múltiplos sistemas (AMS) a resposta a agentes dopaminérgicos pode aproximar-se daquela observada na DP e, eventualmente, persistir até fases mais avançadas da moléstia.

A DP apresenta habitualmente evolução lenta sob tratamento e os pacientes mantém-se independentes por pelo menos cinco anos após a 
instalação das manifestações motoras da doença. Portanto, diante de uma evolução desfavorável com limitações motoras graves após poucos anos, devese rever o diagnóstico em busca de parkinsonismo secundário ou atípico.

Outro aspecto a ser valorizado como confirmatório do diagnóstico de DP é o aparecimento, em longo de prazo, de discinesias induzidas por levodopa.

Por fim, mesmo considerados todos estes critérios para o diagnóstico, a margem de erro no diagnóstico é de no mínimo $10 \%$ mesmo nos casos atendidos em centros especializados (Litvan et al., 1996; Mckeith et al., 2005; Josephs et al., 2003; Wadia e Lang, 2007; Lubarsky e Juncos, 2008; Gilman et al., 2008; Barsottini et al., 2010; Bor-Seng-Shu et al., 2010).

\subsubsection{Exames complementares no diagnóstico da DP}

Os exames de neuroimagem estrutural (Tomografia Computadorizada [TC] e Ressonância Magnética [RM]) são de grande utilidade na diferenciação entre a DP e as síndromes parkinsonianas de diversas etiologias. Os exames de neuroimagem funcional (Positron Emission Tomography e Single Photon Emission Computed Tomography) utilizando marcadores de transportador de dopamina ou de levodopa também podem auxiliar nesta diferenciação, mas não são exames disponíveis para uso de rotina (Barsottini et al., 2010). Contudo, não há anormalidades evidenciáveis por nenhum desses exames que sejam características da DP.

Anormalidades da ecogenicidade na substância negra demonstráveis por sonografia transcraniana têm sido descritas em pacientes com DP, 
recurso diagnóstico já introduzido em nosso meio (Bor-Seng-Shu et al., 2010). Mais de $90 \%$ dos portadores da DP apresentam estes tipos de alterações que podem ser também encontradas em cerca de $10 \%$ nos grupos controle. Entretanto, o significado dessas alterações ainda permanece por ser devidamente elucidado por novos estudos. Este método de neuroimagem é particularmente útil na diferenciação entre DP e Tremor Essencial (TE).

O exame do olfato por meio de testes padronizados é outro meio auxiliar no diagnóstico da DP. Está comprovado que na maioria dos pacientes com DP, por ocasião do início das manifestações motoras, já há grave déficit olfatório, o que não ocorre em pacientes com parkinsonismo atípico ou TE (Silveira-Moriyama et al., 2008).

Há ainda perspectivas promissoras quanto a aquisição de imagens de ressonância magnética pela tratografia que, conforme estudos preliminares, pode mostrar alterações na substância negra em pacientes com DP (Vaillancourt et al., 2009).

Outra técnica que poderá trazer contribuição futura para o diagnóstico da DP é a aferição em fluídos biológicos de marcadores (proteínas) envolvidos na etiopatogenia da DP, como a alfasinucleína, com o objetivo de distinguir indivíduos normais de portadores da doença (Foulds et al., 2010). 


\subsection{Doença de Parkinson - Tratamento}

\subsubsection{Terapia sintomática}

A terapia sintomática tem como objetivo controlar as manifestações clínicas da DP por meio de intervenções sobre as anormalidades bioquímicas da DP. A mais relevante delas é a redução dopaminérgica no striatum, seguida pelo aumento colinérgico nesta região dos núcleos da base. Portanto, as principais drogas utilizadas no tratamento da DP têm como mecanismo básico de ação o aumento da disponibilidade de dopamina e a redução da atividade colinérgica no striatum.

As principais drogas utilizadas no tratamento sintomático da DP são as que promovem o aumento da atividade dopaminérgica: a levodopa (precursor de DA), os agonistas dopaminérgicos (atuam diretamente sobre os receptores dopaminérgicos D1, D2 e D3), a amantadina (inibe a recaptação de DA) e os inibidores das enzimas degradadoras de DA que são a selegilina e rasagilina (inibidores de monoamino-oxidase B) e tolcapone e entacapone (inibidores da catecol-ortometiltransferase). As drogas que reduzem a atividade colinérgica são os anticolinérgicos (biperideno e trihexifenidil).

\subsubsection{Levodopa}

A introdução da levodopa nos anos de 1960 representou um grande avanço no manejo da doença de Parkinson. O tratamento com levodopa associado a inibidores periféricos de dopa-decarboxilase, que inibem a transformação periférica de levodopa em dopamina, fornece benefício significativo para a maioria dos pacientes portadores de DP e se associa a 
melhora das atividades de vida diária, independência, sobrevida e empregabilidade (Olanow et al., 2009b; Rajput, 2001)

O tratamento em longo prazo com levodopa, no entanto, é associado com uma série de efeitos adversos, tais como perda de eficácia, flutuações do desempenho motor, discinesias e alterações neuropsiquiátricas, como distúrbios visuais, alucinações e delírios. A busca por novas drogas que possibilitem melhora no controle clínico da DP, principalmente visando retardar o desenvolvimento das complicações motoras ou tratá-las, levou ao desenvolvimento de novas opções terapêuticas abordadas adiante.

\section{Complicações Motoras Relacionadas a LD}

No início da DP, o tratamento com LD leva a uma resposta clínica sustentada. Com o avanço da DP, a maioria dos pacientes experimenta complicações relacionadas ao tratamento com levodopa, a saber: a) wearing off (redução da duração do efeito, retardo de efeito/delayed on e distonia de fim de efeito/distonia de off, relacionadas a alterações farmacocinéticas; b) discinesias e flutuações erráticas/on-off, relacionadas a alterações farmacocinéticas e farmacodinâmicas; c) freezing.

As causas incluem a redução progressiva dos neurônios nigrais e fatores farmacocinéticos e farmacodinâmicos relacionados à própria levodopa, incluindo a redução da capacidade de armazenamento da levodopa exógena e extensão do processo degenerativo a outros sistemas neuronais.

Estudos recentes indicam que de $38 \%$ a $50 \%$ dos pacientes desenvolvem wearing off apenas dois anos após o início da terapia dopaminérgica (Parkinson Study Group, 2000). O wearing off se caracteriza 
pela reemergência do quadro parkinsoniano antes do horário de tomada da próxima dose de medicação, com passagem de on para off inicialmente de forma insidiosa, mas progressivamente tornando-se mais abrupta. Acinesia noturna, com acentuação do parkinsonismo durante o sono e acinesia matinal, com esta acentuação ocorrendo no despertar e antes da primeira dose da medicação são fenômenos relacionados ao wearing off.

Embora este fenômeno seja reconhecido principalmente pela piora das manifestações motoras da DP, o mesmo não se restringe apenas a estas. Flutuações não-motoras também podem estar presentes, associadas ou não, às motoras e são de três tipos: disautonômicas (taquicardia, sudorese, alteração de ritmo respiratório), mentais (lentificação do pensamento, ansiedade, pânico e depressão) e sensoriais (parestesias e dor). Witjas et al. (2002) em estudo sobre as manifestações não motoras do wearing off constataram que as manifestações motoras sempre são acompanhadas por algum tipo de manifestação não-motora.

Discinesias são movimentos involuntários, hipercinéticos, que podem ocorrer os picos plasmáticos de levodopa, no início e fim do efeito (discinesias bifásicas) ou ainda durante o período de off. Podem consistir em coréia, estereotipias, balismo ou distonia. As discinesias bifásicas são geralmente estereotipias, coréia ou balismos, enquanto as discinesias de off tendem a ser distônicas, com frequência dolorosas, e ocorrer ao despertar pela manhã, antes da medicação. Todas as discinesias tendem a ser mais evidentes no lado do corpo ou membro mais afetado pelo parkinsonismo. Entre as possíveis causas de discinesias está a estimulação intermitente dos 
receptores dopaminérgicos exercida pela dopamina gerada a partir da LD. Sabe-se que em condições fisiológicas a estimulação de receptores determinada pela dopamina endógena é contínua ou tônica. A estimulação intermitente de receptores dopaminérgicos pela levodopa decorre de oscilações de sua biodisponibilidade que pode sofrer interferência de condições variáveis de esvaziamento gástrico, absorção intestinal e passagem pela barreira hematoencefálica. A estimulação intermitente de receptores dopaminérgicos estriatais, por meio de mecanismos interativos entre esses receptores e receptores de glutamato, gera respostas anormais a partir de neurônios estriatais cuja expressão clínica são as discinesias induzidas por LD.

Pode-se então inferir que todas as intervenções farmacológicas que melhorem a biodisponibilidade da levodopa devem contribuir para minimizar as complicações crônicas da levodopaterapia. Entre essas intervenções podemos incluir medidas dietéticas, objetivando reduzir a competição dos aminoácidos ingeridos, formulações de LD de liberação gradual e inibidores enzimáticos da catecol-orto-metiltransferase (COMT) com capacidade de poupar LD e evitar a formação de 3-orto metildopa (3-OMD). 


\subsubsection{Inibidores da catecol-orto-metiltransferase (COMT)}

A COMT é uma enzima com distribuição ubiquitária nos diversos tecidos, que catalisa a transferência do radical metil da $S$ - adenosil - L metionina para os substratos alvo. No sistema nervoso central, tem papel relevante na inativação extraneuronal por meio de ortometilação de catecolaminas (dopamina e noradrenalina) e seus metabólitos deaminados (ácido 3,4 - dihidroxifenilacético, DOPAC e 3,4 - dihidroxifeniletilglicol). Conforme citado anteriormente, admite-se que entre os fatores que determinam o aparecimento das flutuações do desempenho motor e discinesias relacionados ao uso crônico da levodopa está a formação da 3metoxi-4-hidroxi-L-fenilalanina a partir da levodopa. Essa conversão ocorre inicialmente no trato intestinal e é dependente da ação da COMT. Esse processo acarreta dissipação da levodopa e redução de sua absorção intestinal determinada por competição da 3-OMD pelo mesmo sistema de transporte que é saturável. Uma vez na circulação, a levodopa ainda continua sendo metabolizada pela COMT a 3-OMD, principalmente no fígado, persistindo o processo de dissipação periférica e a competição pelo sistema de transporte, agora na barreira hematoencefálica.

Com base nestes dados, inibidores da COMT têm sido desenvolvidos para otimizar o efeito da levodopa, sendo que duas drogas deste grupo já tiveram sua eficácia comprovada: tolcapone (com ação central e periférica) e entacapone, de ação predominantemente periférica. O uso destas medicações está condicionado ao uso concomitante da levodopa e sua principal indicação é o tratamento do wearing off e perda de potência da levodopa. 


\subsubsection{Agonistas dopaminérgicos}

Os agonistas dopaminérgicos são drogas que estimulam diretamente os receptores dopaminérgicos. Numerosos já foram testados, como os derivados ergolíneos bromocriptina, lisurida, pergolida e o não-ergolíneo piribedil. Posteriormente outros três agonistas dopaminérgicos foram introduzidos no arsenal terapêutico da DP: o ropinirol, o pramipexol, a rotigotina e a cabergolina, sendo os três últimos disponíveis no Brasil. Além destes, há a apomorfina, o mais antigo deles, não disponível no Brasil, e cujo uso é limitado por suas características farmacológicas.

O objetivo do tratamento com agonistas dopaminérgicos na fase inicial da DP, quando a incapacidade motora é leve a moderada, é prevenir o aparecimento de flutuações motoras e discinesias. Pacientes podem ser mantidos em monoterapia com agonistas por até mais de três anos. Entretanto, todos os pacientes acabam por necessitar dos benefícios adicionais da levodopa, em fases mais avançadas da evolução de sua moléstia. Atualmente, com base em alguns estudos clínicos comparativos entre agonistas dopaminergicos (AD) e LD, há uma tendência em considerar-se que o emprego dos $A D$ isoladamente ou em associação com LD em fases iniciais da DP pode reduzir a incidência de flutuações motoras e discinesias. Além disto, os AD têm meia vida mais longa que a dopamina, o que implica em estimulação mais tônica dos receptores dopaminérgicos, podendo assim reduzir o risco de aparecimento de discinesias e flutuações motoras. 


\subsubsection{Anticolinérgicos}

Os anticolinérgicos biperideno e triexifenidil são as mais antigas drogas usadas no tratamento da DP. Os seus mecanismos de ação têm como base a redução da atividade colinérgica, contribuindo para o restabelecimento do equilíbrio acetilcolina/dopamina em nível estriatal. Vêm progressivamente perdendo espaço por terem capacidade insatisfatória de controlar a bradicinesia, apesar de terem bons efeitos sobre o tremor. Outro fator é a indução de efeitos colaterais anticolinérgicos sistêmicos, como retenção urinária, constipação intestinal e, em idosos, comprometimento cognitivo, indução de estado confusional e alucinações. Além dessas limitações há também preocupação quanto a efeitos mais permanentes que estas drogas podem induzir sobre áreas cerebrais que integram os processos cognitivos. Perry et al. (2003) demonstraram maior densidade alterações anatomopatológicas de tipo Alzheimer (placa amiloide e emaranhado neurofibrilar) em pacientes com DP que haviam recebido tratamento com anticolinérgicos por mais de dois anos do que naqueles tratados com essas drogas por período inferior.

Portanto, atualmente, os anticolinérgicos são drogas de segunda linha no tratamento da DP e melhor indicadas para pacientes mais jovens que apresentam tremor como manifestação predominante da doença. 


\subsubsection{Amantadina}

O efeito antiparkinsoniano deste agente antiviral foi descoberto casualmente. A sua potência é consideravelmente menor que a da levodopa e as investigações sobre seu mecanismo de ação evidenciam uma atividade dopaminérgica, principalmente pelo bloqueio da recaptação de dopamina na fenda sináptica e atividade anticolinérgica. Estudos recentes têm demonstrado que a amantadina atua como antagonista de receptor N-Metil-D-aspartato (NMDA), um dos tipos de receptor para ácido glutâmico. Portanto, a amantadina poderia atuar reduzindo a hiperatividade de projeção glutamatérgica do núcleo subtalâmico sobre o segmento interno do globo pálido, aspecto crucial na fisiopatologia da DP. Além disso, estudos clínicos recentes mostraram menor ocorrência de discinesias induzidas pela levodopa em pacientes que faziam uso de amantadina (Olanow et al., 2009b).

\subsubsection{O tratamento neuroprotetor na DP}

Ao longo das últimas décadas mais de 50 estudos têm demonstrado, de forma consistente, que o hábito de fumar está associado à prevalência reduzida de DP e alguns estudos relacionam este possível efeito neuroprotetor à nicotina. Entretanto, em pacientes com DP já instalada não altera a progressão da moléstia (Kandinov et al., 2007; Quik et al., 2012).

Estudos experimentais sugerem que antagonistas de receptores ionotrópicos ou metabotrópicos de glutamato possam exercer efeito neuroprotetor na DP, contrapondo-se à excitoxicidade (Blandini, 2010). 
O consumo regular de café e o hábito de fumar reduzem significativamente o risco de DP. A cafeína é um inibidor de receptores A2A de adenosina que são largamente encontrados na circuitaria dos gânglios da base, especialmente no striatum. A istradefilina, um bloqueador de receptores $\mathrm{A} 2 \mathrm{~A}$ de adenosina, tem efeito sintomático em pacientes com DP e possivelmente efeito neuroprotetor (Saaksjarvi et al., 2008).

Quanto ao hábito de fumar, o efeito protetor seria mediado pela nicotina. Recentemente foi proposta uma hipótese que concilia o efeito protetor do café e o do fumo com o hipotético início da DP no trato intestinal aventando-se a possibilidade de que esses fatores de redução de risco atuariam no intestino modificando, na flora intestinal, e criando um meio menos propício (menor atividade inflamatória?) para o surgimento de alterações moleculares da AS, possivelmente responsáveis pelo seu acúmulo.

Alguns estudos mostram que indivíduos com níveis séricos mais elevados de urato têm menor probabilidade de desenvolver DP e naqueles pacientes com DP já instalada essa caraterística metabólica se correlaciona com evolução mais favorável. Esse efeito neuroprotetor é atribuído às propriedades antioxidantes e de formar complexos com metais (Cipriani et al., 2010).

Com base nos atuais conhecimentos sobre a etiologia e os mecanismos de morte neuronal na DP algumas propostas de terapia neuroprotetora estão em estudo, entre as quais se destacam: pioglitazona (anti-inflamatório não hormonal), nanopartículas da coenzima Q10 (reparador mitocondrial), inosina (precursor de urato), a isradipina (bloqueador de canais de cálcio) e antagonistas de receptores de glutamato de tipo mGluR5. 
Outra droga que brevemente estará disponível no Brasil é o metanosulfato de safinamida que tem ação anticonvulsivante e antiparkinsoniana (sintomática e possivelmente neuroprotetora). A sua ação farmacológica é complexa, pois atua como inibidor de monoamino oxidase B (IMAO-B), inibidor de recaptação de dopamina e antagonista de glutamato (Malek e Grosset, 2012).

As drogas já testadas como modificadoras da evolução da DP e em uso atualmente são a selegilina e a rasagilina (deverá ser comercializada ainda este ano). Ambas são propargilaminas que atuam como inibidores seletivos e irreversíveis de monoamino oxidase $B$ (MAO-B).

A selegilina é metabolizada no fígado e os catabólitos resultantes são a metanfetamina, a anfetamina, a desmetil selegilina e a efedrina. As anfetaminas resultantes da metabolização da selegilina podem provocar efeitos colaterais, tais como oscilações da pressão arterial, arritmia cardíaca e insônia. O efeito neuroprotetor da selegilina foi avaliado em estudo com pacientes em fase inicial da DP, sem tratamento sintomático. Comparada com placebo, a selegilina retardou a introdução de terapia sintomática. A ressalva que se faz aos resultados deste estudo é que a avaliação dos grupos-placebo e o que recebeu a droga ativa foi feita em apenas duas semanas após a retirada e, portanto, poderia haver efeito sintomático residual decorrente do prolongamento da ação da dopamina endógena, que é catabolizada pela IMAO-B. Ainda que persistam controvérsias sobre o efeito neuroprotetor esta droga tem sido largamente utilizada na dose de 10 mg ao dia, especialmente em pacientes em fase inicial da DP. 
A rasagilina é IMAO-B de segunda geração e, portanto, de introdução mais recente como agente neuroprotetor na DP. A dose recomendada é de 1 mg ao dia, em dose única Diferentemente da selegilina, a metabolização hepática da rasagilina não gera a formação de metabólitos ativos o que torna esta droga mais segura quanto ao perfil de efeitos adversos, que geralmente são mínimos (Parkinson Study Group, 2002).

Os estudos para avaliar o efeito da rasagilina como agente modificador da DP foram desenvolvidos com uma metodologia diferente dos empregados nos ensaios com a selegilina. No desenho destes estudos, havia três grupos de pacientes em fase inicial da DP, virgens de tratamento: um grupo recebendo rasagilina desde o início, outro recebendo placebo e um terceiro que começou a receber a droga ativa apenas seis meses depois. Os resultados mostraram que os dois grupos que receberam rasagilina apresentaram evolução melhor quanto à progressão do quadro motor que o grupo-placebo e, comparados entre si, o grupo que recebeu a droga ativa desde o início teve evolução melhor que o grupo que iniciou o uso da medicação após seis meses. Com esta estratégia metodológica procurou-se contornar o efeito sintomático da droga sobre os resultados observados. Em estudo recente, Poewe et al. (2015) demonstraram que o tratamento com rasagilina reduz a progressão, ainda que de forma modesta, de manifestações não motoras da DP. Os efeitos sintomáticos dos IMAO-B sobre o parkinsonismo são decorrentes do prolongamento da ação das dopaminas endógena e exógena (esta advinda da metabolização da levodopa). Estes efeitos têm sido mais claramente demonstrados com o uso da rasagilina (Olanow et al., 2009a). 


\subsubsection{Tratamento cirúrgico}

A cirurgia de estimulação cerebral profunda (ECP) para controle da DP vem sendo usada de maneira crescente para manejo das complicações do tratamento com levodopa. A estimulação de núcleo subtalâmico promove efeitos clínicos semelhantes ao efeito da levodopa, sem flutuações permitindo a redução da dose das drogas de ação dopaminérgica, com subsequente controle das discinesias. A bradicinesia, a rigidez e o tremor são controlados de forma satisfatória por longo prazo, enquanto as manifestações axiais apresentam resposta variável. O teste de resposta a levodopa permite uma avaliação aproximada da melhora que pode ser obtida com a cirurgia. O candidato ideal para a cirurgia é aquele gravemente comprometido na condição off, geralmente com pontuação na escala UPDRS parte três superior a 30 pontos, mas independente na condição on, com UPDRS parte três inferior aos 30 pontos e com complicações motoras relacionadas ao tratamento com levodopa ou tremor refratário (Fonoff, 2012)

Tradicionalmente os pacientes eram operados após mais de uma década de duração da DP. Em 2013, o estudo conduzido por Schüepbach et al. mostrou melhora da qualidade de vida, do comprometimento motor, da manutenção das atividades de vida diária, maior redução de complicações motoras induzidas pela levodopa e aumento do tempo com boa mobilidade e sem discinesias nos pacientes operados mais precocemente em comparação àqueles mantidos em tratamento medicamentoso. Neste trabalho, os pacientes foram operados com um mínimo de quatro anos de 
evolução da DP (média de 7,5 anos) e com até três anos após desenvolvimento de flutuações motoras e discinesias que interferissem com as atividades do paciente, sugerindo que a neuromodulação é uma opção terapêutica válida em estágios mais precoces da doença. Quando realizada em fases mais precoces e em pacientes com menos sintomas não responsivos à levodopa os resultados cirúrgicos tendem a ser superiores (Schüepbach et al., 2013 e 2014).

Pacientes com idade superior a 75 anos, geralmente excluídos dos estudos, também podem se beneficiar da ECP. DeLong et al. Revisaram um banco de dados com 1757 pacientes entre 50 e 90 anos de idade operados entre 2000 e 2009 quanto a permanência hospitalar e complicações em 90 dias e não houve diferenças significativas entre pacientes acima de 75 anos ou abaixo de 75 (Shalash et al., 2014; DeLong et al., 2014).

Os sintomas axiais estão entre os mais incapacitantes da DP avançada, levando a quedas e isolamento social. A estimulação do NST não tem a mesma eficácia sobre marcha e equilíbrio como tem sobre os sintomas cardinais. Alternativas para esta limitação tem sido buscada, como uso de diferentes parâmetros de estimulação ou ainda uso de outros alvos (Vingerhoets et al., 2012). 


\subsection{Complicações da DP avançada}

Atualmente, as manifestações não dopaminérgicas da DP, como demência, freezing e instabilidade postural, levando a quedas, são a maior fonte de morbidade, mortalidade e perda de qualidade de vida para a maioria dos portadores de doença de Parkinson avançada. Koller et al. (1989) demonstraram que 38 em cada 100 parkinsonianos caem, sendo $13 \%$ deles mais de uma vez por semana. Destes $13 \%$ sofrem fraturas, $18 \%$ hospitalização e $3 \%$ ficam restritos à cadeira de rodas. Em um estudo recente dados igualmente preocupantes foram encontrados, mesmo com a evolução do tratamento nas últimas décadas. Neste estudo, $60 \%$ de 489 parkinsonianos admitidos em um serviço de neurologia haviam tido quedas no ano anterior. O risco de quedas aumenta com a progressão da DP para fases mais avançadas (Park et al. 2015).

\subsection{Sistemas de controle do equilíbrio}

A manutenção da postura é desafiadora. Apesar dos ganhos advindos da liberação das mãos em bípedes, os processos neuromusculares para controle postural são obviamente mais complexos. É necessário manter a estabilidade em ortostatismo na presença da gravidade, deve haver resposta adequada para antecipação de movimentos voluntários e é fundamental que haja adaptabilidade, tanto para reagir a estímulos externos quanto para manter o organismo bípede em movimento (MacPherson e Horak, 2012).

Equilíbrio pode ser definido como o controle do centro de massa corporal sobre sua base de suporte para adquirir estabilidade e orientação postural (Park et al., 2015). 


\subsubsection{Mecanismos e sistemas neurais envolvidos}

Sistemas sensoriais, motores, associativos e musculoesqueléticos estão envolvidos no controle postural e do equilíbrio. Informações aferentes são integradas e possíveis correções necessárias são enviadas ao sistema motor para que as execute (Park et al., 2015).

Em um indivíduo saudável, as informações sensoriais são geradas pelo sistema somestésico ou porção egocêntrica; o sistema vestibular, referencial geocêntrico; e o sistema visual ao referencial alocêntrico (Freitas, 2005; Horak et al., 1996).

\subsubsection{Sistemas sensoriais}

O controle das ações motoras depende do fluxo de sinais que estimulam variados sistemas sensoriais do corpo, que lidam com formas variadas de energia: mecânica e receptores de pressão; cinética e receptores de movimento; radiante e receptores de luz e som; térmica e receptores de calor. A informação captada é codificada para impulsos nervosos, transmitida pelas vias aferentes até o SNC, pré-processada no tálamo e então decodificadas nas regiões sensoriais primárias do cérebro.

A propriocepção é a capacidade dos sistemas sensoriais de captar sinais gerados pelo corpo de um indivíduo, seja no interior dos fusos musculares, tendões e articulações que captam respectivamente estiramentos, tensão, posição e movimento; ou no ouvido interno, que constitui o aparelho vestibular. Há assim informação sobre postura e movimento do corpo. 
A exterocepção é a capacidade de outro conjunto de sensores em identificar o ambiente próximo e remoto, seja através do tato, visão ou audição. Assim são extraídas informações do ambiente circundante sobre posição e deslocamento do corpo que permitem regular os próprios movimentos (Teixeira, 2006).

\subsubsection{Sistemas de Integração sensório-motora}

Reflexos como os medulares vestibulares, são importantes para manter funções básicas de controle de equilíbrio (MacPherson e Horak, 2012), mas a percepção é o que desempenha a decodificação dos diversos sistemas sensoriais para que o indivíduo faça uso adequado das informações. O processamento em nível consciente só é possível em uma parcela reduzida da informação aferente disponível, o que é determinado pela atenção seletiva. Assim, a modalidade sensorial escolhida é privilegiada no acesso aos centros de integração sensoriomotores. Outros focos escolhidos podem ser a atividade cognitiva, organização e controle de atividade motoras. Quanto mais complexos forem os movimentos realizados, mais recursos atencionais serão exigidos, centralizando a atenção seletiva nos processos efetores, e não nos sistemas sensoriais (Teixeira, 2006).

Por último, para que os movimentos voluntários possam ser integrados com o controle postural, deve haver capacidade de aprendizado, que exige a integração de diversos sistemas neurais, em especial a cognição. O córtex ocupa o nível mais alto do controle motor. A antecipação é função perceptiva que possibilita planejar a duração dos movimentos de 
forma que eles sejam concluídos no momento adequado. Entre a vontade de realizar um movimento e sua efetiva execução é preciso que haja planejamento, que os comandos motores sejam enviados aos músculos para que sejam ativas e, finalmente, o movimento realizado.

As áreas pré-motoras recebem informação dos córtices associativos parietal posterior e pré-frontal, se projetando para o córtex motor primário e estes para a medula espinhal pelo trato córtico-espinhal, também regulando tratos motores que se originam no tronco encefálico. Os núcleos da base e cerebelo também se relacionam com estes níveis, regulando e planejando a execução do movimento. Ambos recebem estímulos corticais e se projetam ao córtex através do tálamo, por vias separadas. Agem também sobre neurônios do tronco encefálico que, por sua vez, conectam-se com a medula. Alterações nesta circuitaria tálamo-cortical, pela via direta ou indireta, geram todos os espectros de distúrbios do movimento, hipercinéticos ou hipocinéticos, sendo o último representado pela doença de Parkinson. A ausência de estimulação dopaminérgica pela substância negra pars compacta ao striatum leva ao aumento da atividade da via indireta pelo receptor D2 e redução da atividade da via direta pelo receptor D1. A via final comum desta alteração é a hiperatividade do globo pálido interno, levando a uma inibição da via tálamo-cortical e neurônios tegmentais do mesencéfalo e às características hipocinéticas da DP. 


\subsubsection{Mecanismos fisiopatológicos do equilíbrio na DP}

Além da clássica patologia da DP relacionada à degeneração de neurônios dopaminérgicos nigrais, sabe-se atualmente que o processo degenerativo se estende também aos sistemas serotoninérgico, noradrenérgico e colinérgico.

Dentre os sintomas cardinais da doença de Parkinson, ou seja, bradicinesia, tremor de repouso, rigidez e instabilidade postural, os três primeiros respondem adequadamente a terapia dopaminérgica. Já a instabilidade postural, embora possa ter resposta, é habitualmente menos responsiva ao tratamento com levodopa e agonistas dopaminérgicos (Olanow et al., 2009b).

Disfunção colinérgica tem sido associada à instabilidade postural e disfunção de marcha. Em um estudo com positron emission tomography ou tomografia por emissão de pósitrons (PET), maior redução da atividade colinérgica cortical e talâmica foi encontrada em pacientes com história de quedas se comparado aos que não caem e a controles.

A maior parte dos neurônios colinérgicos do encéfalo excetuando os neurônios motores é encontrada no mesencéfalo e prosencéfalo basal (núcleo basal de Meynert, septo medial, substância inominada e banda diagonal de Broca). Os neurônios do núcleo pedúnculo-pontino (PPN) e núcleos laterodorsais tegmentais do mesencéfalo são a maior fonte de inervação colinérgica ao tronco cerebral e tálamo e são críticos no controle da atenção e ciclo sono-vigília, com a participação do núcleo basal de Meynert. Através das projeções ao córtex aumentam a resposta a estímulos aferentes sensoriais. 
O estudo de Bohnen et al. (2009) ressaltam a importância do núcleo pedúnculopontino no controle do movimento e postura. Em portadores de parkinsonismo atípico, em especial paralisia supranuclear progressiva, que cursam com quedas precoces e frequentes, há redução ainda mais significativa da atividade colinérgica no córtex e estruturas do encéfalo como mesencéfalo e cerebelo, estas relacionados a projeções do NPP.

A instabilidade postural se correlaciona com pior desempenho em testes que avaliam disfunção executiva e de atenção, o que se torna mais claro em com testes de dupla tarefa. Adultos normais tendem a priorizar a postura nestes testes duais em detrimento da outra atividade concomitante (motora ou cognitiva), enquanto nos portadores de DP não há esta priorização, aumentando o risco de quedas.

Outro estudo que corrobora os dados expostos é o de Chung et al. (2010), que mostra redução pela metade do risco de quedas em pacientes em uso de inibidores de acetilcolinesterase, que aumentam a atividade colinérgica em todo o encéfalo.

Portanto, parece haver uma inter-relação na atividade dos sistemas colinérgicos dependentes das projeções dos núcleos do prosencéfalo basal e do NPP.

O sistema colinérgico parece estar envolvido de forma importante nos mecanismos de estabilidade postural. Desta forma, o núcleo pedúnculopontino tem sido apontado como uma das estruturas chave no controle da estabilidade postural e seu comprometimento na DP é um fato conhecido. Com base nestes conhecimentos, intervenções farmacológicas com o uso 
de inibidores de acetilcolinesterase como acima referido, ou intervenções pela neurocirurgia funcional sobre este núcleo por meio da técnica de estimulação cerebral profunda tem sido realizada como tentativas de obter melhor controle da instabilidade postural (Ferraye et al., 2011; RosenbergKatz et al., 2015).

\subsection{Alterações Posturais na Doença de Parkinson}

A postura fletida assumida progressivamente pelos pacientes com DP, associada à rotação dos ombros e flexão dos quadris e joelhos é um dos fatores que contribuem para a perda de estabilidade postural. Quando esta postura é assumida, mesmo em indivíduos saudáveis há aumento da retropulsão pélvica com comprometimento da estabilidade postural. A fisiopatologia das alterações posturais na doença de Parkinson ainda não está completamente elucidada, mas o tônus muscular de repouso aumentado, principalmente na musculatura flexora é um fator que contribui de forma significativa, levando a um alinhamento postural que não está em concordância com a gravidade. Isto levaria a uma mudança do centro de massa corporal em relação à base de suporte, causando alteração do equilíbrio e aumentando o risco de quedas principalmente quando associado a alterações distônicas ou deformidades posturais, tais como camptocormia, anterocolo, escoliose e síndrome de Pisa. 


\subsection{ECP e Alterações Axiais na DP}

O tratamento com levodopa aumenta a oscilação de pacientes portadores de doença de Parkinson, em parte devido às discinesias induzidas por levodopa. As discinesias podem, inclusive, ser uma causa de quedas em pacientes no sob efeito de medicação. Nestes casos pode haver interferência do tratamento cirúrgico. Palidotomia e ECP de globo pálido interno reduzem as oscilações, enquanto os efeitos da estimulação de núcleo subtalâmico apresentam resultados inconsistentes.

Em pacientes adequadamente selecionados, a ECP do núcleo subtalâmico (NST) promove um estado de ativação constante semelhante ao melhor efeito da medicação, possibilitando a redução da medicação e de suas complicações motoras.

Fuentes et al. (2009), afirmam que a estimulação epidural da coluna dorsal pode ser uma alternativa para o tratamento de distúrbios de locomoção na doença de Parkinson. O estudo realizado em ratos com depleção de dopamina e lesionados por 6-hidroxidopamina mostraram recuperação da locomoção nestes animais. Esta recuperação foi acompanhada por ruptura das oscilações aberrantes córtico-estriatais de baixa frequência restaurando padrões de atividade neuronal que se parecem com o estado que normalmente precede a iniciação espontânea da locomoção. 


\subsection{Avaliação do Equilíbrio}

\subsubsection{Pull test}

A percepção de que instabilidade postural era uma manifestação da DP foi descrita por Romberg, em 1853. Em 1880, Charcot descreveu uma maneira de quantificar este sinal puxando as roupas dos pacientes e na década de 1960 Hoehn e Yahr modificaram a forma de avaliação para um empurrão no esterno. A avaliação como é realizada hoje, foi desenvolvida por Fahn, nos anos de 1980, sendo incluída como um dos quesitos da UPDRS em 1987 (Hunt e Sethi, 2006). O pull test é usado como um instrumento de medida da instabilidade postural na DP e em outros distúrbios do movimento. Durante o teste, o examinador deve realizar uma perturbação externa do equilíbrio (puxão pelas costas) e verificar se há recuperação do equilíbrio. A instabilidade postural identificada pelo pull test é um preditor importante de risco de quedas, perda de independência e institucionalização, além de marcar a transição do estágio II para o estágio III de Hoehn e Yahr.

\subsubsection{Escalas}

\subsubsection{Escala clínica - UPDRS}

A escala denominada UPDRS foi desenvolvida em 1987 propondo-se a incorporar elementos de outras escalas existentes e oferecer uma forma de avaliação completa, mais eficiente e flexível para monitorar as alterações neurológicas e mentais decorrentes da DP assim como do seu tratamento. É dividida em quatro partes: a primeira avalia o estado mental, a segunda aborda as atividades de vida diária, a terceira consiste no exame motor e a 
quarta avalia complicações do tratamento. É considerada o "padrão-ouro" para avaliar o comprometimento clínico pela DP sendo amplamente usada em estudos sobre a moléstia (Kompoliti et al., 2007). É de aplicação relativamente fácil e com boa confiabilidade interexaminador. Agências governamentais regulatórias dos Estados Unidos e Europa têm usado dados da UPDRS para embasar a autorização para novas drogas e avaliação de efeito placebo. Tem sido também utilizada em praticamente todos os estudos recentes relacionados a tratamento cirúrgico na DP.

Apesar de todas as vantagens que oferece, no entanto, a escala apresenta algumas limitações. A parte quatro, que inclui detecção de manifestações não motoras e complicações do tratamento, segundo Kompoliti et al. (2007) é muito vaga e difícil de usar em estudos clínicos. A parte três, que se refere ao exame motor, embora tenha uma boa reprodutibilidade em seu total, apresenta itens de baixa confiabilidade interexaminador. Dentre estes, se destaca a avaliação da estabilidade postural, que depende diretamente da força do estímulo. Outros são a fala, expressão facial, postura, tremor de ação, rigidez e bradicinesia global.

\subsubsection{Escalas de avaliação de equilibrio}

A escala de equilíbrio de Berg (Berg et al., 1992) é utilizada para avaliar a presença de instabilidade postural. Consiste em 14 itens, pontuados de zero a quatro, que avaliam a habilidade do paciente manter $\mathrm{o}$ equilíbrio em atividades funcionais. É utilizada em indivíduos idosos para monitorar alterações que podem ocorrer durante o envelhecimento, analisar 
a evolução de pacientes em centros de reabilitação e detectar a probabilidade de quedas durante atividades funcionais (Kornetti et al., 2004). A pontuação total é de 56 . O paciente restrito à cadeira de rodas recebe pontuação entre zero e 20 . O que deambula com auxílio é classificado entre 31 e 40, enquanto pacientes independentes recebem pontuação acima de 40. Resultado acima ou igual 45 é considerado satisfatório, uma vez que abaixo desta pontuação foi percebido maior risco de quedas (Kornetti et al., 2004, Qutubuddin et al., 2005). Scalzo et al. (2009) realizaram a validação da versão brasileira da Berg Balance Scale (BBS) para pacientes com doença de Parkinson. A BBS mostrou-se um instrumento útil para avaliar o equilíbrio na DP correlacionando-se com o estágio da doença e com o nível de independência. Com essa escala, é possível avaliar, de forma quantitativa, as alterações do equilíbrio na DP.

O BESTest é um teste completo de avaliação de equilíbrio dinâmico bastante utilizado para avaliação do equilíbrio em pacientes com DP que consiste de 36 itens agrupados em 6 subsistemas (biomecânico, limites de estabilidade e verticalidade, ajustes posturais antecipatórios, respostas posturais, orientação sensorial e estabilidade na marcha) implicados na aquisição e manutenção do equilíbrio e cada item recebe uma pontuação de zero a 3, sendo o máximo 108 (Horak et al., 2009).

O Mini-BESTest (MBT) inclui as seções 4 a 6 do BESTest (ajuste postural antecipatório, resposta postural, orientação sensorial, estabilidade da marcha) (King et al., 2012) e vem sendo usado por ter aplicação mais fácil e repruduzir de forma fidedigna ao BESTest o risco de quedas em portadores de DP (Leddy et al., 2011). 
Possui 14 itens, que são pontuados de zero a 2, sendo o escore máximo 28 e o mínimo zero ponto, sendo que o maior escore traduz melhor equilíbrio. O teste avalia aspectos que sabidamente podem estar alterados em pacientes com DP, entre eles a estabilidade dinâmica da marcha com e sem tarefa cognitiva por meio do item 14 (Timed up and Go Test) e as respostas posturais às perturbações externas através do pull test (O'Hoski et al., 2014).

\subsubsection{Posturografia}

As formas de avaliação do equilíbrio usadas para avaliar pacientes com doença de Parkinson baseiam-se geralmente em parâmetros semiquantitativos e são com frequência examinador-dependentes. A posturografia, ao contrário, é um método objetivo e quantitativo que tem se mostrado mais sensível e precisa para este tipo de avaliação. Pode ser estática, quando a superfície é plana e estável, ou dinâmica quando a superfície é irregular ou móvel. A avaliação pode ser também feita observando-se a resposta a estímulos externos. Ao manter-se em posição ortostática, o centro de massa do indivíduo localiza-se dentro de uma base de suporte definida pelos pés. Esta posição, no entanto, não é estática, pois há oscilações constantes que representam um estado complexo de atividade sensório-motora modulado por circuitos que contribuem para o controle do equilíbrio (Freitas, 2005).

Estas oscilações podem ser medidas por plataformas de força, que detectam as flutuações do centro de pressão, ou por acelerômetros, que 
detectam flutuações no centro de massa. Essas flutuações podem então ser caracterizadas por variáveis tais como área, frequência, velocidade e deslocamento máximo anteroposterior e laterolateral (Duarte e Freitas, 2010)

Aumento da oscilação, principalmente médio-lateral, é associado com quedas em algumas condições, dentre as quais doença de Parkinson (Błaszczyk et al., 2007).

Oscilações posturais podem ser anormais em pacientes portadores de DP mesmo antes de qualquer evidência clínica e antes do início do tratamento com levodopa. Nestes pacientes, as oscilações tendem a ser mais rápidas e de frequência mais alta, além de terem maior amplitude lateral do que em controles saudáveis. Embora o fechamento dos olhos possa aumentar a oscilação na maioria dos indivíduos, pode haver diferenças significativas neste aspecto em comparação a controles saudáveis (Fioretti et al., 2004).

Anormalidades do equilíbrio podem ser assim encontradas em pacientes portadores de DP em fase inicial, antes da introdução do tratamento. Em fase avançada também pode ser útil como método mais apropriado para identificar estas alterações de equilíbrio e sua resposta a intervenções terapêuticas, tanto clínicas quanto cirúrgicas (Błaszczyk et al., 2011). 


\section{MÉtodos}


Este trabalho é um estudo transversal comparativo, realizado no Instituto de Ortopedia e Traumatologia do Hospital das Clínicas da Faculdade de Medicina da Universidade de São Paulo (HC-FMUSP).

\subsection{Casuística}

Vinte e seis pacientes em pré-operatório de cirurgia estimulação cerebral profunda e 46 pacientes em pós-operatório foram convidados a participar por contato telefônico. Destes, todos os 26 em pós-operatório e 31 em pós-operatório consentiram e foram avaliados após assinar o termo de consentimento livre e esclarecido. O contato foi feito de forma consecutiva a partir dos nomes e contatos dos pacientes inseridos em tabela de pacientes do serviço.

Os critérios de inclusão e exclusão, descritos a seguir, são os adotados pela divisão de Neurocirurgia Funcional do Instituto de Psiquiatria do HC-FMUSP.

\section{Critérios de Inclusão}

a) Pacientes com diagnóstico clínico de Doença de Parkinson Idiopática conforme os critérios internacionais (Nutt e Wooten et al., 2005; Frank et al., 2006; Savitt et al., 2006), que não apresentam resposta 
adequada ao tratamento com medicação ou que apresentem complicações relacionadas ao uso prolongado de levodopa.

b) Pacientes que possam ser anestesiados ou em que a anestesia local ou geral não incorra em risco maior que o esperado na população geral.

c) Pacientes intelectualmente aptos compreender e assinar o termo de consentimento.

d) Pacientes com exames hematológicos, de coagulação e metabólicos normais.

\section{Critérios de exclusão}

a) Idade inferior a 18 anos.

b) Impossibilidade de consentir sua participação no estudo.

c) Pacientes em vigência do tratamento com anticoagulantes antiagregantes plaquetários.

d) Pacientes com anormalidades anatômicas que impossibilitem o acesso para o implante de eletródios (ex. tumores cranianos ou intracranianos ou cistos).

e) Pacientes com infecção não-controlada ou outras condições médicas pré-existentes não-controladas (ex. diabetes descompensada, hipertensão arterial, pneumo ou cardiopatia sintomática).

f) História de isquemia miocárdica primária ou secundária, insuficiência cardíaca congestiva, arritmia cardíaca ou bloqueio de ramo refratários ao tratamento. 
g) Tratamento concomitante com outras drogas experimentais.

h) Mulheres grávidas ou em fase de amamentação.

i) Condições psicológicas, familiares, sociológicas ou geográficas que impossibilitem o acompanhamento médico pós-operatório.

Observação: Critérios utilizados para seleção de pacientes para cirurgia de doença de Parkinson, sendo os mesmos no grupo operado e controle deste estudo.

Para facilitar o entendimento, na Figura 1 encontra-se o organograma da divisão dos grupos. 


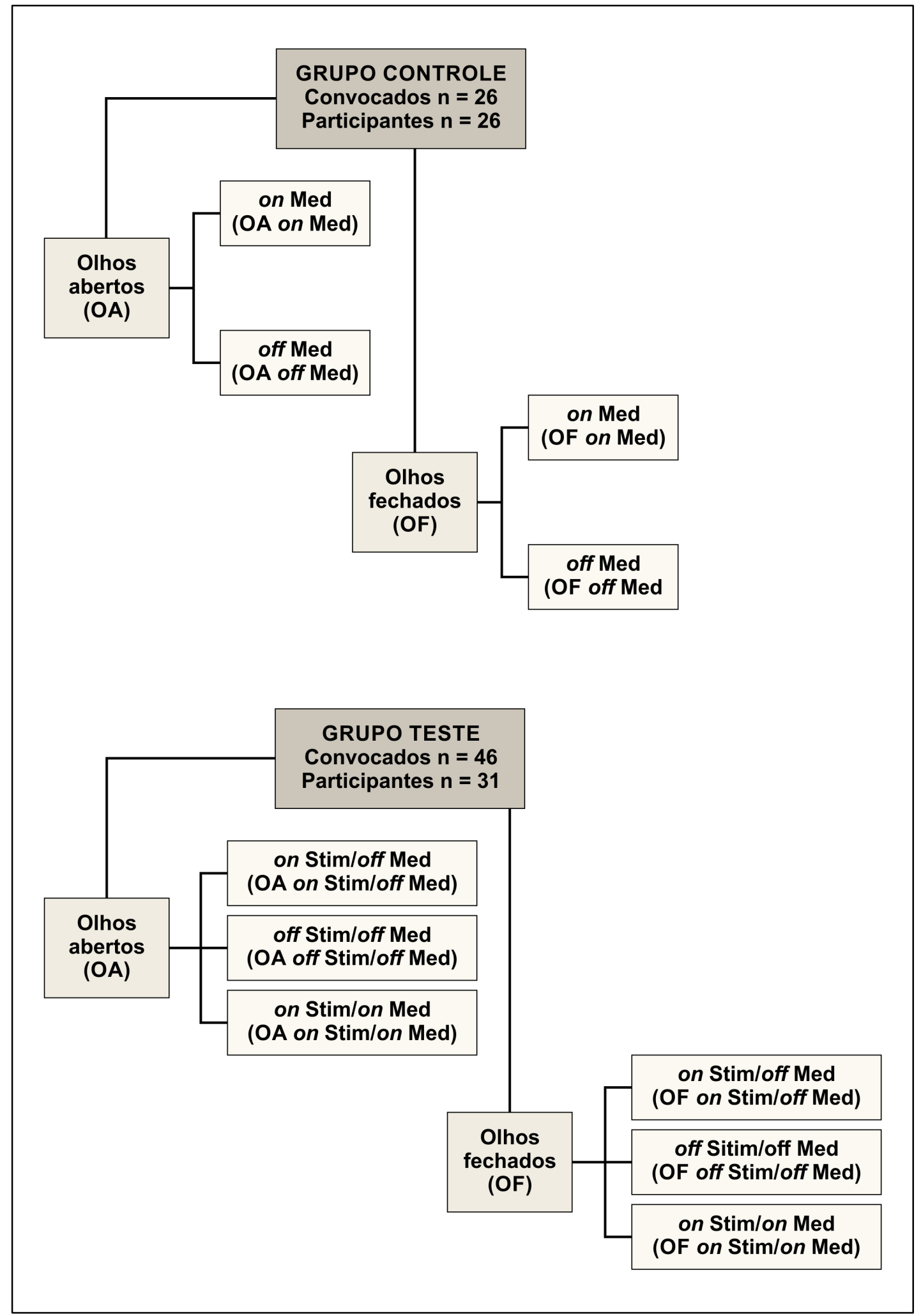

Figura 1 - Organograma da divisão dos grupos 


\subsection{Métodos}

Foram realizadas avaliações clínica e posturográfica.

\subsubsection{Avaliação clínica}

A avaliação clínica foi realizada por médico neurologista especializado em distúrbios de movimentos.

Todos os pacientes compareceram para avaliação inicial sem o uso de qualquer medicação antiparkinsoniana há pelo menos 12 horas (estado off-medicação para os não-operados e off-medicação on-estimulação (ECP) para os operados) e avaliados com a escala Hoehn e Yahr e com a parte três da escala UPDRS e, logo após, submetidos a avaliação com posturografia descrita a seguir.

Os pacientes do grupo não-operado receberam então uma dose de levodopa equivalente a $30 \%$ da dose total diária equivalente de levodopa. Após obtenção do estado descrito como melhor on foram reavaliados com as mesmas escalas e novamente submetidos à posturografia.

Já os pacientes operados eram então submetidos ao desligamento do aparelho de estimulação cerebral profunda e reavaliados após um período mínimo de duas horas, quando descrevessem o estado como pior off, chamado de estado off-medicação off-ECP, sendo novamente submetidos à avaliação com as escalas Hoehn e Yahr e UPDRS parte três e posturografia. Eram então submetidos ao religamento do gerador e tomavam $30 \%$ da dose equivalente diária de levodopa, sendo um mínimo de 100 mg. Após obtenção do estado melhor on eram então novamente avaliados, desta vez sob efeito 
da medicação e estimulação (estado on-medicação on-ECP), com as escalas Hoehn e Yahr, UPDRS parte três e submetidos à posturografia.

\subsubsection{Avaliação Posturográfica}

\subsubsection{Instrumentos}

A posturografia foi realizada por meio de uma plataforma de força que foi ligada na corrente elétrica 30 minutos antes de iniciar os testes, para que o equipamento fosse aquecido, conforme recomendações do fabricante.

Para análise do equilíbrio postural foram registradas as forças de reação do solo e a quantificação das oscilações dos corpos dos sujeitos. Para isso, os pacientes permaneceram sobre uma plataforma de força portátil (modelo AccuSwayPlus, marca Advanced Mechanical Technology Inc., AMTI, Watertown, Massachusetts), medindo $50 \mathrm{~cm} \times 50 \mathrm{~cm}$ com uma altura de 45 milímetros, sendo a principal grandeza física obtida a partir deste equipamento foi o centro de pressão (CP). Para tanto, as forças $(F)$ e momentos $(\mathrm{M})$ registrados pela plataforma nas três direções (laterolateral $\mathrm{X}$, anteroposterior - $\mathrm{Y}$ e vertical - Z) foram utilizados para calcular as posições do CP nas direções anteroposterior (AP) e laterolateral (LL).

Para aquisição dos dados a plataforma de força foi conectada uma caixa de interface (PJB-101) para amplificação dos sinais e a mesma foi conectada com um computador por meio de cabo RS-232. Os dados foram coletados e armazenados pelo software Balance Clinic $^{\circledR}$, configurado para uma frequência de $100 \mathrm{~Hz}$ com um filtro de quarta ordem tipo Butterworth, com uma frequência de corte de $10 \mathrm{~Hz}$ (Duarte e Freitas, 2010). 
A plataforma foi zerada antes de cada teste.

\subsubsection{Posicionamento}

Inicialmente os pacientes foram orientados quanto ao procedimento do teste e foi solicitado que permanecem descalços. Antes de realizar as avaliações, os pacientes subiram descalços na plataforma adotando a base de suporte que iriam utilizar durante os testes, não podendo ultrapassar a largura dos quadris. Para que a mesma base de suporte fosse reproduzida em todas as coletas, foi realizado o desenho dos pés na posição em que se encontravam na plataforma (em uma folha de papel sulfite fixada na plataforma) além de marcações de quatro pontos específicos de cada pé correspondentes a: região distal da falange distal do hálux, cabeça do quinto metatarso, maléolo lateral e medial. Posteriormente os pacientes desciam da plataforma e se sentavam em uma cadeira. Neste momento o avaliador, com o auxílio de um bastão próprio para esta finalidade, fornecido pelo fabricante, aplicava uma força de 10 libras (Ibs) para registrar os oito pontos demarcados na folha de papel, para que o programa pudesse registrar a base de apoio.

Após a configuração da base de suporte, a plataforma era zerada e os pacientes eram orientados a subirem na plataforma e adotar apoio bipodálico conforme havia sido demarcado na folha de papel. Foram orientados a permanecer da forma mais estática possível, com os braços relaxados ao longo do corpo e fixando o olhar em um ponto pré-determinado e demarcado, localizado a um metro de distância e $10 \mathrm{~cm}$ abaixo de sua 
estatura. Uma vez posicionados e orientados quanto ao exame, foi dado o comando verbal de início do teste, mas o mesmo só iniciava efetivamente após cinco segundos, para descartar as oscilações iniciais decorrentes da adaptação postural. A cada uma das tentativas, seja com olhos abertos ou fechados, os pacientes eram orientados para que se sentassem em uma cadeira para evitar a fadiga. Desta forma, foram realizadas três tentativas com os olhos abertos e três com os olhos fechados. A duração de cada tentativa foi de 60 segundos. Ao término de cada teste os dados eram salvos no software, era feita uma análise dos sinais e antes de iniciar cada novo teste a plataforma era novamente zerada. Os resultados foram dados pela média aritmética dos três testes realizados em cada condição, processados no software de análise Balance Clinic $^{\circledR}$.

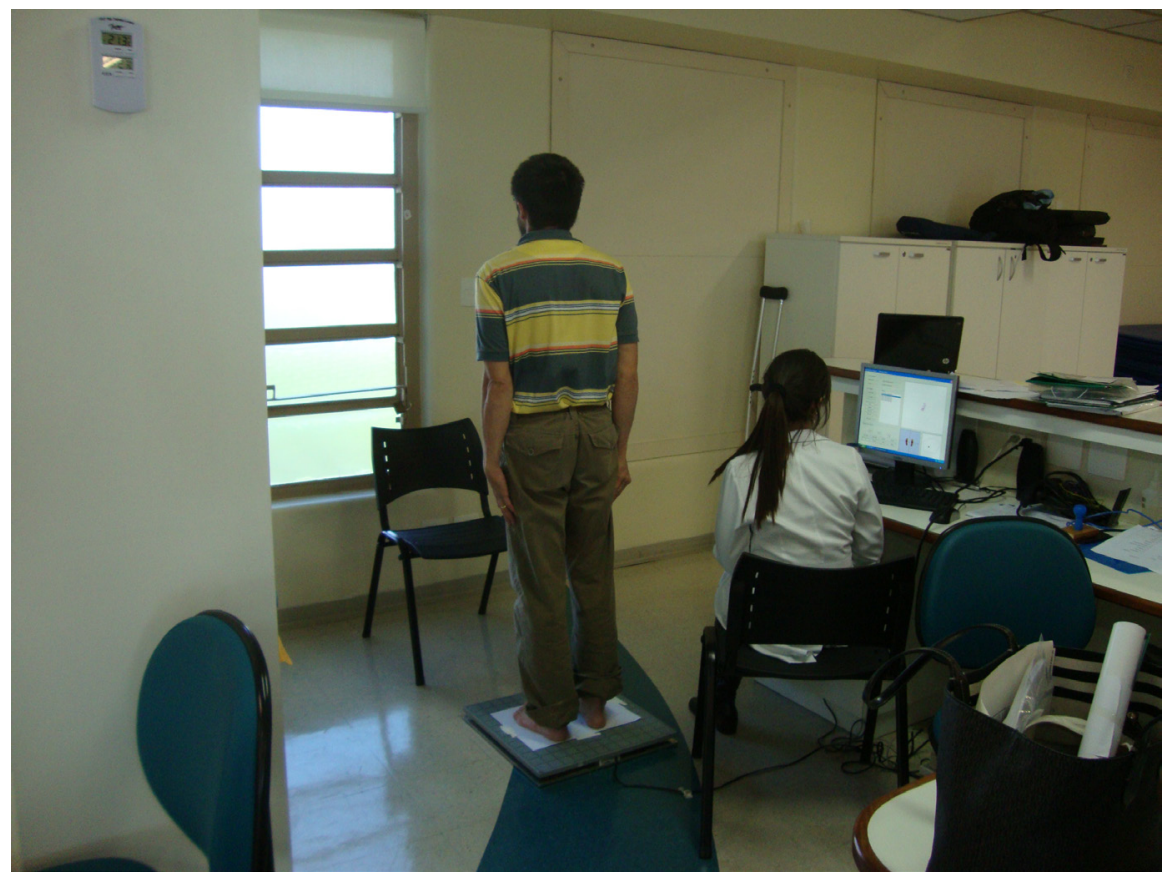

Figura 2 - Paciente realizando a avaliação posturográfica no laboratório 


\subsubsection{Variáveis}

As variáveis estabilométricas analisadas para olhos abertos e fechados foram:

- Amplitude média de deslocamento do CP nos planos laterolateral (XSD) e anteroposterior (YSD), que são a raiz quadrática média (RMS) dos deslocamentos do CP em cada direção, expressa centímetros (cm).

- Velocidade média resultante (VAvg), que é a velocidade média calculada pelo deslocamento total do CP em todas as direções pelo período, expressa em centímetros por segundo $(\mathrm{cm} / \mathrm{s})$.

- Área elíptica de 95\% de deslocamento (Área 95), que é uma elipse onde $95 \%$ de todo deslocamento do CP esteja dentro, expressa em centímetros quadrados $\left(\mathrm{cm}^{2}\right)$.

- Path length, que corresponde a todo o caminho percorrido pelo centro de pressão do paciente, expresso em centímetros $(\mathrm{cm})$.

A análise estatística apresentará uma análise descritiva das variáveis mensuradas. Os mesmos parâmetros estabilométricos serão analisados para olhos abertos e fechados:

- Amplitude média de deslocamento do CP nos planos YSD e XSD, que são as RMS dos deslocamentos do CP em cada direção, expressa centímetros $(\mathrm{cm})$.

- VAvg, que é a velocidade média calculada pelo deslocamento total do CP em todas as direções pelo período, expressa em centímetros por segundo $(\mathrm{cm} / \mathrm{s})$. 
- Área elíptica de 95\% de deslocamento (Área 95), sendo uma elipse onde $95 \%$ de todo deslocamento do CP esteja dentro, expressão em centímetros quadrados $\left(\mathrm{cm}^{2}\right)$.

- Path length expresso em centímetros (cm).

\subsubsection{Análise Estatística}

O teste paramétrico t-Student ou, quando apropriado, o teste não paramétrico de Mann-Whitney foi realizado para comparar os grupos pré e pós-operatórios. O teste paramétrico t-Student para duas amostras dependentes ou, quando apropriado, o teste não paramétrico de postos com sinal de Wilcoxon foi utilizado para comparar o grupo pré-operatório nas duas situações. A análise de variância de dois fatores de Friedman por postos foi utilizada para comparar o grupo pós-operatório nas três situações.

\subsection{Dados demográficos}

Foram avaliados 26 pacientes não-operados, sendo seis mulheres $(23,1 \%)$ e 20 homens $(76,9 \%)$ e 31 pacientes operados, sendo 11 mulheres $(35,5 \%)$ e 20 homens $(64,5 \%)$.

Os dados relativos à idade dos pacientes, tempo de doença e dose equivalente de levodopa foram avaliados pelo teste t-Student por seguirem distribuição Gaussiana de acordo com o teste de Normalidade de RyanJoiner (Tabela 1) 
Tabela 1 - Dados demográficos da população estudada

\begin{tabular}{lcccccccc}
\hline Variável & Grupo & N & Média & Mediana & $\begin{array}{c}\text { Desvio } \\
\text { padrão }\end{array}$ & Mínimo & Máximo & $\begin{array}{c}\text { Valor } \\
\mathbf{p}\end{array}$ \\
\hline Idade & Não-op & 26 & 61,27 & 61,50 & 9,07 & 41,00 & 78,00 & 0,978 \\
& Pós-op & 31 & 61,19 & 66,00 & 11,63 & 39,00 & 78,00 & \\
Tempo de & Não-op & 26 & 14,00 & 14,00 & 3,83 & 8,00 & 20,00 & \\
Doença & Pós-op & 31 & 15,58 & 15,00 & 6,81 & 7,00 & 32,00 & 0,276 \\
DeqLDopa & Não-op & 26 & 1155,20 & 1040,00 & 486,40 & 225,00 & 2340,00 & \\
& Pós-op & 31 & 603,70 & 500,00 & 348,50 & 0,00 & 1300,00 & 0,000 \\
\hline
\end{tabular}

Não-op = Grupo não-operado; Pós-op = Grupo operado

Pode-se concluir, com 95\% de confiança, que não existe diferença estatisticamente significativa na idade e no tempo de doença entre os grupos operado e não-operado (valor $p>0,05$ ). Em relação à dosagem de medicação pode-se afirmar que o grupo não-operado apresentou maior dosagem média do que o grupo operado (valor $p<0,05$ ), sendo que a diferença média foi de $47,7 \%$ a menos de medicação para o grupo operado (Gráfico 1) 
Gráfico 1 - Boxplot da dosagem de medicação

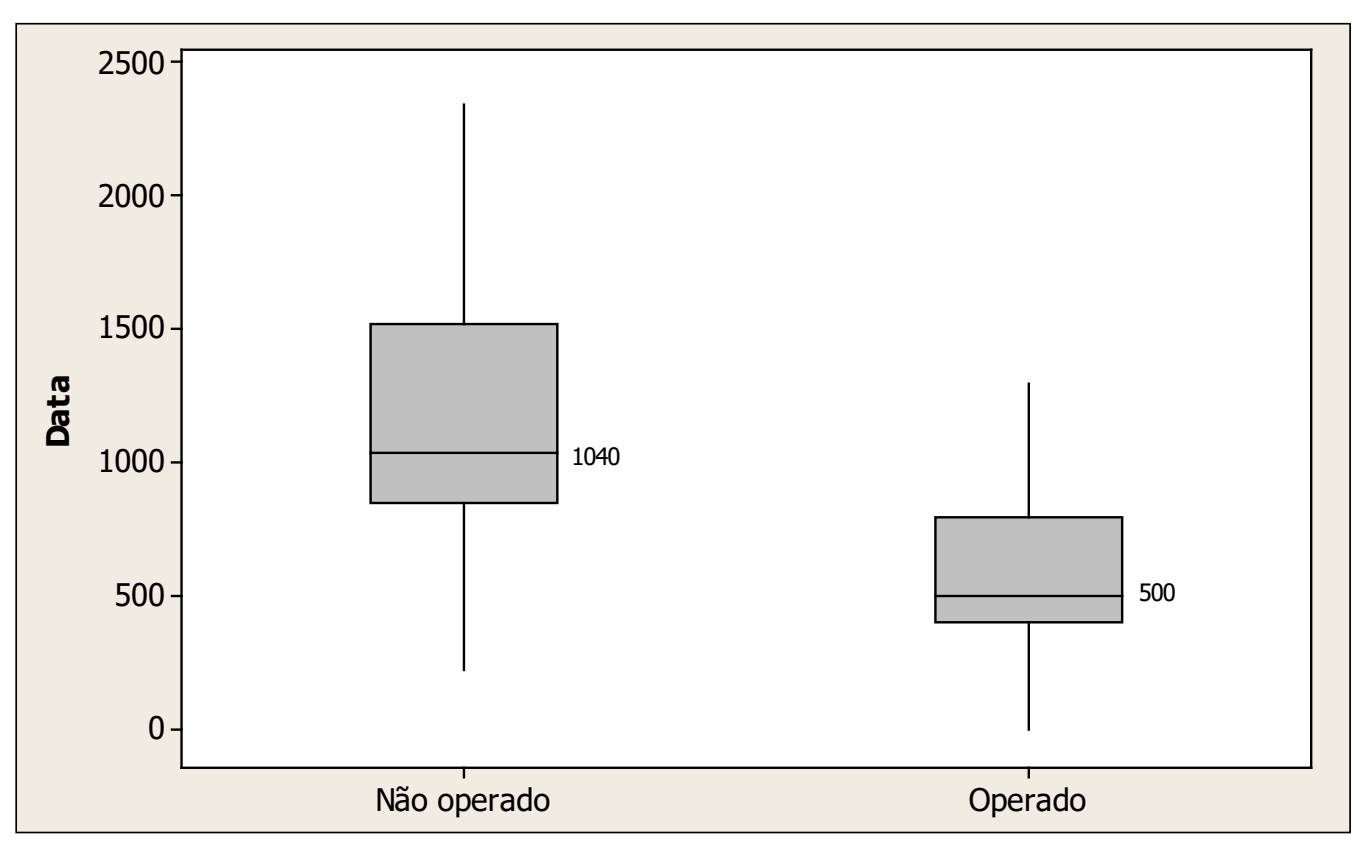




\section{Resultados}




\subsection{Avaliação Clínica}

Quando avaliada a gravidade da DP dos grupos pela escala UPDRS, foi utilizado o teste $t$ de Student. Os dados seguem distribuição normal de acordo com o teste de Ryan Joiner.

Foi considerada pontuação axial aquela atribuída a marcha, estabilidade postural, levantar da cadeira, postura e bradicinesia global, sendo a pontuação máxima possível equivalente a 20 pontos. No total geral foram considerados todos os quesitos da parte três do UPDRS, sendo o máximo possível de 108 pontos.

Pode-se perceber, portanto, que a diferença média entre a pontuação axial on e off medicação é de 5,54 pontos, o equivalente a uma melhora de aproximadamente $56 \%$ com o uso da levodopa (Tabela 2 e Gráfico 2).

\section{Tabela 2 - UPDRS axial e geral dos pacientes não-operados}

\begin{tabular}{lccccccc}
\multicolumn{1}{c}{ Variável } & $\mathbf{n}$ & Média & Mediana & $\begin{array}{c}\text { Desvio } \\
\text { padrão }\end{array}$ & Mínimo & Máximo & $\begin{array}{c}\text { Valor } \\
\mathbf{p}^{*}\end{array}$ \\
\hline Total axial on & 26 & 4,31 & 4,00 & 1,85 & 1,00 & 7,00 & 0,000 \\
Total axial off & 26 & 9,85 & 9,50 & 2,96 & 5,00 & 16,00 & \\
Total geral on & 26 & 21,00 & 20,50 & 7,68 & 8,00 & 36,00 & 0,000 \\
Total geral off & 26 & 52,88 & 52,50 & 11,03 & 32,00 & 74,00 & \\
\hline
\end{tabular}

* Teste t-Student para amostras pareadas 


\section{Gráfico 2 - Boxplot UPDRS axial dos pacientes não-operados}

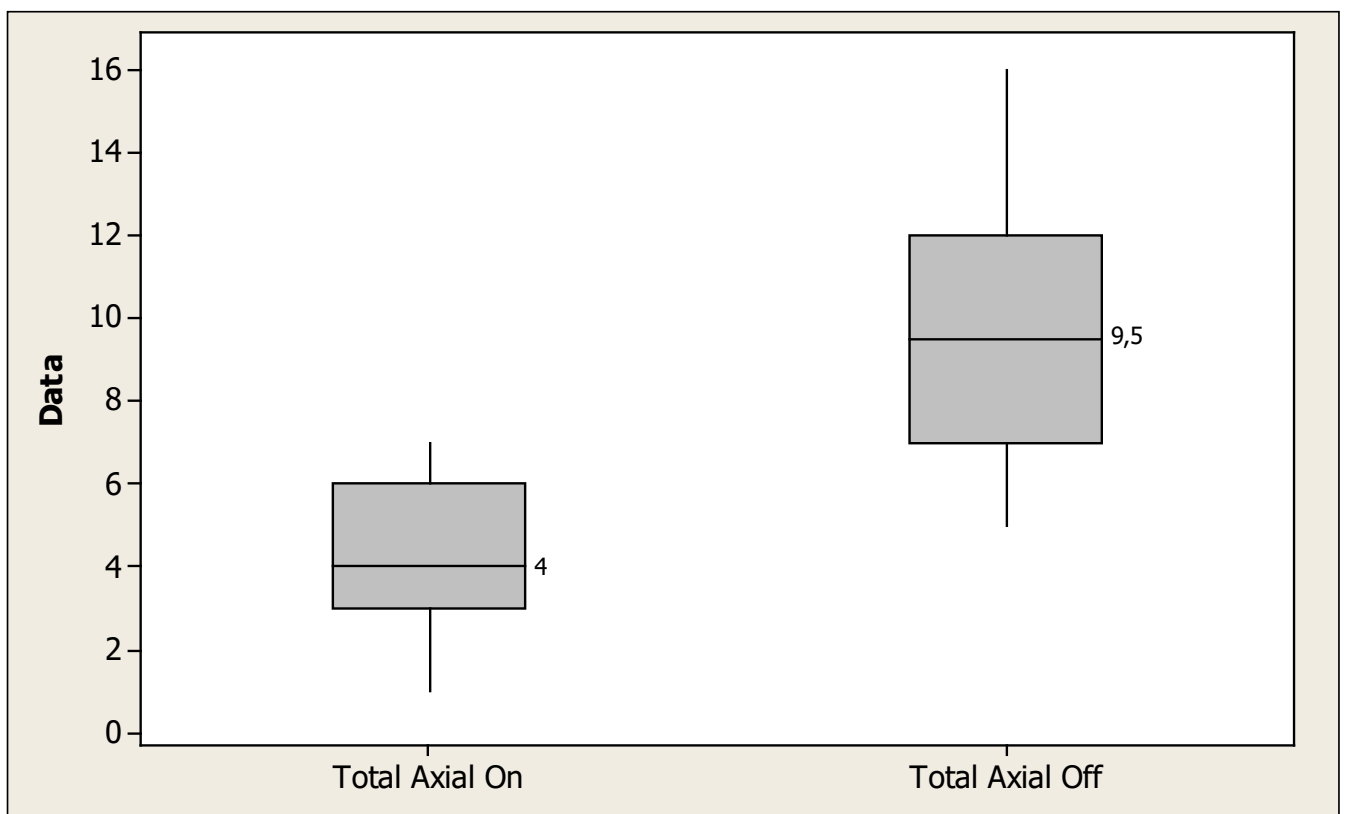

Avaliando-se a pontuação global, há uma redução média de 31,88 pontos, ou o equivalente a uma melhora de $60 \%$ após administração da levodopa (Gráfico 3).

\section{Gráfico 3 - Boxplot UPDRS geral dos pacientes não-operados}

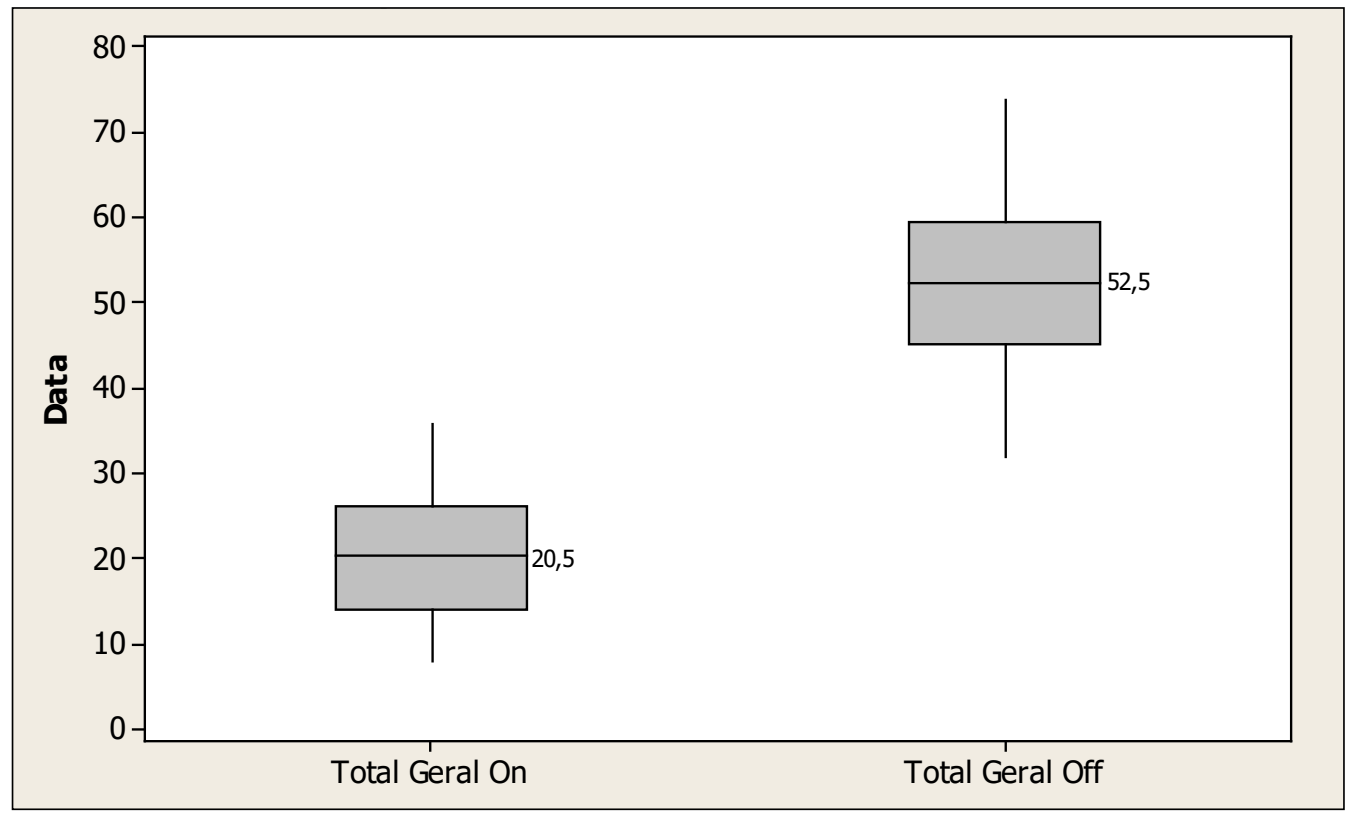


Os pacientes já submetidos à cirurgia foram avaliados nos estados on-medicação/on-ECP, off-medicação/off-ECP e off-medicação/on-ECP. Os resultados da avaliação com UPDRS entre estes grupos foi feito pelo teste de Friedman, que é um teste não-paramétrico, já que de acordo com o teste de Normalidade de Ryan Joiner apenas três variáveis seguem distribuição normal e todas as demais não a seguem (Tabela 3).

Tabela 3 - UPDRS global e axial dos pacientes operados

\begin{tabular}{lccccccc}
\multicolumn{1}{c}{ Variável } & $\mathbf{n}$ & Média & Mediana & $\begin{array}{c}\text { Desvio } \\
\text { padrão }\end{array}$ & Mínimo & Máximo & $\begin{array}{c}\text { Valor } \\
\mathbf{p}^{*}\end{array}$ \\
\hline $\begin{array}{l}\text { Total axial on- } \\
\text { ECPloff-Med }\end{array}$ & 31 & 5,16 & 5,00 & 2,33 & 1,00 & 13,00 & \\
$\begin{array}{l}\text { Total axial off- } \\
\text { ECPloff-Med }\end{array}$ & 31 & 10,10 & 9,00 & 3,20 & 5,00 & 17,00 & 0,000 \\
$\begin{array}{l}\text { Total axial on- } \\
\text { ECPlon-Med }\end{array}$ & 31 & 4,16 & 4,00 & 2,52 & 1,00 & 13,00 & \\
$\begin{array}{l}\text { Total geral on- } \\
\text { ECPloff-Med }\end{array}$ & 31 & 22,52 & 21,00 & 7,57 & 7,00 & 45,00 & \\
$\begin{array}{l}\text { Total geral off- } \\
\text { ECPloff-Med }\end{array}$ & 31 & 52,65 & 50,00 & 8,04 & 40,00 & 73,00 & 0,000 \\
$\begin{array}{l}\text { Total geral on- } \\
\text { ECPlon-Med }\end{array}$ & 31 & 16,61 & 16,00 & 7,31 & 5,00 & 40,00 & \\
\hline
\end{tabular}

*Teste não paramétrico de Friedman para amostras relacionadas

Onde: on-ECP = sob efeito de estimulação; on-Med = sob efeito de medicação; off-ECP = sem efeito de estimulação; off-Med = sem efeito de medicação

Há diferença estatisticamente significativa entre os três grupos, mesmo em comparações individuais, com ganho adicional ao se administrar a medicação acima do ECP de acordo com o teste de Wilcoxon Signed Rank quando comparadas as amostras em pares. Na parte axial, há redução de nove para quatro pontos ao ligar a ECP e uma redução adicional de um ponto na mediana ao se administrar medicação com ECP ligada. Há, portanto, uma melhora de $44 \%$ com ECP e $55,5 \%$ ao somar o efeito de ECP e medicação na parte axial. Já o escore geral apresenta redução de $58 \%$ ao 
se ligar a ECP, com uma melhora adicional ao se administrar levodopa totalizando $68 \%$ de melhora com o tratamento.

$\mathrm{Na}$ Tabela 4 pode-se observar a comparação entre os grupos operados e não-operados, mostrando que são semelhantes tanto no estado off quanto no estado on quanto ao componente axial.

\section{Tabela 4 - Comparação do UPDRS axial dos grupos operados e não- operados}

\begin{tabular}{lccccccc}
\multicolumn{1}{c}{ Variável } & $\mathbf{n}$ & Média & Mediana & $\begin{array}{c}\text { Desvio } \\
\text { padrão }\end{array}$ & Mínimo & Máximo & $\begin{array}{c}\text { Valor } \\
\mathbf{p}\end{array}$ \\
\hline Total Axial on & 26 & 4,31 & 4,00 & 1,85 & 1,00 & 7,00 & \\
Total axial on- & 31 & 5,16 & 5,00 & 2,33 & 1,00 & 13,00 & $0,136^{*}$ \\
ECP/off-Med & 26 & 4,31 & 4,00 & 1,85 & 1,00 & 7,00 & \\
Total Axial on & 26 & 4,00 & 2,52 & 1,00 & 13,00 & $0,547^{* *}$ \\
Total axial on- & 31 & 4,16 & 4,00 & \\
ECP/on-Med & 26 & 9,85 & 9,50 & 2,96 & 5,00 & 16,00 & \\
Total Axial off & $26,5,00$ & \\
Total axial off- & 31 & 10,10 & 9,00 & 3,20 & 5,00 & 17,00 & $0,762^{*}$ \\
ECP/off-Med & & & & & & & \\
\hline
\end{tabular}

* Teste t-Student

** Teste não-paramétrico Mann-Whitney

Onde: on-ECP = sob efeito de estimulação; on-Med = sob efeito de medicação; off-ECP = sem efeito de estimulação; off-Med = sem efeito de medicação

Comparação entre o UPDRS total dos grupos, mostrando que em off são equivalentes. O on-ECP é semelhante ao on-medicação, mas ao se comparar com os pacientes on-ECP/on-medicação, estes têm melhora adicional, traduzida pela pontuação mais baixa (Tabela 5). 
Tabela 5 - Comparação do UPDRS geral dos pacientes operados e nãooperados

\begin{tabular}{lccccccc}
\multicolumn{1}{c}{ Variável } & $\mathbf{n}$ & Média & Mediana & $\begin{array}{c}\text { Desvio } \\
\text { padrão }\end{array}$ & Mínimo & Máximo & $\begin{array}{c}\text { Valor } \\
\mathbf{p}\end{array}$ \\
\hline Total geral on & 26 & 21,00 & 20,50 & 7,68 & 8,00 & 36,00 & \\
$\begin{array}{l}\text { Total geral on- } \\
\text { ECPloff-med }\end{array}$ & 31 & 22,52 & 21,00 & 7,57 & 7,00 & 45,00 & $0,458^{*}$ \\
Total geral on & 26 & 21,00 & 20,50 & 7,68 & 8,00 & 36,00 & \\
Total geral on- & 31 & 16,61 & 16,00 & 7,31 & 5,00 & 40,00 & $0,028^{* *}$ \\
ECPlon-med & 26 & 52,88 & 52,50 & 11,03 & 32,00 & 74,00 & \\
Total geral off & 26 & & & & \\
Total geral off- & 31 & 52,65 & 50,00 & 8,04 & 40,00 & 73,00 & $0,925^{*}$ \\
ECP/off-med & & & & & & & \\
\hline
\end{tabular}

* Teste t-Student; ** Teste não-paramétrico Mann-Whitney

A gravidade dos grupos em estado off é semelhante pela escala Hoehn e Yahr. Também quando comparados os grupos com melhor on, não há diferença entre eles (Tabela 6).

Tabela 6 - Gravidade segundo a escala de Hoehn e Yahr (on e off)

\begin{tabular}{lccccccc}
\multicolumn{1}{c}{ Variável } & $\mathbf{n}$ & Média & Mediana & $\begin{array}{c}\text { Desvio } \\
\text { padrão }\end{array}$ & Mínimo & Máximo & $\begin{array}{c}\text { Valor } \\
\mathbf{p}^{*}\end{array}$ \\
$\begin{array}{l}\text { Hoehn e Yahr } \\
\text { off }\end{array}$ & 26 & 3,173 & 3,000 & 0,565 & 2,500 & 5,000 & \\
$\begin{array}{l}\text { Hoehn e Yahr } \\
\text { off-ECPloff- } \\
\text { med }\end{array}$ & 31 & 3,435 & 3,000 & 0,680 & 2,500 & 5,000 & 0,125 \\
$\begin{array}{l}\text { Hoehn e Yahr } \\
\text { on }\end{array}$ & 26 & 2,346 & 2,500 & 0,368 & 2,000 & 3,000 & \\
$\begin{array}{l}\text { Hoehn e Yahr } \\
\text { on-ECPlon- } \\
\text { med }\end{array}$ & 31 & 2,323 & 2,500 & 0,509 & 1,500 & 4,000 & $0,845^{* *}$ \\
\hline
\end{tabular}

* Teste de Mann-Whitney, variáveis não-paramétricas pelo teste de Ryan Joyner; **Teste t-Student, distribuição normal 


\subsection{Posturografia}

Foram avaliadas as oscilações do centro de pressão (COP) de cada paciente sobre a plataforma de força. A plataforma fornece diversos parâmetros derivados da medida destas oscilações e aqui serão apresentados cinco destes parâmetros, os mais frequentes na literatura: o parâmetro XSD, que corresponde à raiz quadrática média do deslocamento mediolateral do COP; YSD, raiz quadrática média do deslocamento anteroposterior do COP; Path Length (PL), ou a distância total em centímetros percorrido pelo COP do paciente sobre a plataforma durante os 60 segundos em apoio bipodal sobre a plataforma estática; velocidade do deslocamento do centro de pressão sobre a plataforma, derivado do total do deslocamento e do tempo de análise; e a área 95\%, que corresponde à área de uma elipse que engloba $95 \%$ dos pontos percorridos pelo COP do paciente. Todos os dados são obtidos como a média de três tentativas sucessivas de avaliação de 60 segundos cada.

Os pacientes não-operados foram avaliados com e sem medicação. Os operados foram avaliados sem estimulação e sem medicação, apenas com estimulação, sem medicação e com estimulação e medicação. Todas as avaliações foram feitas com os olhos abertos (OA) e com os olhos fechados (OF). 


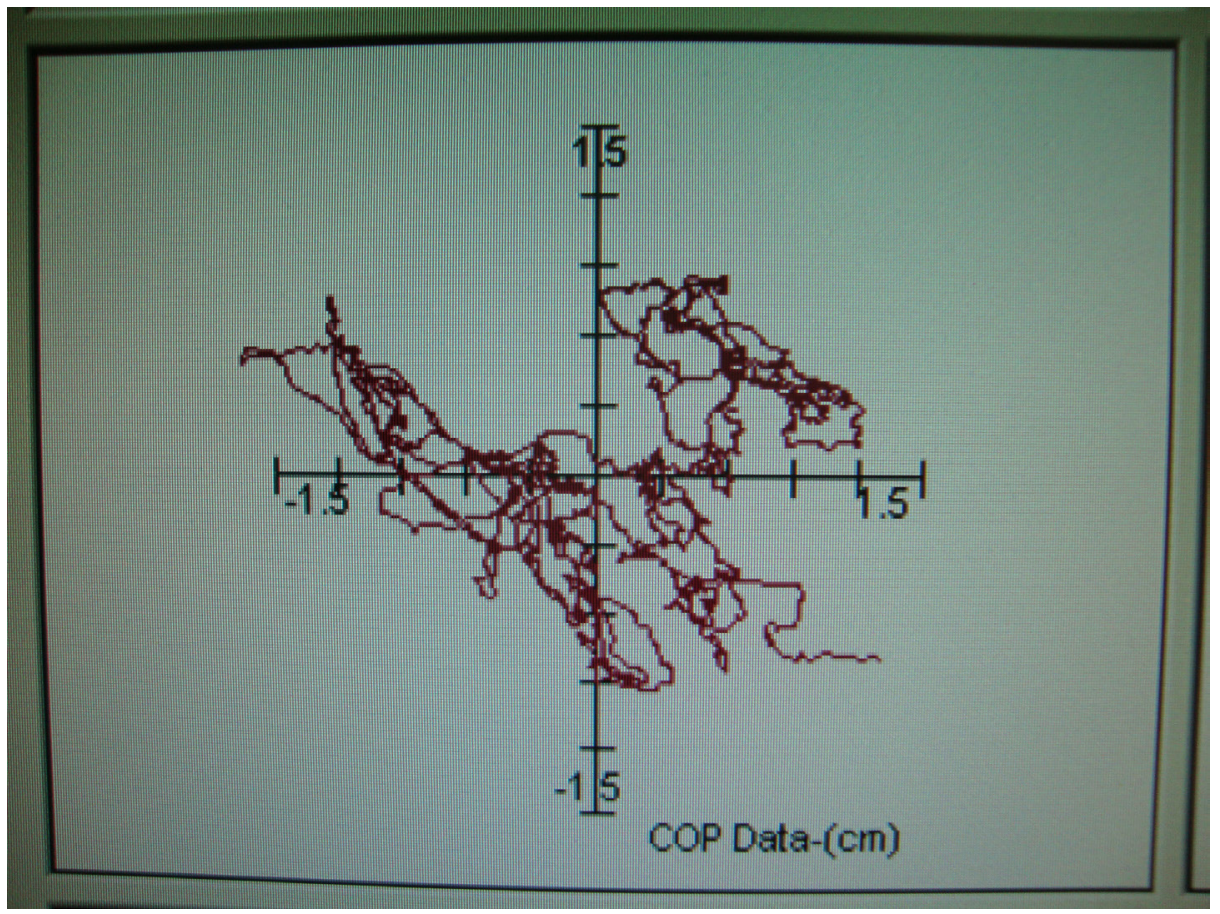

Figura 1 - Figura gerada pelo programa de computador desenhando as oscilações

\subsubsection{Parâmetro XSD}

Com os olhos abertos, os pacientes operados, com e sem medicação, oscilaram significativamente menos do que aqueles não-operados com medicação no eixo mediolateral (Gráfico 4 e Tabela 7). 
Gráfico 4 - Boxplot do desvio padrão da oscilação laterolateral com olhos abertos, em cm

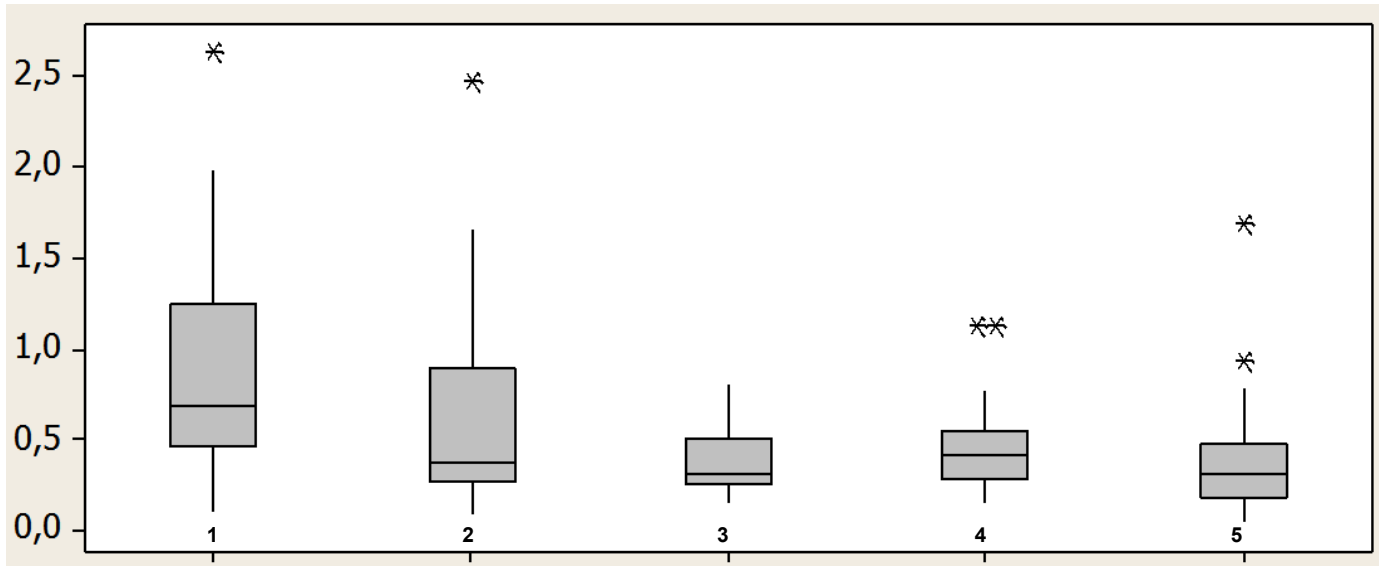

1 - Não operados com LD; 2 - Não operados sem LD; 3 - Operados com ECP sem LD; 4 - Operados sem ECP sem LD; 5 - Operado com ECP com LD.

Tabela 7 - Raiz quadrática média da oscilação mediolateral com olhos abertos

\begin{tabular}{lccccccc}
\hline \hline \multicolumn{1}{c}{ Variável } & $\mathbf{n}$ & Média & Mediana & $\begin{array}{c}\text { Desvio } \\
\text { padrão }\end{array}$ & Mínimo & Máximo & $\begin{array}{c}\text { Valor } \\
\mathbf{p}^{*}\end{array}$ \\
$\begin{array}{l}\text { XSD OA off-ECP off- } \\
\text { med }\end{array}$ & 31 & 0,456 & 0,406 & 0,241 & 0,145 & 1,128 & - \\
$\begin{array}{l}\text { XSD OA on-ECP off- } \\
\text { med }\end{array}$ & 31 & 0,382 & 0,312 & 0,18 & 0,141 & 0,796 & 0,1313 \\
$\begin{array}{l}\text { XSD OA on-ECP on- } \\
\text { med }\end{array}$ & 31 & 0,382 & 0,3 & 0,324 & 0,047 & 1,681 & 0,1526 \\
$\begin{array}{l}\text { XSD OA controle on- } \\
\text { med }\end{array}$ & 25 & 0,87 & 0,683 & 0,617 & 0,105 & 2,624 & - \\
$\begin{array}{l}\text { XSD OA on-ECP off- } \\
\text { med }\end{array}$ & 31 & 0,382 & 0,312 & 0,18 & 0,141 & 0,796 & 0,0003 \\
$\begin{array}{l}\text { XSD OA on-ECP on- } \\
\text { med }\end{array}$ & 31 & 0,382 & 0,3 & 0,324 & 0,047 & 1,681 & 0,0003 \\
$\begin{array}{l}\text { XSD OA controle off- } \\
\text { med }\end{array}$ & 25 & 0,602 & 0,366 & 0,578 & 0,08 & 2,468 & \\
$\begin{array}{l}\text { XSD OA off-ECP off- } \\
\text { med }\end{array}$ & 31 & 0,456 & 0,406 & 0,241 & 0,145 & 1,128 & 0,9803 \\
\hline
\end{tabular}

Onde: $\mathrm{XSD}$ = plano laterolateral; $\mathrm{OA}=$ olhos abertos; on-ECP = sob efeito de estimulação; on-med = sob efeito de levodopa; off-ECP = sem efeito de estimulação; off-med = sem efeito de levodopa

Com os olhos fechados os pacientes operados também oscilaram significativamente menos com ECP e, ainda menos com ECP e medicação no eixo laterolateral (Gráfico 5 e Tabela 8). 


\section{Gráfico 5 - Boxplot do desvio-padrão da oscilação laterolateral com olhos fechados, em cm}

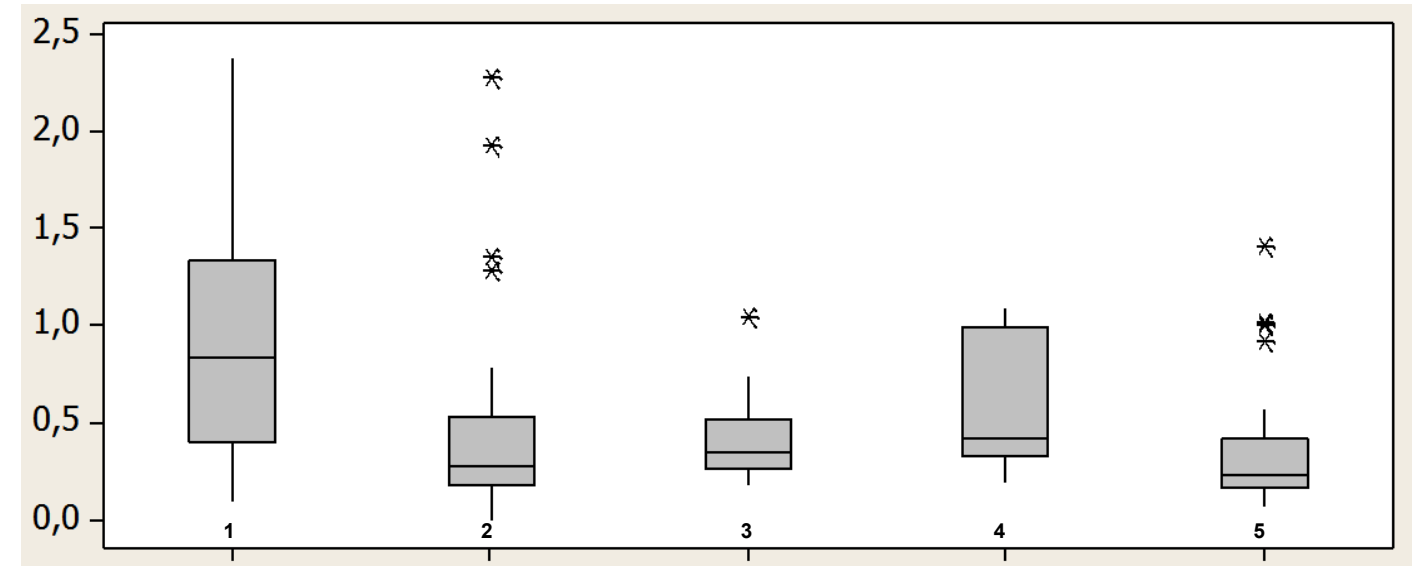

1 - Não operados com LD; 2 - Não operados sem LD; 3 - Operados com ECP sem LD; 4 - Operados sem ECP sem LD; 5 - Operado com ECP com LD.

Tabela 8 - Raiz quadrática média da oscilação laterolateral com olhos fechados

\begin{tabular}{lccccccc}
\hline \hline \multicolumn{1}{c}{ Variável } & $\mathbf{n}$ & Média & Mediana & $\begin{array}{c}\text { Desvio } \\
\text { padrão }\end{array}$ & Mínimo & Máximo & $\begin{array}{c}\text { Valor } \\
\mathbf{p}^{*}\end{array}$ \\
\hline $\begin{array}{l}\text { XSD OF off-ECP off- } \\
\text { med }\end{array}$ & 31 & 0,58 & 0,411 & 0,338 & 0,191 & 1,091 & - \\
$\begin{array}{l}\text { XSD OF on-ECP off- } \\
\text { med }\end{array}$ & 31 & 0,408 & 0,342 & 0,201 & 0,183 & 1,055 & 0,0048 \\
$\begin{array}{l}\text { XSD OF on-ECP on- } \\
\text { med }\end{array}$ & 31 & 0,358 & 0,241 & 0,322 & 0,061 & 1,409 & 0,004 \\
$\begin{array}{l}\text { XSD OF controle on- } \\
\text { med }\end{array}$ & 25 & 0,94 & 0,844 & 0,654 & 0,101 & 2,374 & - \\
$\begin{array}{l}\text { XSD OF on-ECP off- } \\
\text { med }\end{array}$ & 31 & 0,408 & 0,342 & 0,201 & 0,183 & 1,055 & 0,0004 \\
$\begin{array}{l}\text { XSD OF on-ECP on- } \\
\text { med }\end{array}$ & 31 & 0,358 & 0,241 & 0,322 & 0,061 & 1,409 & 0 \\
$\begin{array}{l}\text { XSD OF controle off- } \\
\text { med }\end{array}$ & 25 & 0,526 & 0,28 & 0,582 & 0 & 2,281 & \\
$\begin{array}{l}\text { XSD OF off-ECP off- } \\
\text { med }\end{array}$ & 31 & 0,58 & 0,411 & 0,338 & 0,191 & 1,091 & 0,094 \\
\hline
\end{tabular}

Onde: $X S D$ = plano laterolateral; $O F$ = olhos fechados; on-ECP = sob efeito de estimulação; on-med = sob efeito de levodopa; off-ECP = sem efeito de estimulação; off-med = sem efeito de levodopa 


\subsubsection{YSD}

A amplitude da oscilação anteroposterior com os olhos abertos é maior nos pacientes não-operados on-medicação. Nos pacientes operados, há redução significativa nos pacientes sob estimulação em comparação àqueles off-ECP/off-medicação. Há ainda redução adicional da oscilação ao se acrescentar medicação aos pacientes on-ECP (Gráfico 6 e Tabela 9).

\section{Gráfico 6 - Boxplot do desvio-padrão da oscilação anteroposterior com} olhos abertos, em cm

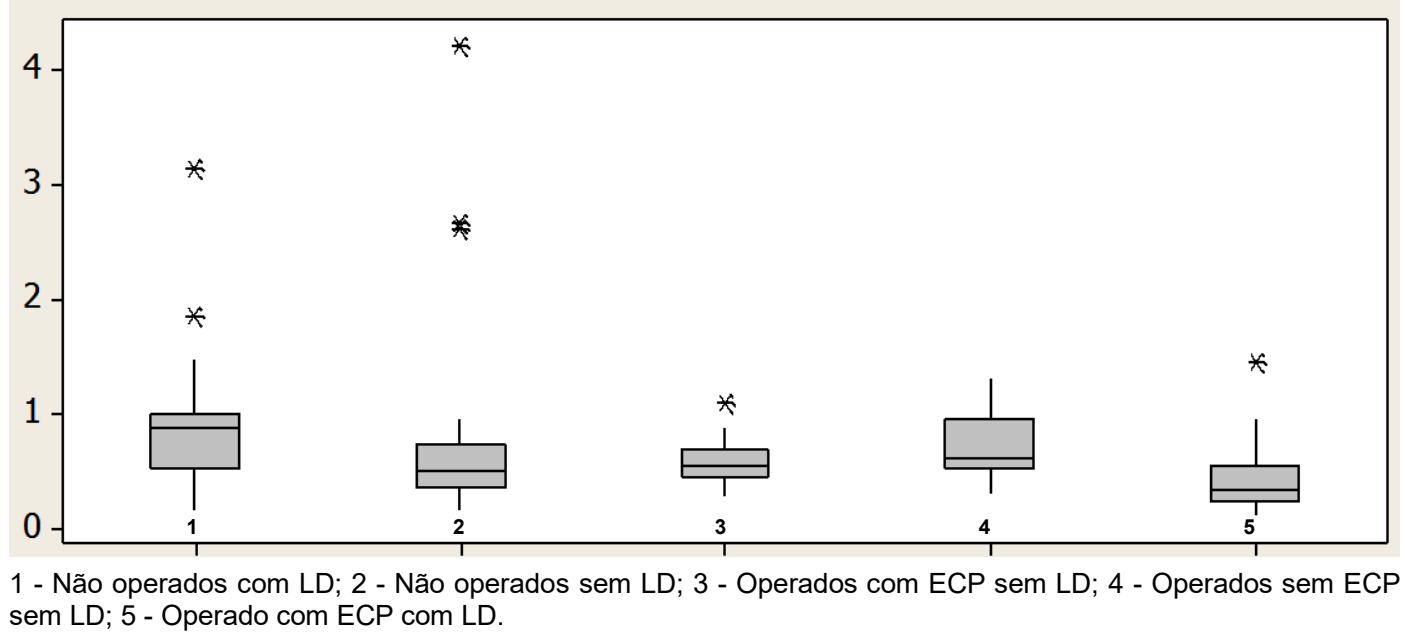


Tabela 9 -Raiz quadrática média da oscilação anteroposterior com olhos abertos

\begin{tabular}{|c|c|c|c|c|c|c|c|}
\hline Variável & n & Média & Mediana & $\begin{array}{l}\text { Desvio } \\
\text { padrão }\end{array}$ & Mínimo & Máximo & $\begin{array}{l}\text { Valor } \\
p^{*}\end{array}$ \\
\hline $\begin{array}{l}\text { YSD OA off-ECP off- } \\
\text { med }\end{array}$ & 31 & 0,717 & 0,622 & 0,282 & 0,297 & 1,308 & - \\
\hline $\begin{array}{l}\text { YSD OA on-ECP off- } \\
\text { med }\end{array}$ & 31 & 0,576 & 0,546 & 0,176 & 0,289 & 1,092 & 0,0031 \\
\hline $\begin{array}{l}\text { YSD OA on-ECP on- } \\
\text { med }\end{array}$ & 31 & 0,425 & 0,327 & 0,279 & 0,122 & 1,454 & 0,0008 \\
\hline $\begin{array}{l}\text { YSD OA controle on- } \\
\text { med }\end{array}$ & 25 & 0,898 & 0,878 & 0,605 & 0,163 & 3,137 & - \\
\hline $\begin{array}{l}\text { YSD OA on-ECP off- } \\
\text { med }\end{array}$ & 31 & 0,576 & 0,546 & 0,176 & 0,289 & 1,092 & 0,0069 \\
\hline $\begin{array}{l}\text { YSD OA on-ECP on- } \\
\text { med }\end{array}$ & 31 & 0,425 & 0,327 & 0,279 & 0,122 & 1,454 & 0,0001 \\
\hline $\begin{array}{l}\text { YSD OA controle off- } \\
\text { med }\end{array}$ & 25 & 0,823 & 0,503 & 0,941 & 0,169 & 4,2 & \multirow{2}{*}{0,0896} \\
\hline $\begin{array}{l}\text { YSD OA off-ECP off- } \\
\text { med }\end{array}$ & 31 & 0,717 & 0,622 & 0,282 & 0,297 & 1,308 & \\
\hline
\end{tabular}

A amplitude da oscilação anteroposterior com os olhos fechados mantém o padrão encontrado com os olhos abertos e é maior nos pacientes não-operados on-medicação. Nos pacientes operados, há redução significativa nos pacientes sob estimulação em comparação àqueles offECP/off-medicação. Há ainda redução adicional da oscilação ao se acrescentar medicação aos pacientes on-ECP (Gráfico 7 e Tabela 10). 


\section{Gráfico 7 - Boxplot do desvio-padrão da oscilação anteroposterior com olhos fechados em cm}

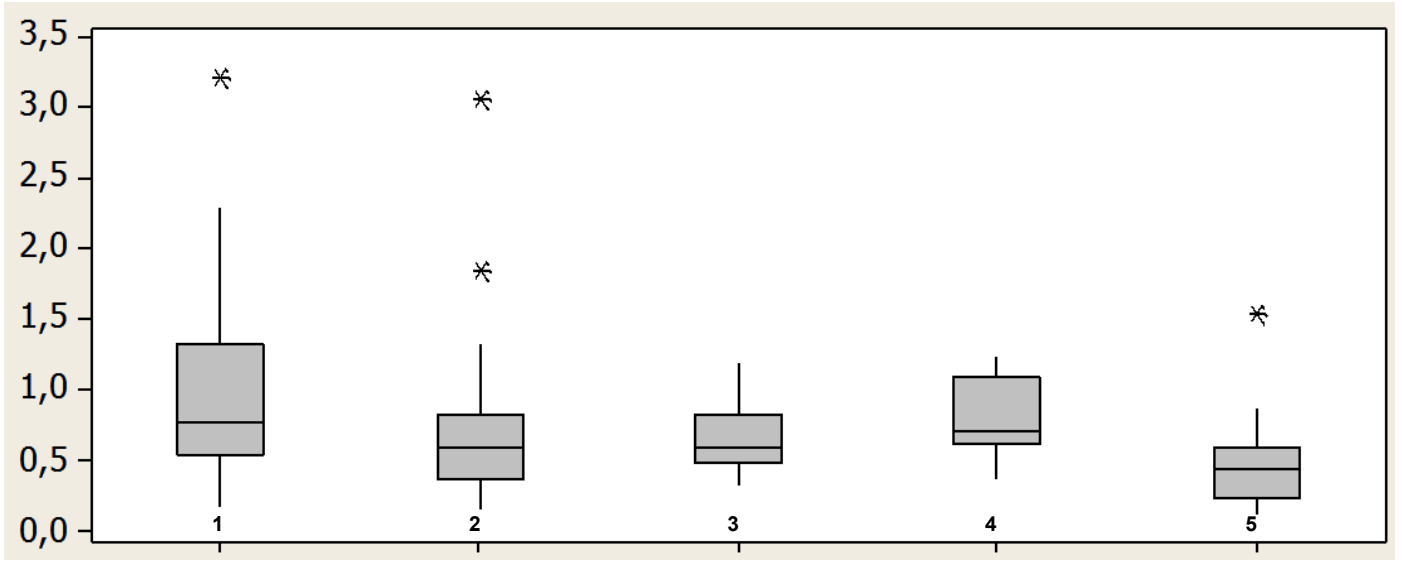

1 - Não operados com LD; 2 - Não operados sem LD; 3 - Operados com ECP sem LD; 4 - Operados sem ECP sem LD; 5 - Operado com ECP com LD.

Tabela 10 - Raiz quadrática média da oscilação anteroposterior com olhos fechado

\begin{tabular}{lccccccc}
\hline \hline \multicolumn{1}{c}{ Variável } & $\mathbf{n}$ & Média & Mediana & $\begin{array}{c}\text { Desvio } \\
\text { padrão }\end{array}$ & Mínimo & Máximo & $\begin{array}{c}\text { Valor } \\
\mathbf{p}^{*}\end{array}$ \\
\hline $\begin{array}{l}\text { YSD OF off-ECP off- } \\
\text { med }\end{array}$ & 31 & 0,823 & 0,71 & 0,26 & 0,376 & 1,227 & - \\
$\begin{array}{l}\text { YSD OF on-ECP off- } \\
\text { med }\end{array}$ & 31 & 0,656 & 0,599 & 0,214 & 0,334 & 1,189 & 0,0006 \\
$\begin{array}{l}\text { YSD OF on-ECP on- } \\
\text { med }\end{array}$ & 31 & 0,456 & 0,448 & 0,29 & 0,115 & 1,55 & 0 \\
$\begin{array}{l}\text { YSD OF controle on- } \\
\text { med }\end{array}$ & 25 & 1,009 & 0,767 & 0,71 & 0,183 & 3,223 & - \\
$\begin{array}{l}\text { YSD OF on-ECP off- } \\
\text { med }\end{array}$ & 31 & 0,656 & 0,599 & 0,214 & 0,334 & 1,189 & 0,0386 \\
$\begin{array}{l}\text { YSD OF on-ECP on- } \\
\text { med }\end{array}$ & 31 & 0,456 & 0,448 & 0,29 & 0,115 & 1,55 & 0,0001 \\
$\begin{array}{l}\text { YSD OF controle off- } \\
\text { med }\end{array}$ & 25 & 0,739 & 0,604 & 0,62 & 0,159 & 3,059 & \\
$\begin{array}{l}\text { YSD OF off-ECP off- } \\
\text { med }\end{array}$ & 31 & 0,823 & 0,71 & 0,26 & 0,376 & 1,227 & 0,0547 \\
\hline
\end{tabular}

Onde: YSD = plano anteroposterior; OF = olhos fechados; on-ECP = sob efeito de estimulação; on-med = sob efeito de levodopa; off-ECP = sem efeito de estimulação; off-med = sem efeito de levodopa 


\subsubsection{Path Length}

Quando avaliado todo o caminho percorrido pelo centro de pressão do paciente em centímetros durante o minuto sobre a plataforma de força, identifica-se que os pacientes que menos oscilam são aqueles on ECP on MED na condição de olhos abertos (Gráfico 8 e Tabela 11).

\section{Gráfico 8 - Boxplot path length da oscilação em um minuto com olhos abertos em cm}

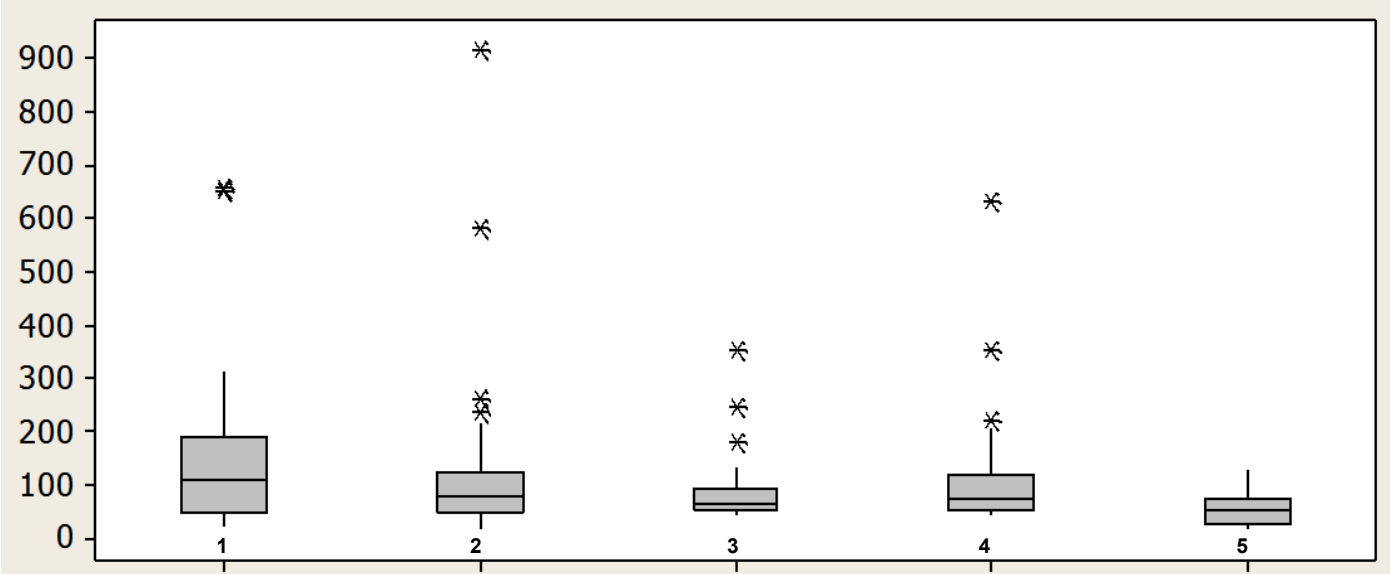

1 - Não operados com LD; 2 - Não operados sem LD; 3 - Operados com ECP sem LD; 4 - Operados sem ECP sem LD; 5 - Operado com ECP com LD.

Tabela 11 - Path length da oscilação em um minuto com olhos abertos

\begin{tabular}{|c|c|c|c|c|c|c|c|}
\hline Variável & n & Média & Mediana & $\begin{array}{l}\text { Desvio } \\
\text { padrão }\end{array}$ & Mínimo & Máximo & $\begin{array}{l}\text { Valor } \\
\text { p* }^{*}\end{array}$ \\
\hline PL OA off-ECP off-med & 31 & 124,4 & 70,6 & 150,1 & 39,3 & 631,5 & - \\
\hline PL OA on-ECP off-med & 31 & 85,7 & 60,4 & 65,8 & 39,6 & 353,2 & 0,0778 \\
\hline PL OA on-ECP on-med & 31 & 55,5 & 49,46 & 34,33 & 13,82 & 127,73 & 0,0002 \\
\hline $\begin{array}{l}\text { PL OA controle on- } \\
\text { med }\end{array}$ & 23 & 165,3 & 106,8 & 173,1 & 20,3 & 657,7 & - \\
\hline PL OA on-ECP off-med & 31 & 85,7 & 60,4 & 65,8 & 39,6 & 353,2 & 0,0689 \\
\hline PL OA on-ECP on-med & 31 & 55,5 & 49,46 & 34,33 & 13,82 & 127,73 & 0,0009 \\
\hline $\begin{array}{l}\text { PL OA controle off- } \\
\text { med }\end{array}$ & 23 & 148,5 & 78,7 & 206,5 & 17,4 & 917 & 0,9303 \\
\hline PL OA off-ECP off-med & 31 & 124,4 & 70,6 & 150,1 & 39,3 & 631,5 & \\
\hline
\end{tabular}

Onde: $\mathrm{PL}=$ Path length - distância total percorrida pelo centro de pressão do paciente, em $\mathrm{cm}$; OA = olhos abertos; on-ECP = sob efeito de estimulação; on-med = sob efeito de levodopa; off-ECP = sem efeito de estimulação; off-med = sem efeito de levodopa 
Quando avaliado todo o caminho percorrido pelo centro de pressão do paciente em centímetros durante o minuto sobre a plataforma de força, é identificado que os pacientes que menos oscilam são aqueles on-ECP/onmedicação na condição de olhos abertos, seguidos por aqueles on-ECP/off medicação. (Gráfico 9 e Tabela 12).

\section{Gráfico 9 - Boxplot path length da oscilação em um minuto com olhos fechados, em cm}

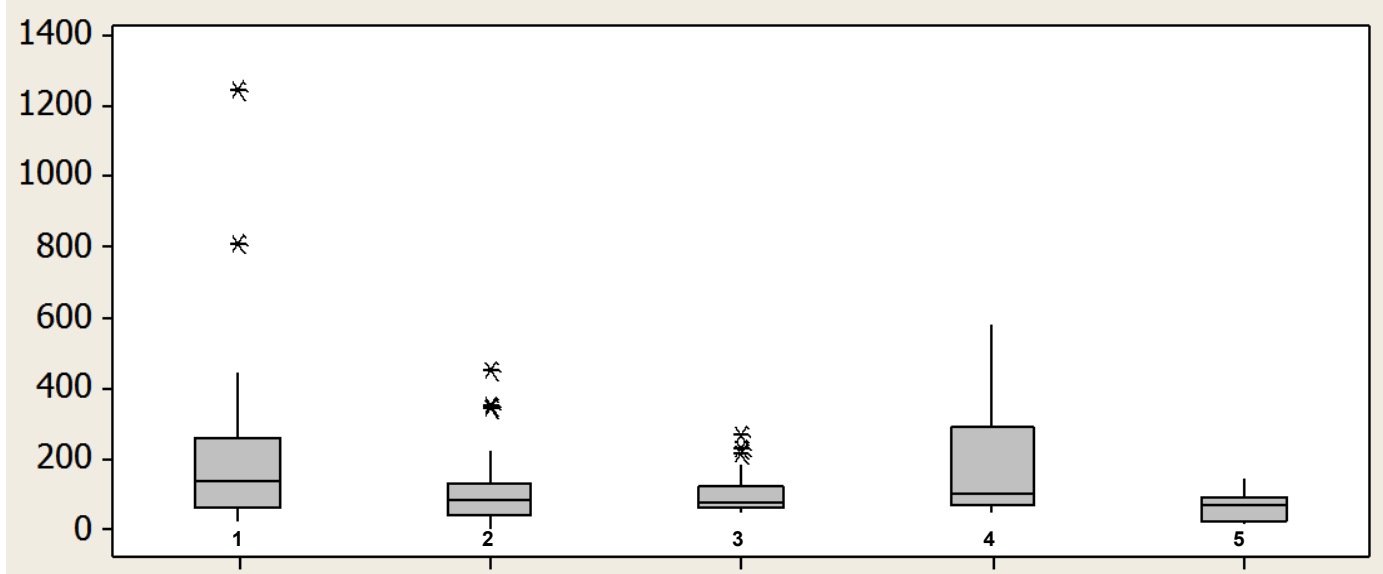

1 - Não operados com LD; 2 - Não operados sem LD; 3 - Operados com ECP sem LD; 4 - Operados sem ECP sem LD; 5 - Operado com ECP com LD.

Tabela 12 - Path length da oscilação em um minuto com olhos fechados

\begin{tabular}{|c|c|c|c|c|c|c|c|}
\hline Variável & $\mathbf{n}$ & Média & Mediana & $\begin{array}{l}\text { Desvio } \\
\text { padrão }\end{array}$ & Mínimo & Máximo & $\begin{array}{l}\text { Valor } \\
p^{*}\end{array}$ \\
\hline PL OF off-ECP off-med & 31 & 160 & 100,1 & 128,1 & 49,4 & 583,5 & - \\
\hline PL OF on-ECP off-med & 31 & 99,4 & 77,8 & 56,3 & 45,7 & 272,7 & 0,0005 \\
\hline PL OF on-ECP on-med & 31 & 65 & 70,1 & 37,81 & 17,74 & 144,12 & 0 \\
\hline $\begin{array}{l}\text { PL OF controle on- } \\
\text { med }\end{array}$ & 23 & 227,4 & 137,2 & 283,7 & 27,1 & 1247,7 & - \\
\hline PL OF on-ECP off-med & 31 & 99,4 & 77,8 & 56,3 & 45,7 & 272,7 & 0,0481 \\
\hline PL OF on-ECP on-med & 31 & 65 & 70,1 & 37,81 & 17,74 & 144,12 & 0,0002 \\
\hline $\begin{array}{l}\text { PL OF controle off- } \\
\text { med }\end{array}$ & 23 & 117,6 & 87,4 & 117,8 & 0 & 456,7 & 0,1323 \\
\hline PL OF off-ECP off-med & 31 & 160 & 100,1 & 128,1 & 49,4 & 583,5 & \\
\hline
\end{tabular}

Onde: $\mathrm{PL}=$ Path length - distância total percorrida pelo centro de pressão do paciente, em $\mathrm{cm}$; OF = olhos fechados; on-ECP = sob efeito de estimulação; on-med = sob efeito de levodopa; off-ECP = sem efeito de estimulação; off-med = sem efeito de levodopa 


\subsection{4 Área 95\%}

A avaliação da área que corresponde a $95 \%$ da elipse ocupada pela oscilação dos pacientes com os olhos abertos mostra que os pacientes sem tratamento são equivalentes. Os pacientes não-operados oscilam mais quando on-medicação. A área de oscilação é menor nos pacientes onECP/off-medicação e ainda menos naqueles on-ECP/on-medicação (Gráfico 10 e Tabela 13).

Gráfico 10 - Boxplot da área correspondente à $95 \%$ da elipse ocupada pela oscilação dos pacientes com olhos abertos, em $\mathrm{cm}^{2}$

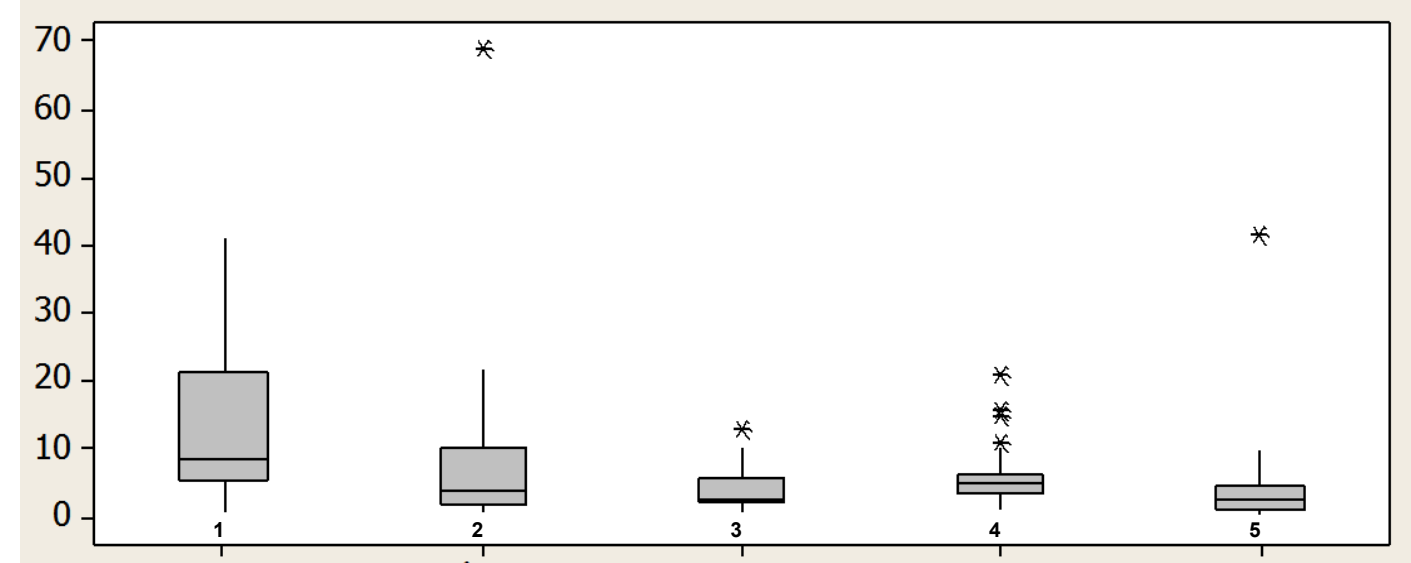

1 - Não operados com LD; 2 - Não operados sem LD; 3 - Operados com ECP sem LD; 4 - Operados sem ECP sem LD; 5 - Operado com ECP com LD. 
Tabela 13 - Área correspondente a $95 \%$ da elipse ocupada pela oscilação dos pacientes com olhos abertos

\begin{tabular}{lccccccc}
\hline \hline \multicolumn{1}{c}{ Variável } & $\mathbf{n}$ & Média & Mediana & $\begin{array}{c}\text { Desvio } \\
\text { padrão }\end{array}$ & Mínimo & Máximo & $\begin{array}{c}\text { Valor } \\
\mathbf{p}^{*}\end{array}$ \\
\hline $\begin{array}{l}\text { Area OA off-ECP off- } \\
\text { med }\end{array}$ & 31 & 6,129 & 4,614 & 5,148 & 0,787 & 20,623 & - \\
$\begin{array}{l}\text { Area OA on-ECP off- } \\
\text { med }\end{array}$ & 31 & 4,049 & 2,559 & 2,797 & 0,57 & 12,612 & 0,0077 \\
$\begin{array}{l}\text { Area OA on-ECP on- } \\
\text { med }\end{array}$ & 31 & 4,17 & 2,41 & 7,44 & 0,11 & 41,35 & 0,0435 \\
$\begin{array}{l}\text { Area OA controle on- } \\
\text { med }\end{array}$ & 25 & 13,96 & 8,31 & 12,37 & 0,39 & 41,14 & - \\
$\begin{array}{l}\text { Area OA on-ECP off- } \\
\text { med }\end{array}$ & 31 & 4,049 & 2,559 & 2,797 & 0,57 & 12,612 & 0,0003 \\
$\begin{array}{l}\text { Area OA on-ECP on- } \\
\text { med }\end{array}$ & 31 & 4,17 & 2,41 & 7,44 & 0,11 & 41,35 & 0,0001 \\
$\begin{array}{l}\text { Area OA controle off- } \\
\text { med }\end{array}$ & 25 & 7,83 & 3,57 & 13,81 & 0,29 & 68,78 & \\
$\begin{array}{l}\text { Area OA off-ECP off- } \\
\text { med }\end{array}$ & 31 & 6,129 & 4,614 & 5,148 & 0,787 & 20,623 & 0,2164 \\
\hline
\end{tabular}

Onde: Area = área correspondente a $95 \%$ da elipse percorrida pelo centro de pressão do paciente; OA = olhos abertos; on-ECP = sob efeito de estimulação; on-med = sob efeito de levodopa; off-ECP = sem efeito de estimulação; off-med = sem efeito de levodopa

A avaliação da área que corresponde a $95 \%$ da elipse ocupada pela oscilação dos pacientes com os olhos fechados mostra que os pacientes operados off-ECP/off-medicação oscilam mais do que os não-operados offmedicação. Os pacientes não-operados oscilam mais quando onmedicação. A área de oscilação é menor nos pacientes on-ECP/offmedicação e ainda menos naqueles on-ECP/on-medicação (Gráfico 11 e Tabela 14). A área de oscilação com olhos fechados se correlaciona com a presença de discinesias com coeficiente 0,5. 


\section{Gráfico 11 - Boxplot da área correspondente a 95\% da elipse ocupada pela oscilação dos pacientes com olhos fechados em $\mathrm{cm}^{2}$}

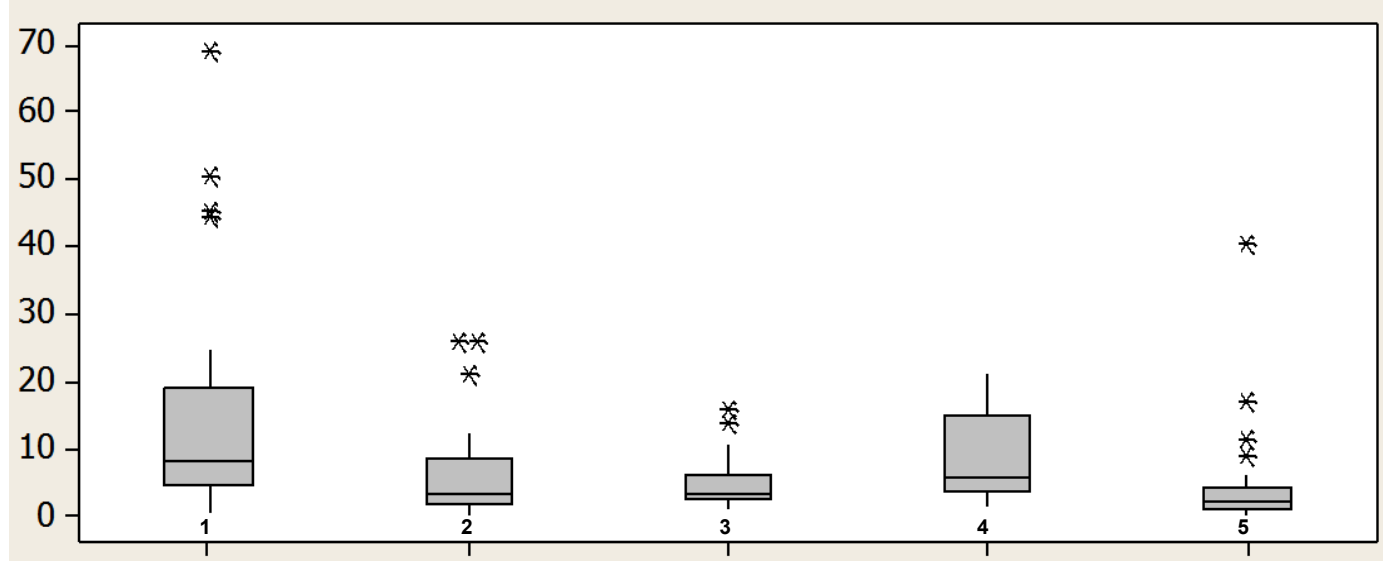

1 - Não operados com LD; 2 - Não operados sem LD; 3 - Operados com ECP sem LD; 4 - Operados sem ECP sem LD; 5 - Operado com ECP com LD.

Tabela 14 -Área correspondente à $95 \%$ da elipse ocupada pela oscilação dos pacientes com olhos fechados, em $\mathrm{cm}^{2}$

\begin{tabular}{lccccccc}
\hline \hline \multicolumn{1}{c}{ Variável } & $\mathbf{n}$ & Média & Mediana & $\begin{array}{c}\text { Desvio } \\
\text { padrão }\end{array}$ & Mínimo & Máximo & $\begin{array}{c}\text { Valor } \\
\mathbf{p}^{*}\end{array}$ \\
\hline $\begin{array}{l}\text { Area OF off-ECP off- } \\
\text { med }\end{array}$ & 31 & 9,14 & 5,71 & 7,26 & 1,21 & 21,21 & - \\
$\begin{array}{l}\text { Area OF on-ECP off- } \\
\text { med }\end{array}$ & 31 & 5,099 & 3,275 & 4,033 & 1,059 & 15,896 & 0,0005 \\
$\begin{array}{l}\text { Area OF on-ECP on- } \\
\text { med }\end{array}$ & 31 & 4,24 & 2,27 & 7,6 & 0,15 & 40,25 & 0,0011 \\
$\begin{array}{l}\text { Area OF controle on- } \\
\text { med }\end{array}$ & 25 & 15,9 & 8 & 17,78 & 0,37 & 68,85 & - \\
$\begin{array}{l}\text { Area OF on-ECP off- } \\
\text { med }\end{array}$ & 31 & 5,099 & 3,275 & 4,033 & 1,059 & 15,896 & 0,0032 \\
$\begin{array}{l}\text { Area OF on-ECP on- } \\
\text { med }\end{array}$ & 31 & 4,24 & 2,27 & 7,6 & 0,15 & 40,25 & 0,0001 \\
$\begin{array}{l}\text { Area OF controle off- } \\
\text { med }\end{array}$ & 25 & 6,4 & 3,4 & 7,62 & 0,19 & 25,95 & \\
$\begin{array}{l}\text { Area OF off-ECP off- } \\
\text { med }\end{array}$ & 31 & 9,14 & 5,71 & 7,26 & 1,21 & 21,21 & 0,0249 \\
\hline
\end{tabular}

Onde: Area = área correspondente a $95 \%$ da elipse percorrida pelo centro de pressão do paciente; OF = olhos fechados; on-ECP = sob efeito de estimulação; on-med = sob efeito de levodopa; off-ECP = sem efeito de estimulação; off-med = sem efeito de levodopa 


\subsubsection{Velocidade}

A avaliação da velocidade da oscilação dos pacientes com os olhos abertos mostra que os pacientes sem tratamento são equivalentes. Os pacientes não-operados oscilam mais quando on medicação. A velocidade de oscilação é menor nos pacientes on-ECP/off-medicação e ainda menos naqueles on-ECP/on-medicação (Gráfico 12 e Tabela 15).

\section{Gráfico 12 - Boxplot da velocidade de oscilação dos pacientes com olhos abertos em cm/seg}

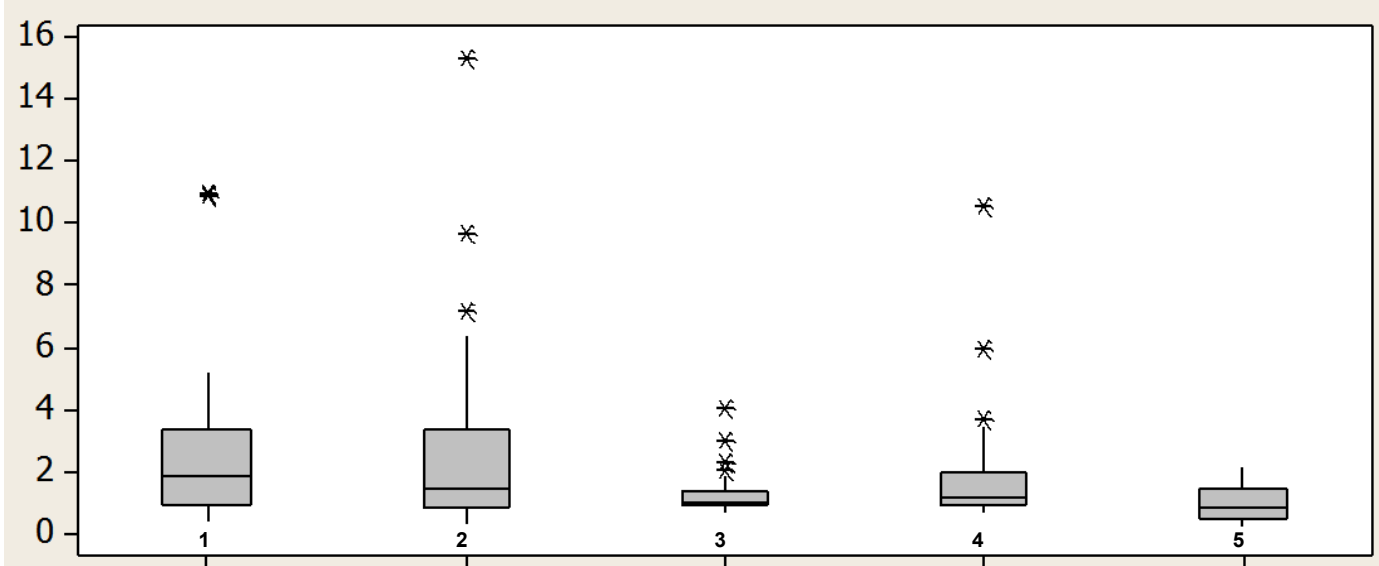

1 - Não operados com LD; 2 - Não operados sem LD; 3 - Operados com ECP sem LD; 4 - Operados sem ECP sem LD; 5 - Operado com ECP com LD. 
Tabela 15 - Velocidade de oscilação dos pacientes com olhos abertos

\begin{tabular}{lccccccc}
\hline \multicolumn{1}{c}{ Variável } & $\mathbf{n}$ & Média & Mediana & $\begin{array}{c}\text { Desvio } \\
\text { padrão }\end{array}$ & Mínimo & Máximo & $\begin{array}{c}\text { Valor } \\
\mathbf{p}^{*}\end{array}$ \\
\hline $\begin{array}{l}\text { Vel OA off-ECP off- } \\
\text { med }\end{array}$ & 31 & 1,841 & 1,176 & 1,967 & 0,656 & 10,525 & - \\
$\begin{array}{l}\text { Vel OA on-ECP off- } \\
\text { med }\end{array}$ & 31 & 1,258 & 1 & 0,73 & 0,623 & 4,03 & 0,0224 \\
$\begin{array}{l}\text { Vel OA on-ECP on- } \\
\text { med }\end{array}$ & 31 & 0,937 & 0,824 & 0,579 & 0,23 & 2,129 & 0,0004 \\
\hline $\begin{array}{l}\text { Vel OA controle on- } \\
\text { med }\end{array}$ & 25 & 2,746 & 1,802 & 2,773 & 0,338 & 10,961 & - \\
$\begin{array}{l}\text { Vel OA on-ECP off- } \\
\text { med }\end{array}$ & 31 & 1,258 & 1 & 0,73 & 0,623 & 4,03 & 0,0147 \\
$\begin{array}{l}\text { Vel OA on-ECP on- } \\
\text { med }\end{array}$ & 31 & 0,937 & 0,824 & 0,579 & 0,23 & 2,129 & 0,0004 \\
\hline $\begin{array}{l}\text { Vel OA controle off- } \\
\text { med }\end{array}$ & 25 & 2,782 & 1,442 & 3,498 & 0,289 & 15,283 & \\
$\begin{array}{l}\text { Vel OA off-ECP off- } \\
\text { med }\end{array}$ & 31 & 1,841 & 1,176 & 1,967 & 0,656 & 10,525 & 0,553 \\
\hline \hline
\end{tabular}

Onde: Vel = velocidade do deslocamento do centro de pressão do paciente em $\mathrm{cm} / \mathrm{segundo} ; \mathrm{AF}=$ olhos abertos; on-ECP = sob efeito de estimulação; on-med = sob efeito de levodopa; off-ECP = sem efeito de estimulação; offmed $=$ sem efeito de levodopa

A avaliação da velocidade da oscilação dos pacientes com os olhos fechados mostra que os pacientes sem tratamento são equivalentes. Os pacientes não-operados oscilam mais quando on-medicação. A velocidade de oscilação é menor nos pacientes on-ECP/off-medicação e ainda menos naqueles on-ECP/on-medicação (Gráfico 13 e Tabela 16). 


\section{Gráfico 13 - Boxplot da velocidade de oscilação dos pacientes com olhos fechados, em cm/seg}

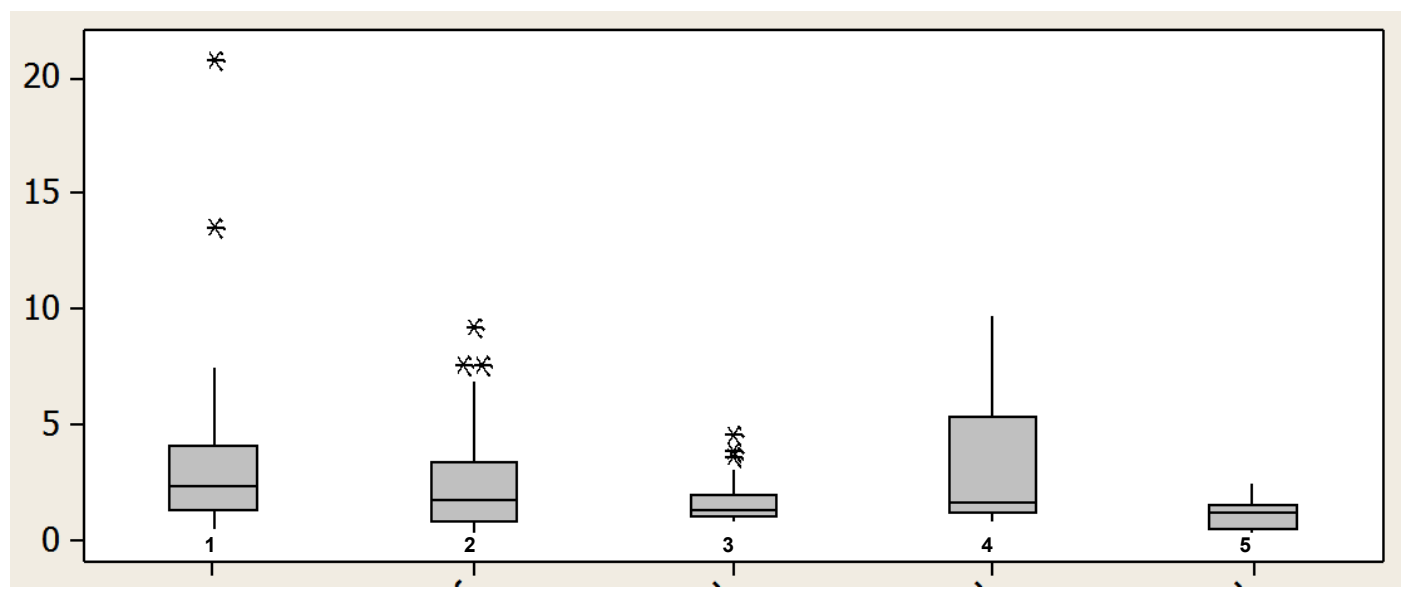

1 - Não operados com LD; 2 - Não operados sem LD; 3 - Operados com ECP sem LD; 4 - Operados sem ECP sem LD; 5 - Operado com ECP com LD.

Tabela 16 - Velocidade de oscilação dos pacientes com olhos fechados

\begin{tabular}{lccccccc}
\hline \hline \multicolumn{1}{c}{ Variável } & $\mathrm{n}$ & Média & Mediana & $\begin{array}{c}\text { Desvio } \\
\text { padrão }\end{array}$ & Mínimo & Máximo & $\begin{array}{c}\text { Valor } \\
\mathrm{p}^{*}\end{array}$ \\
\hline $\begin{array}{l}\text { Vel OF off-ECP off- } \\
\text { med }\end{array}$ & 31 & 3,616 & 1,668 & 3,505 & 0,823 & 9,725 & - \\
$\begin{array}{l}\text { Vel OF on-ECP off- } \\
\text { med }\end{array}$ & 31 & 1,658 & 1,297 & 0,938 & 0,761 & 4,545 & 0,0004 \\
$\begin{array}{l}\text { Vel OF on-ECP on- } \\
\text { med }\end{array}$ & 31 & 1,086 & 1,176 & 0,631 & 0,296 & 2,402 & 0 \\
$\begin{array}{l}\text { Vel OF controle on- } \\
\text { med }\end{array}$ & 25 & 3,703 & 2,287 & 4,547 & 0,452 & 20,795 & - \\
$\begin{array}{l}\text { Vel OF on-ECP off- } \\
\text { med }\end{array}$ & 31 & 1,658 & 1,297 & 0,938 & 0,761 & 4,545 & 0,0296 \\
$\begin{array}{l}\text { Vel OF on-ECP on- } \\
\text { med }\end{array}$ & 31 & 1,086 & 1,176 & 0,631 & 0,296 & 2,402 & 0,0001 \\
$\begin{array}{l}\text { Vel OF controle off- } \\
\text { med }\end{array}$ & 25 & 2,641 & 1,727 & 2,614 & 0,328 & 9,158 & \\
$\begin{array}{l}\text { Vel OF off-ECP off- } \\
\text { med }\end{array}$ & 31 & 3,616 & 1,668 & 3,505 & 0,823 & 9,725 & 0,2483 \\
\hline \hline
\end{tabular}

Onde: $\mathrm{Vel}=$ velocidade do deslocamento do centro de pressão do paciente em $\mathrm{cm} / \mathrm{segundo}$; OF = olhos fechados; on-ECP = sob efeito de estimulação; on-med = sob efeito de levodopa; off-ECP = sem efeito de estimulação; off-med = sem efeito de levodopa 


\section{DiscussÃo}


O grupo não-operado mostrou ser semelhante ao grupo operado quanto a: estágio Hoehn e Yahr, duração da DP, idade dos participantes e gravidade pela UPDRS, permitindo a comparação entre ambos para avaliar o efeito da estimulação e da medicação sobre o equilíbrio.

A melhora clínica mensurada pela UPDRS obtida com a ECP foi semelhante à melhora com LD no grupo não-operado. Houve uma melhora adicional nos pacientes com ECP ao se administrar também LD. Esta melhora mais significativa da ECP com LD no grupo operado não se aplica às manifestações axiais, onde o efeito foi um pouco inferior (bradicinesia global, postura, marcha, estabilidade postural e levantar-se de uma cadeira). O efeito da ECP com LD somadas sobre estas manifestações na UPDRS foi semelhante à LD isolada no grupo não operado.

A dose de medicação dopaminérgica nos pacientes operados foi reduzida aproximadamente pela metade, o que é consistente com os dados da literatura (Nantel et al., 2012)

Esta casuística tem a média dos pacientes em estado off com escore na UPDRS de 52 pontos e em on de 21 pontos, o que é semelhante à literatura, que relata que a média do UPDRS em off pré-operatório é superior a 50 pontos e o estado em on está usualmente abaixo dos 20 pontos ou entre 20 e 30 pontos (Lang et al., 2006) 
A média de melhora no teste de resposta à levodopa é de $40 \%$ a $70 \%$ na literatura (Lang et al., 2006), e nesta casuística é de 60\%. É consenso na literatura que as manifestações axiais têm resposta inferior tanto à levodopa quanto à estimulação (Lang et al., 2006; Olanow et al., 2009b). Neste estudo a melhora das alterações axiais com medicação foi de $56 \%$ e com a ECP de 44\%. Neste último grupo, adicionando-se a medicação, a melhora atingiu 55,5\%. Segundo Lang et al. (2006) a UPDRS é a única ferramenta clínica de avaliação com sensibilidade suficiente para identificar mudanças induzidas pela ECP.

Os resultados observados nos pacientes estudados estão, então, em concordância com os da literatura, que indica que a ECP do NST promove um estado constante de melhora semelhante ao melhor efeito medicamentoso, com redução da dose de medicamentos e das complicações motoras relacionadas ao uso da medicação.

A gravidade da DP, critérios de inclusão e exclusão e o tipo e dose de medicação geram resultados controversos na literatura sobre o impacto da DP e do tratamento sobre a instabilidade postural (Frenklach et al., 2009; Błaszczyk e Orawiec et al., 2011).

Em nosso estudo, na avaliação com a UPDRS o efeito da medicação no grupo não operado é semelhante ao da associação de ECP e LD sobre as manifestações axiais, enquanto a ECP isolada é um pouco menos eficaz. Tais dados não foram confirmados após o uso da plataforma de força, cujos dados serão discutidos a seguir (Johnson et al., 2013).

A plataforma foi empregada com o intuito de melhorar a sensibilidade da avaliação do equilíbrio dos pacientes. Os parâmetros relacionados à 
amplitude de oscilações, que incluem $\mathrm{X}, \mathrm{Y}$ e área; e aqueles relacionados à quantidade das oscilações, que consistem em path length e velocidade, fornecem dados complementares sobre o equilíbrio estático (Guehl et al., 2006).

Inicialmente serão discutidos os resultados do grupo controle, que consistiu em pacientes não operados nos estados com (on) e sem (off) LD.

Os dados coletados com o uso da plataforma nos pacientes sob efeito da LD mostraram um aumento dos deslocamentos nos eixos $\mathrm{X}, \mathrm{Y}$ e da área de deslocamento, que correspondem à amplitude. Contudo, os parâmetros velocidade e path length, que traduzem o número de oscilações não se alteraram. Assim, a área de oscilação, mas não o número de oscilações, mostrou-se ampliada em pacientes não operados sob o uso da LD. Os dados encontrados neste grupo são consistentes com a hipótese de que um aumento da oscilação corporal pode ser induzido pela LD. Maurer et al. (2003) atribuem o aumento das oscilações à redução no tônus postural sem melhora no controle postural. Guehl et al. (2006) obtiveram resultados semelhantes aos constatados no nosso estudo, ou seja, que a levodopa tem efeitos distintos sobre a área e o número de deslocamentos.

A redução no tônus muscular causada pela LD em pacientes com alterações posturais tende então a aumentar a amplitude de oscilação. Neste trabalho, a área de oscilação com olhos fechados teve alta correlação (Spearman 0,5) com a presença de discinesias, que devem ser consideradas como uma das causas deste aumento. Pacientes sem LD tendem a oscilar com menor amplitude pelo maior tônus muscular. Possíveis 
alterações adicionais causadas pelo tremor se traduziriam em um maior número de oscilações, e não da amplitude, mas isto não foi detectado neste estudo.

Após a ECP houve mudanças importantes nos parâmetros estabilométricos da posturografia em comparação com o grupo não-operado. No grupo operado, parâmetros relacionados à área e ao deslocamento total do centro de pressão tendem a coincidir, mantendo tendência à maior oscilação na situação off ECP/off medicação. Um achado deste estudo a ser destacado é que a condição on ECP/off medicação há tendência a reduzir a oscilação com redução ainda maior ao se acrescentar levodopa. Sugere-se então um efeito sinérgico entre medicação e ECP para maior estabilidade postural. Este é um aspecto, então, em que o efeito da LD não se assemelha ao efeito da ECP. Além disso, o efeito da LD no paciente operado torna-se diferente do efeito da mesma medicação sobre os não operados, passando a reduzir as oscilações.

Estes dados sugerem que a levodopa e o ECP de núcleo subtalâmico agem em sistemas neurológicos diferentes. Considerando os mecanismos colinérgicos relacionados a alterações de marcha e equilíbrio, que incluem a participação do núcleo pedunculopontino (Yarnall et al., 2011), há provavelmente relação entre a estimulação de STN e mecanismos nãodopaminérgicos. De acordo com Guehl et al. (2006), a modulação da atividade do NST ocasionaria mudanças no tônus muscular através da circuitaria dos núcleos da base e no controle postural por meio de influência na atividade do núcleo pedunculopontino. 
Takakusaki et al. (2004) demonstraram que a estimulação do núcleo pedunculopontino em gatos causa hipotonia muscular através da inibição da resposta dos motoneurônios. A mudança no tônus muscular causada pela estimulação em vias não-dopaminérgicas poderia explicar por que a oscilação postural responde de maneira diferente à levodopaterapia e à ECP.

A redução colinérgica de tônus muscular pela estimulação do PPN já é bem conhecida durante o sono REM. Os neurônios colinérgicos mesopontinos do PPN, assim como os do núcleo tegmental laterodorsal parecem estar envolvidos na dessincronização cortical do eletroencefalograma durante o sono REM através de suas projeções ascendentes aos núcleos talâmicos, que são responsáveis pela atonia durante o sono REM através de suas projeções descendentes para a formação ponto-medular (Takakusaki et al., 2004).

Sidiropoulos et al. (2013) levantaram a hipótese de que possa haver disseminação de corrente para estruturas próximas ou excitação de fibras próximas a áreas locomotoras. Considerando que PPN e NST não são estruturas com proximidade anatômica, mas têm conexões recíprocas, é esperado que haja impacto funcional ao estimular fibras de conexão, tornando a hipótese de excitação de fibras mais provável.

Outro ponto que suporta a teoria do estímulo de fibras ao invés da estimulação diretamente do PPN por contiguidade é a frequência adequada de estimulação dos núcleos (Thevathasan et al., 2012; Maurer et al., 2003). O STN deve ser estimulado a mais de $100 \mathrm{~Hz}$, enquanto o PPN deve ser 
estimulado a menos de $40 \mathrm{~Hz}$. Apesar de relatos de que estimulação de baixa frequência de STN poderia melhorar alterações de marcha e equilíbrio em DP, o estudo já mencionado de Sidiropoulos et al. (2013) não confirmou esta hipótese.

Desta forma, a redução das oscilações por redução das discinesias gerada pela ECP de NST estão correlacionadas em um parâmetro (área de olhos fechados). Além disso, é comprovada redução adicional das oscilações pelo efeito conjunto da ECP e LD pelo uso da posturografia, gerando novo conhecimento a ser explorado em estudos futuros sobre mecanismos de ação da ECP.

O uso da plataforma de força neste trabalho demostrando as alterações acima citadas permite dizer que a UPDRS não é sensível o suficiente para detectar alterações no equilíbrio provocadas pelas intervenções terapêuticas disponíveis. A plataforma de força é ferramenta útil para fornecer dados mais detalhados e assim como outros métodos quantitativos, pode acrescentar dados que levem à modificação de conceitos atuais em trabalhos futuros.

As limitações deste trabalho consistem em não terem sido utilizadas outras escalas clínicas para avaliação, como a MiniBest, BesTEST e Berg. O estado pós-operatório com estimulação desligada e sob efeito da medicação também não foi realizada por ter sido considerada uma condição que não é vista na prática diária, além de aumentar o tempo de avaliação. 
7 Conclusões 
a) Os resultados observados na posturografia indicam que a LD em pacientes não operados contribui para um aumento da área de oscilação corporal, especialmente nos pacientes com discinesias, enquanto a ECP de NST tende a reduzir esta oscilação.

b) A ECP bilateral de STN reduz as oscilações do centro de pressão do paciente registradas na posturografia, especialmente quando se acrescenta também medicação.

c) A posturografia é método adequado e mais sensível do que a UPDRS para detectar alterações nos sintomas axiais da DP e pode ser utilizada para avaliação do controle postural. 


\section{REFERÊNCIAS}


Appel SH. Inflammation in Parkinson's disease: cause or consequence? Mov Disord. 2012; 27:1075-7.

Bach J-P, Ziegler U, Deuschl G, Dodel R, Doblhammer-Reiter G. Projected numbers of people with movement disorders in the years 2030 and 2050. Mov Disord. 2011; 26(12):2286-90.

Barbosa ER. Manifestaciones premotoras de la enfermedad de Parkinson. Rev Neurol. 2010; 50 (Supl 1):S9-11.

Barsottini OGP, Felício AC, Aquino CCHA, Pedroso JL. Progressive supranuclear palsy. New concepts. Arq Neuropsiquiatr. 2010; 68(6):938-46.

Berg KO, Wood-Dauphinee SL, Williams JI, Maki B. Measuring balance in the elderly: validation of an instrument. Can J Public Health. 1992; 83(Suppl 2):S7-11.

Blandini F. An update on the potential role of excitotoxicity in the pathogenesis of Parkinson's disease. Function Neurol. 2010; 25:65-71.

Błaszczyk JW, Orawiec R, Duda-Kłodowska D, Opala G. Assessment of postural instability in patients with Parkinson's disease. Exp Brain Res. 2007; 183(1):107-14 
Błaszczyk JW, Orawiec R. Assessment of postural control in patients with Parkinson's disease: sway ratio analysis. Hum Mov Sci. 2011; 30(2):396-404.

Bohnen NI, Muller MLTM, Koeppe RA, Studenski SA, Kilbourn MA, Frey KA, Albin RL. History of falls in Parkinson disease is associated with reduced cholinergic activity. Neurology. 2009; 7(20)3:1670-6.

Boonstra TA, van der Kooij H, Munneke M, Bloem BR. Gait disorders and balance disturbances in Parkinson's disease: clinical update and pathophysiology. Curr Opin Neurol. 2008; 21(4):461-71.

Bor-Seng-Shu E, Fonoff ET, Barbosa ER, Teixeira MJ. Substantia nigra hyperechogenicity in Parkinson's disease. Acta Neurochir. 2010; 152(12):2085-87.

Braak H, Del Tredici K, Rub U, de Vos RA, Jansen Steur EN, Braak E. Staging of brain pathology related to sporadic Parkinson's disease. Neurobiol Aging. 2003; 24(2):197-211.

Braak H, Ghebremedhin E, Rüb U, Bratzke H, Del Tredici K. Stages in the development of Parkinson's disease-related pathology. Cell Tissue Res. $2004 ; 318(1): 121-34$

Chung KA, Lobb BM, Nutt JG, Horak FB. Effects of a central cholinesterase inhibitor on reducing falls in Parkinson disease. Neurology. 2010; 75(14):1263-9.

Cipriani S, Chen X, Schwarzschild M. Urate: a novel biomarker of Parkinson's disease risk, diagnosis and prognosis. Biomark Med. 2010; $4: 701-12$ 
de Lau LM, Breteler MM. Epidemiology of Parkinson's disease. Lancet Neurol. 2006; 5(6):525- 35.

de Rijk MC, Tzourio C, Breteler MM, Dartigues JF, Amaducci L, Lopez-Pousa S, Manubens-Bertran JM, Alpérovitch A, Rocca WA. Prevalence of parkinsonism and Parkinson's disease in Europe: the EUROPARKINSON Collaborative Study. European Community Concerted Action on the Epidemiology of Parkinson's disease. J Neurol Neurosurg Psychiatry. 1997; $62(1): 10-5$.

DeLong MR, Huang KT, Gallis J, Lokhnygina Y, Parente B, Hickey P, Turner DA, Lad SP. Effect of advancing age on outcomes of deep brain stimulation for Parkinson disease. JAMA Neurol. 2014; 71(10):1290-5.

Duarte M, Freitas SM. Revision of posturography based on force plate for balance evaluation. Rev Bras Fisioter. 2010; 14(3):183-92.

Fall PA, Saleh A, Fredrickson M, Olsson JE, Granérus AK. Survival time, mortality and cause of death in elderly patients with Parkinson's disease: a 9year follow-up. Mov Disord. 2003; 18(11):1312-6.

Fearnley JM, Lees AJ. Ageing and Parkinson's disease: substantia nigra regional selec- tivity. Brain. 1991; 114:2283-301.

Ferraye MU, Debû B, Fraix V, Krack P, Charbardès S, Seigneuret E, Benabid AL, Pollak P. Subthalamic nucleus versus pedunculopontine nucleus stimulation in Parkinson disease: synergy or antagonism? J Neural Transm. 2011; 118(10):1469-75. 
Fioretti S, Guidi M, Ladislao L, Ghetti G. Analysis and reliability of posturographic parameters in Parkinson patients at an early stage. Conf Proc IEEE Eng Med Biol Soc. 2004; 1:651-4.

Fonoff ET. Efeitos da estimulação elétrica crônica bilateral do núcleo subtalâmico sobre os sintomas motores e não motores em doentes com doença de Parkinson idiopática [tese livre-docência]. Faculdade de Medicina da Universidade de São Paulo: São Paulo, 2012.

Fonoff FC, Fonoff ET, Barbosa ER, Quaranta T, Machado RB, de Andrade DC, Teixeira MJ, Fuentes D. Correlation between impulsivity and executive function in patients with Parkinson disease experiencing depression and anxiety symptoms. J Geriatr Psychiatry Neurol. 2015; 28(1):49-56.

Foulds P, Mann DMA, Mitchell JD, Allsop D. Progress towards a molecular biomarker for Parkinson disease. Nat Rev. 2010; 6(7):359-61.

Frank C, Pari G, Rossiter JP. Approach to diagnosis of Parkinson disease. Can Fam Physician. 2006; 52:862-8.

Freitas SMSF. Coordenação postural em adultos e idosos durante movimentos voluntários na postura ereta [tese]. Escola de Educação Física e Esporte da Universidade de São Paulo: São Paulo, 2005.

Frenklach A, Louie S, Koop MM, Bronte-Stewart H. Excessive postural sway and the risk of falls at different stages of Parkinson's disease. Mov Disord. $2009 ; 24(3): 377-85$. 
Fuentes R, Petersson P, Siesser WB, Caron MG, Nicolelis MA. Spinal cord stimulation restores locomotion in animal models of Parkinson's disease. Science. 2009; 323(5921):1578-82.

Gilman S, Wenning GK, Low PA, Brooks DJ, Mathias CJ, Trojanowski JQ, Wood NW, Colosimo C, Dürr A, Fowler CJ, Kaufmann H, Klockgether T, Lees A, Poewe W, Quinn N, Revesz T, Robertson D, Sandroni P, Seppi K, Vidailhet M. Second consensus statement on the diagnosis of multiple system atrophy. Neurology. 2008; 71(9): 670-6.

Guehl D, Dehail P, de Sèze MP, Cuny E, Faux P, Tison F, Barat M, Bioulac B, Burbaud P. Evolution of postural stability after subthalamic nucleus stimulation in Parkinson's disease: a combined clinical and posturometric study. Exp Brain Res. 2006; 170(2):206-15.

Horak FB, Frank J, Nutt J. Effects of dopamine on postural control in parkinsonian subjects: scaling, set, and tone. J Neurophysiol. 1996; 75(6):2380-96.

Horak FB, Wrisley DM, Frank J. The Balance Evaluation Systems Test (BESTest) to differentiate balance deficits. Phys Ther. 2009; 89(5):484-98.

Hughes AJ, Ben-Shlomo Y, Daniel SE, Lees AJ. What features improve the accuracy of clinical diagnosis in Parkinson's disease: a clinicopathologic study. Neurology. 1992a; 42(6):1142-6. 
Hughes AJ, Daniel SE, Kilford L, Lees AJ. Accuracy of clinical diagnosis of idiopathic Parkinson's disease: a clinico-pathological study of 100 cases. J Neurol Neurosurg Psychiatry. 1992b; 55(3):181-4.

Hunt AL, Sethi KD. The pull test: a history. Mov Disord. 2006; 21(7):894-9.

Johnson L, James I, Rodrigues J, Stell R, Thickbroom G, Mastaglia F. Clinical and posturographic correlates of falling in Parkinson's disease. Mov Disord. 2013; 28(9):1250-6.

Josephs KA, Dickson DW. Diagnostic accuracy of progressive supranuclear palsy in the Society for Progressive Supranulear Palsy brain bank. Mov Disord. 2003; 18(9):1018-26.

Kandinov B, Giladi N, Korczyn AD. The effect of cigarette smoking, tea, and coffee con- sumption on the progression of Parkinson's disease. Parkinsonism Relat Disord. 2007; 13:243- 5.

Kannarkat GT, Boss JM, Tansey MG. The Role of Innate and Adaptive Immunity in Par- kinson's Disease. J Parkinsons Dis. 2013; 3:493-514.

King LA, Mancini M, Priest K, Salarian A, Rodrigues-de-Paula F, Horak F. Do clinical scales of balance reflect turning abnormalities in people with Parkinson's disease? J Neurol Phys Ther. 2012; 36(1):25-31.

Kleiner-Fisman G, Herzog J, Fisman DN, Tamma F, Lyons KE, Pahwa R, Lang AE, Deuschl G. Subthalamic nucleus deep brain stimulation: summary and meta-analysis of outcomes. Mov Disord. 2006; 21(Suppl 14):S290-304. 
Koller WC, Glatt S, Vetere-Overfield B, Hassanein R. Falls and Parkinson's disease. Clin Neuropharmacol. 1989; 12(2):98-105.

Kompoliti K, Comella C, Goetz C. Clinical rating scales in movement disorders. In: Jankovic J, Tolosa E. Parkinson's disease and movement disorders. $5^{\text {a }}$ ed. 2007. Cap. 48, p. 692-701.

Kornetti DL, Fritz SL, Chiu YP, Light KE, Velozo CA. Rating scale analysis of the Berg Balance Scale. Arch Phys Med Rehabil. 2004; 85(7):1128-35.

Lang AE, Houeto JL, Krack P, Kubu C, Lyons KE, Moro E, Ondo W, Pahwa R, Poewe W, Tröster Al, Uitti R, Voon V. Deep brain stimulation: preoperative issues. Mov Disord. 2006; 21(Suppl 14):S171-96.

Leddy AL, Crowner BE, Earhart GM. Utility of the Mini-BESTest, BESTest, and BESTest sections for balance assessments in individuals with Parkinson disease. J Neurol Phys Ther. 2011; 35(2):90-7.

Litvan I, Agyd I, Calne D, Campbell G, Dubois B, Duvoisin RC, Goetz CG, Golbe LI, Grafman J, Growdon JH, Hallett M, Jankovic J, Quinn NP, Tolosa E, Zee DS. Clinical research criteria for the diagnosis of progressive supranuclear palsy (Steele-Richardson-Olszewisky syndrome): report of the NINDS-SPSP international workshop. Neurology. 1996; 47(1):1-9.

Lubarsky M, Juncos JL. Progressive supranuclear palsy: a current review. Neurologist 2008; 14(2):79-88. 
Ma SY, Roytt M, Collan Y, Rinne JO. Unbiased morphometrical measurements show loss of pigmented nigral neurones with ageing. Neuropathol Appl Neurobiol. 1999; 25:394-9.

MacPherson JM, Horak FB. Posture. In: Kandel E, Schwartz J, Jessell T, Siegelbaum S, Hudspeth AJ (eds.). Principles of neural science. $5^{\mathrm{a}}$ ed. New York: McGraw-Hill; 2012. Cap. 41, p. 935-959.

Malek NM, Grosset DG. Investigational agents in the treatment of Parkinson's disease: focus on safinamide. J Exp Pharmacol. 2012; 4:85-90.

Maurer C, Mergner T, Xie J, Faist M, Pollak P, Lucking CH. Effect of chronic bilateral subthalamic nucleus (STN) stimulation on postural control in Parkinson's disease. Brain. 2003;1 26(5):1146e-63e.

Mckeith IG, Dickson DW, Lowe J, Emre M, O'Brien JT, Feldman H, Cummings J, Duda JE, Lippa C, Perry EK, Aarsland D, Arai H, Ballard CG, Boeve B, Burn DJ, Costa D, Del Ser T, Dubois B, Galasko D, Gauthier S, Goetz CG, GomezTortosa E, Halliday G, Hansen LA, Hardy J, Iwatsubo T, Kalaria RN, Kaufer D, Kenny RA, Korczyn A, Kosaka K, Lee VM, Lees A, Litvan I, Londos E, Lopez OL, Minoshima S, Mizuno Y, Molina JA, Mukaetova-Ladinska EB, Pasquier F, Perry RH, Schulz JB, Trojanowski JQ, Yamada M; Consortium on DLB. Diagnosis and management of dementia with Lewy bodies: third report of DLB Consortium. Neurology. 2005; 65(12): 1863-72. 
Nantel J, McDonald JC, Bronte-Stewart H. Effect of medication and STNDBS on postural control in subjects with Parkinson's disease. Parkinsonism Relat Disord. 2012; 18(3):285-9.

Nussbaum RL, Polymeropoulos MH. Genetics of Parkinson's disease. Hum Mol Genet. 1997; 6(10):1687-91.

Nutt JG, Wooten GF. Clinical practice. Diagnosis and initial management of Parkinson's disease. N Engl J Med. 2005; 353(10):1021-7.

O'Hoski S, Winship B, Herridge L, Agha T, Brooks D, Beauchamp MK, Sibley KM. Increasing the clinical utility of the BESTest, mini-BESTest, and briefBESTest: normative values in Canadian adults who are healthy and aged 50 years or older. Phys Ther. 2014; 94(3):334-42.

Olanow CW, Rascol O, Hauser R, Feigin PD, Jankovic J, Lang A, Langston W, Melamed E, Poewe W, Stocchi F, Tolosa E; ADAGIO Study Investigators. A double-blind, delayedstart trial of rasagiline in Parkinson's disease. $N$ Engl J Med. 2009a; 361(13):1268-7.

Olanow CW, Stern MB, Sethi K. The scientific and clinical basis for the treatment of Parkinson disease. Neurology. 2009b; 72(21 Suppl 4):S1-136.

Pakkenberg B, Gundersen HJ. Neocortical neuron number in humans: effect of sex and age. J Comp Neurol. 1997; 384:312-20.

Park JH, Kang YJ, Horak FB. What Is Wrong with Balance in Parkinson's Disease? J Mov Disord. 2015; 8(3):109-14. 
Parkinson Study Group. A controlled trial of rasagiline in early Parkinson's disease: the TEMPO Study. Arch Neurol. 2002; 59:1937-43.

Parkinson Study Group. Pramipexole vs levodopa as initial treatment for Parkinson disease: a randomized controlled trial. Parkinson Study group. JAMA. 2000; 284(15):1931-8.

Perry EK, Kilford L, Lees AJ, Burn DJ, Perry RH. Increased Alzheimer pathology in Parkinson's disease related to antimuscarinic drugs. Ann Neurol. 2003; 54(2):235-8.

Poewe W, Hauser RA, Lang A; ADAGIO Investigators. Effects of rasagiline on the progression of nonmotor scores of the MDS-UPDRS. Mov Disord. 2015; 30:589-92.

Priyadarshi A, Khuder SA, Schaub EA, Priyadarshi SS. Environmental risk factors and Parkinson's disease: a metaanalysis. Environ Res. 2001; 86(2):122-7.

Quik M, Perez XA, Bordia T. Nicotine as a potential neuroprotective agent for Parkin- son's disease. Mov Disord. 2012; 27:947-57.

Qutubuddin AA, Pegg PO, Cifu DX, Brown R, McNamee S, Carne W. Validating the Berg Balance Scale for patients with Parkinson's disease: a key to rehabilitation evaluation. Arch Phys Med Rehabil. 2005; 86(4):789-92.

Rajput AH. Levodopa prolongs life expectancy and is non-toxic to substantia nigra. Parkinsonism Relat Disord. 2001; 8(2):95-100. 
Rosenberg-Katz K, Herman T, Jacob Y, Mirelman A, Giladi N, Hendler T, Hausdorff JM. Fall risk is associated with amplified functional connectivity of the central executive network in patients with Parkinson's disease. J Neurol. 2015 Aug 2. [Epub ahead of print] PubMed PMID: 26233691.

Saaksjarvi K, Knekt P, Rissanen H, Laaksonen MA, Reunanen A, Männistö S. Prospec- tive study of coffee consumption and risk of Parkinson's disease. Eur J Clin Nutr. 2008; 62(7):908-15.

Sampaio C, Rascol O. Disease-Modifying strategies in Parkinson's Disease. In: Jankovic J, Tolosa E. Parkinson's disease and movement disorders. Baltmote: Lippincott, 2007. Cap. 9, p. 102-103

Savitt JM, Dawson VL, Dawson TM. Diagnosis and treatment of Parkinson disease: molecules to medicine. J Clin Invest. 2006; 116(7):1744-54.

Scalzo PL, Nova IC, Perracini MR, Sacramento DR, Cardoso F, Ferraz HB, Teixeira AL. Validation of the Brazilian version of the Berg balance scale for patients with Parkinson's disease. Arq Neuropsiquiatr. 2009; 67(3B):831-5.

Schrag A. Epidemiology of movement disorders. In: Jankovic J, Tolosa E. Parkinson's disease and movement disorders. Baltmote: Lippincott, 2007. Cap. 5, p. 50-52. 
Schüepbach WM, Rau J, Knudsen K, Volkmann J, Krack P, Timmermann L, Hälbig TD, Hesekamp H, Navarro SM, Meier N, Falk D, Mehdorn M, Paschen S, Maarouf M, Barbe MT, Fink GR, Kupsch A, Gruber D, Schneider GH, Seigneuret E, Kistner A, Chaynes P, Ory-Magne F, Brefel Courbon C, Vesper J, Schnitzler A, Wojtecki L, Houeto JL, Bataille B, Maltête D, Damier P, Raoul S, Sixel-Doering F, Hellwig D, Gharabaghi A, Krüger R, Pinsker MO, Amtage F, Régis JM, Witjas T, Thobois S, Mertens P, Kloss M, Hartmann A, Oertel WH, Post B, Speelman H, Agid Y, Schade-Brittinger C, Deuschl G; EARLYSTIM Study Group. Neurostimulation for Parkinson's disease with early motor complications. N Engl J Med. 2013; 368(7):610-22.

Schüepbach WM, Rau J, Houeto JL, Krack P, Schnitzler A, Schade-Brittinger C, Timmermann L, Deuschl G. Myths and facts about the EARLYSTIM study. Mov Disord. 2014; 29(14):1742-50.

Shalash A, Alexoudi A, Knudsen K, Volkmann J, Mehdorn M, Deuschl G. The impact of age and disease duration on the long term outcome of neurostimulation of the subthalamic nucleus. Parkinsonism Relat Disord. $2014 ; 20(1): 47-52$

Sidiropoulos C. Walsh R, Meaney C, Poon YY, Fallis M, Moro E. Lowfrequency subthalamic nucleus deep brain stimulation for axial symptoms in advanced Parkinson's disease. J Neurol. 2013; 260(9):2306-11.

Silveira-Moriyama L, Carvalho MJ, Katzenchlager R, Petrie A, Ranvaud R, Barbosa ER, Lees AJ. The use of smell tests in the diagnosis of PD in Brazil. Mov Disord. 2008; 23(16):2328-34. 
Souza CO, Voos MC, Chien HS, Brant R, Barbosa AF, Fonoff FC, Caromano FA, Abreu LC, Barbosa ER, Fonoff ET. Combined auditory and visual cueing provided by eyeglasses influence gait performance in Parkinson disease patients submitted to deep brain stimulation: a pilot study. Int Arch Medi. 2015; 132(8):1-8.

Speciali DS, Corrêa JC, Luna NM, Brant R, Greve JM, de Godoy W, Baker R, Lucareli PR. Validation of GDI, GPS and GVS for use in Parkinson's disease through evaluation of effects of subthalamic deep brain stimulation and levodopa. Gait Posture. 2014; 39(4):1142-5.

Takakusaki K, Habaguchi T, Saitoh K, Kohyama J. Changes in the excitability of hindlimb motoneurons during muscular atonia induced by stimulating the pedunculopontine tegmental nucleus in cats. Neuroscience. $2004 ; 124(2): 467-80$.

Teixeira LA. Funções sensoriais e perceptivas. In: Controle motor. Barueri: Manole, 2006. Cap. 3, p. 73-135.

Thevathasan W, Cole MH, Graepel CL, Hyam JA, Jenkinson N, Brittain JS, Coyne TJ, Silburn PA, Aziz TZ, Kerr G, Brown P. A spatiotemporal analysis of gait freezing and the impact of pedunculopontine nucleus stimulation. Brain. 2012; 135(Pt 5):1446-54.

Thobois S. USP30 (Ubiquitin Specific Protease): a new promising target for Parkinson's disease? Mov Disord. 2015; 30:340. 
Tolosa E, Gaig C, Santamaria J, Compta Y. Diagnosis and premotor phase of Parkinson's disease. Neurology. 2009; 72(7 Supp 2): S12-20.

Vaillancourt DE, Spraker MB, Prodoehl J, Abraham I, Corcos DM, Zhou XJ, Comella CL, Little DM. High-resolution diffusion tensor imaging in the substantia nigra of de novo Parkinson disease. Neurology. 2009; 72(16):1378-84.

Van Maele-Fabry G, Hoet P, Vilain F, Lison D. Occupational exposure to pesticides and Parkinson's disease: a systematic review and meta-analysis of cohort studies. Environ Int. 2012; 46:30-43.

Vingerhoets FJ, Tagliati M. Treating PD axial signs with DBS: is two better than one? Neurology. 2012; 78(14):1036-7.

Wadia PM, Lang AE. The many faces of corticobasal degeneration. Park Relat Disord. 2007, 13(Suppl 3):S336-40.

Witjas T, Kaphan E, Azulay JP, Blin O, Ceccaldi M, Pouget J, Poncet M, Chérif AA. Nonmotor fluctuations in Parkinson's disease: frequent and disabling. Neurology. 2002; 59(3):408-13.

Yarnall A, Rochester L, Burn DJ. The interplay of cholinergic function, attention, and falls in Parkinson's disease. Mov Disord. 2011; 26(14):2496503. 